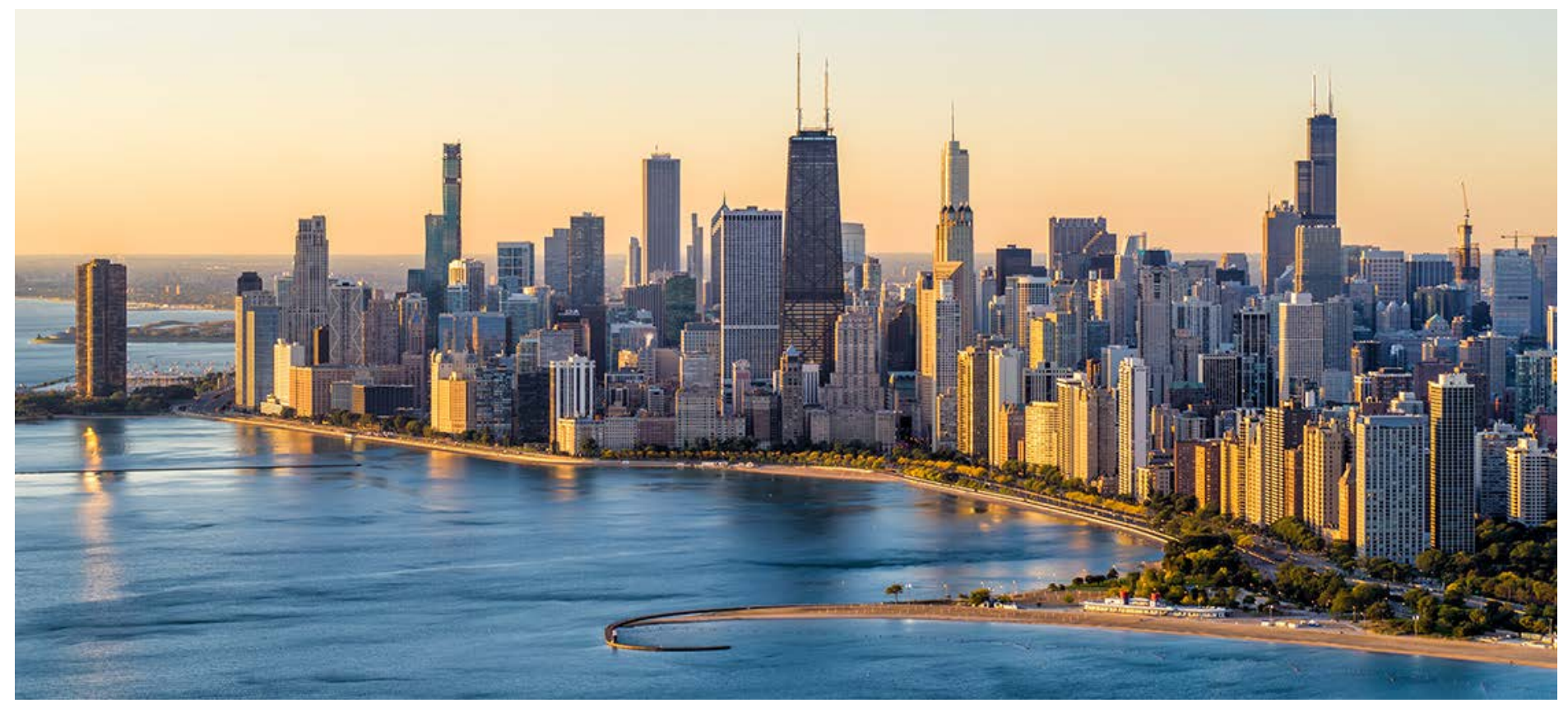

\title{
Energy Efficiency and Performance Evaluation of Self-Contained, Medium Temperature, Reach-In Refrigerated Display Cases
}

Alex Bulk, Greg Shoukas, Omkar Ghatpande, Lauren Klun, and Ramin Faramarzi

Produced under direction of ComEd by the National Renewable Energy Laboratory (NREL) under Technical Services Agreement TSA-19-01159

NREL is a national laboratory of the U.S. Department of Energy Office of Energy Efficiency \& Renewable Energy

Operated by the Alliance for Sustainable Energy, LLC

This report is available at no cost from the National Renewable Energy Laboratory (NREL) at www.nrel.gov/publications.
Strategic Partnership Project Report NREL/TP-5500-80634

October 2021 


\title{
Energy Efficiency and Performance Evaluation of Self-Contained, Medium Temperature, Reach-In Refrigerated Display Cases
}

\author{
Alex Bulk, Greg Shoukas, Omkar Ghatpande, Lauren Klun, \\ and Ramin Faramarzi \\ Produced under direction of ComEd by the National Renewable Energy \\ Laboratory (NREL) under Technical Services Agreement TSA-19-01159
}

\section{Suggested Citation}

Bulk, Alex, Greg Shoukas, Omkar Ghatpande, Lauren Klun, and Ramin Faramarzi. 2021. Energy Efficiency and Performance Evaluation of Self-Contained, Medium Temperature, Reach-In Refrigerated Display Cases. Golden, CO: National Renewable Energy Laboratory. NREL/TP-550080634. https://www.nrel.gov/docs/fy22osti/80634.pdf.

NREL is a national laboratory of the U.S. Department of Energy Office of Energy Efficiency \& Renewable Energy Operated by the Alliance for Sustainable Energy, LLC

This report is available at no cost from the National Renewable Energy Laboratory (NREL) at www.nrel.gov/publications.

Contract No. DE-AC36-08GO28308
Strategic Partnership Project Report NREL/TP-5500-80634 October 2021

National Renewable Energy Laboratory 15013 Denver West Parkway Golden, CO 80401

303-275-3000 • www.nrel.gov 


\section{NOTICE}

This work was authored by the National Renewable Energy Laboratory, operated by Alliance for Sustainable Energy, LLC, for the U.S. Department of Energy (DOE) under Contract No. DE-AC36-08GO28308. Support for the work was also provided by ComEd through CLEAResult under TSA-19-01159. The views expressed in the article do not necessarily represent the views of the DOE or the U.S. Government.

The ComEd Energy Efficiency Program is funded in compliance with state law.

This report is available at no cost from the National Renewable Energy Laboratory (NREL) at www.nrel.gov/publications.

U.S. Department of Energy (DOE) reports produced after 1991 and a growing number of pre-1991 documents are available free via www.OSTI.gov.

Cover photo from iStock 1180689542.

NREL prints on paper that contains recycled content. 


\section{Acknowledgments}

The authors would like to thank the ComEd Energy Efficiency Program and CLEAResult for supporting this research. This report was prepared by the National Renewable Energy Laboratory (NREL) Building Technologies and Science Center.

The authors would also like to specifically express their sincere gratitude to Gabriel Duarte and Leah Scull of CLEAResult and Stephen Labarge of ComEd for their in-depth report review, and to Selam Haile of NREL for providing refrigeration thermodynamics advice and expertise, as well as Lauren Klun for her in-depth review and support as the project controller.

For more information, contact:

Alex Bulk

National Renewable Energy Laboratory

Email: alexander.bulk@nrel.gov 


\section{List of Acronyms}

A

AC

AHRI

ANSI

ASHRAE

BEDAC

ComEd

DBT

DOE

DPT

EPA

FDA

GWP

HFC

HFO

HP

HVAC

$\mathrm{Hz}$

in

$\mathrm{kg}$

$\mathrm{kW}$

$\mathrm{kWh} /$ day

LAP
LED
$\mathrm{mL}$
$\mathrm{m} / \mathrm{s}$
$\mathrm{NREL}$

ampere: unit of current

alternating current

The Air Conditioning, Heating, and Refrigeration Institute: a North American trade association of air-conditioning, heating, and commercial refrigeration equipment manufacturers

American National Standards Institute: a private nonprofit organization that oversees consensus standards for products, services, processes, systems, and personnel

The American Society of Heating, Refrigerating, and Air-Conditioning Engineers: a professional association seeking to advance HVAC and refrigeration systems design and construction

Building and Energy Data Acquisition and Control: data acquisition and control system used in NREL laboratory facilities

The Commonwealth Edison Company: the sole electric utility provider for Chicago and Northern Illinois

dry-bulb temperature: temperature of air when shielded from radiation and moisture

\section{U.S. Department of Energy}

dew-point temperature: temperature of air to achieve saturation at constant pressure and constant water vapor content

U.S. Environmental Protection Agency

U.S. Food and Drug Administration, a federal agency that develops and enforces food safety regulations

global warming potential: a measure of how much heat a greenhouse gas traps in the atmosphere relative to carbon dioxide

hydrofluorocarbon: a type of refrigerant composed of organic compounds that

contain fluorine and hydrogen atoms with a GWP thousands of times greater than carbon dioxide

hydrofluoroolefin: a type of refrigerant composed of unsaturated organic

compounds that contain hydrogen, fluorine, and carbon. They are chemically

stable and offer lower GWP than HFC refrigerants

horsepower: a unit of measurement of power

heating, ventilating, and air conditioning

hertz: unit of electrical frequency

inch: a unit of measurement of length

kilogram: a unit of measurement of mass

kilowatt: a unit of measurement of power

kilowatt hours per day: a unit of measurement of energy consumed over one 24-h period

Laboratory Assessment Plan

light-emitting diode: a semiconductor light source

milliliter: a unit of measurement of volume

meters per second: a unit of measurement of velocity

National Renewable Energy Laboratory 
NRM

OCL

$\mathrm{Ph}$

R134a

$\mathrm{R} 290$

R513a

$\mathrm{RH}$

TC

$\mathrm{V}$

WBT
NREL Reference Method for Evaluating Doored Self-Contained Refrigerator Display Cases

Optimization and Control Laboratory: the NREL laboratory in which the refrigerated display cases are evaluated in an environmental chamber phase: the number of distinct electrical wave cycles

A type of HFC refrigerant composed of 1,1,1,2-Tetrafluoroethane. Due to its low ozone depletion potential, it had become the most common refrigerant in the 1990s but is currently being phased out of production by the EPA SNAP program due to its high GWP.

A type of hydrocarbon refrigerant composed of high-purity propane recommended for use by the EPA. R290's GWP is drastically lower than HFC or HFO refrigerants and has greater thermodynamic potential.

A type of HFO refrigerant composed of Opteon XP10 that exhibits low GWP designed to replace R134a in certain types of refrigeration systems. Although its GWP is significantly lower than R134a, it is still more than 100 times greater than R290.

relative humidity: the ratio of absolute water vapor concentration to the maximum water vapor concentration at a specific temperature thermocouple: a temperature transducer volts: unit of measurement of voltage wet-bulb temperature: temperature of air cooled to saturation by the evaporation of water 


\section{Executive Summary}

This project is part of an effort by Commonwealth Edison Company (ComEd) to evaluate the energy and peak demand savings potential of emerging technologies in the Chicago area. This document focuses on the assessment of energy-efficient, medium-temperature, self-contained refrigerated display cases utilizing environmentally friendly refrigerants. The results of this evaluation will be considered by ComEd and CLEAResult to develop a new energy efficiency rebate measure for ComEd's incentive programs. This rebate measure will become an addition to the Technical Reference Manual [1].

In 2016, the United Nations passed the Kigali Montreal Protocol Amendment, which placed restrictions on certain types of refrigerants [2]. In compliance with this amendment, the U.S. Environmental Protection Agency (EPA) placed a ban on the manufacture of refrigeration systems using hydrofluorocarbons including R134a starting in January 2020. Although the ban has halted manufacture, the EPA continues to allow the use of these refrigerants. Therefore, it is critical to provide incentives for replacing these refrigerants with other environmentally friendly and energy-efficient alternatives.

The energy-efficient refrigerator cases evaluated here (referred to as EE case A and B) contain environmentally friendly refrigerants in compliance with the EPA hydrofluorocarbon ban. These consist of natural refrigerant propane (R290), and HFC drop-in hydrofluoroolefin R513a, respectively. These cases also contain other energy-efficient components including efficient lighting, more robust evaporator and condenser fans, and different-sized heat exchangers. EE case A is also built with materials that better insulate the case, which improves energy efficiency. To ascertain the energy efficiency contribution of these design components, the consumption of the evaporator and condenser fan motors, compressor, and lighting/controller were evaluated individually. The medium-temperature, selfcontained reach-in refrigerated display case was selected due to its widespread use in convenience stores and small supermarkets. Self-contained refrigeration has also seen increased use in restaurants due to curbside pickup during the COVID-19 pandemic.

For this study, the refrigerated display cases' performance was evaluated in a controlled environmental chamber at representative indoor dry-bulb and humidity conditions found in supermarkets within ComEd's service territory climate zone. The test method used in this project was foundationally inspired by the ANSI/ASHRAE 72-2018 method of evaluation [3]; however, modifications to the ANSI/ASHRAE test methodology were implemented to better represent customer operation of the units. In addition to the indoor supermarket conditions, the cases were also evaluated at the "Upper Target," or environmental conditions used in ANSI/ASHRAE 72-2018. The case total power and case components were metered to obtain their daily power $(\mathrm{kW})$ and energy consumption $(\mathrm{kWh})$. The cases were filled with thermal filler mass to replicate thermal mass of product loading. Additionally, product simulators were used to provide product temperature information. Door actuators were mounted to each of the cases' three doors to replicate regular door openings and effects of shopper traffic.

The following table lists the case total and component energy consumption at the Upper Target environmental conditions. The results were averaged across two to three individual 24-hour experiments. The total and component power consumption averaged across the total compressor operation time is also provided. The compressor consumed $52 \%-73 \%$ of the total energy in all cases and $70 \%-84 \%$ of the total power when cycled on. The lighting and controller consumed $18 \%-30 \%$ of the total energy, but only $6 \%-13 \%$ of the mean total power during compressor cycling. The condenser and evaporator fans consumed $3 \%-11 \%$ of the total energy and mean on-cycle power. Both the energy 
and power measurements were normalized to the cases' internal volumetric capacity and corrected to the operation time between defrost cycles.

\begin{tabular}{|c|c|c|c|c|c|}
\hline Baseline Case & $\begin{array}{c}\text { Daily } \\
\text { Energy } \\
\text { Consump- } \\
\text { tion } \\
\text { (kWh/day) }\end{array}$ & $\begin{array}{l}\text { Energy Corrected to } \\
\text { Time-Between-Defrost } \\
\text { and Normalized to } \\
\text { Internal Volume } \\
\left(\mathrm{kWh} / \mathrm{m}^{3} \text { day) }\right.\end{array}$ & $\begin{array}{c}\text { Mean Power } \\
\text { Consumption } \\
\text { (On-Cycle) (W) }\end{array}$ & $\begin{array}{l}\text { Mean On-Cycle } \\
\text { Power } \\
\text { Normalized to } \\
\text { Internal Volume } \\
\left(\mathrm{W} / \mathrm{m}^{3}\right) \\
\end{array}$ & $\begin{array}{c}\text { Average Product } \\
\text { Simulator } \\
\text { Temperature } \\
\end{array}$ \\
\hline Total & $11.26 \pm 0.02$ & $8.64 \pm 0.06$ & $930.71 \pm 371.52$ & $680.65 \pm 279.71$ & $\begin{array}{c}\text { Max (Defrost): } \\
3.67^{\circ} \mathrm{C}\left(38.61^{\circ} \mathrm{F}\right)\end{array}$ \\
\hline Compressor & $6.21 \pm 0.04$ & $4.76 \pm 0.04$ & $662.27 \pm 324.99$ & $484.33 \pm 237.67$ & $\begin{array}{c}\text { Daily Average: } \\
2.99^{\circ} \mathrm{C}\left(37.38^{\circ} \mathrm{F}\right)\end{array}$ \\
\hline Condenser Fan & $0.94 \pm 0.00$ & $0.72 \pm 0.00$ & $99.58 \pm 48.85$ & $72.83 \pm 35.72$ & $\begin{array}{c}\text { Min (Door } \\
\text { Openings): } 2.42^{\circ} \mathrm{C} \\
\left(36.36^{\circ} \mathrm{F}\right) \\
\end{array}$ \\
\hline Evaporator Fans & $1.07 \pm 0.00$ & $0.82 \pm 0.00$ & $44.46 \pm 1.00$ & $32.52 \pm 0.73$ & \\
\hline $\begin{array}{l}\text { Lighting/ } \\
\text { Controller }\end{array}$ & $3.06 \pm 0.01$ & $2.35 \pm 0.01$ & $127.45 \pm 1.03$ & $93.21 \pm 0.75$ & \\
\hline EE Case A & $\begin{array}{l}\text { Daily } \\
\text { Energy } \\
\text { Consump- } \\
\text { tion } \\
\text { (kWh/day) }\end{array}$ & $\begin{array}{l}\text { Energy Corrected to } \\
\text { Time-Between-Defrost } \\
\text { and Normalized to } \\
\text { Internal Volume } \\
\text { (kWh/m } / \mathrm{m}^{3} \text { day) }\end{array}$ & $\begin{array}{l}\text { Mean Power } \\
\text { Consumption } \\
\text { (On-Cycle) (W) }\end{array}$ & $\begin{array}{l}\text { Mean On-Cycle } \\
\text { Power } \\
\text { Normalized to } \\
\text { Internal Volume } \\
\left(\mathrm{W} / \mathrm{m}^{3}\right) \\
\end{array}$ & $\begin{array}{c}\text { Average Product } \\
\text { Simulator } \\
\text { Temperature }\end{array}$ \\
\hline Total & $4.30 \pm 0.01$ & $3.09 \pm 0.00$ & $558.51 \pm 223.39$ & $401.29 \pm 160.50$ & $\begin{array}{l}\text { Max (Off-Cycle): } \\
3.27^{\circ} \mathrm{C}\left(37.89^{\circ} \mathrm{F}\right)\end{array}$ \\
\hline Compressor & $2.89 \pm 0.01$ & $2.07 \pm 0.01$ & $469.05 \pm 147.53$ & $337.01 \pm 147.53$ & $\begin{array}{c}\text { Daily Average: } \\
2.92^{\circ} \mathrm{C}\left(37.26^{\circ} \mathrm{F}\right)\end{array}$ \\
\hline Condenser Fan & $0.13 \pm 0.00$ & $0.09 \pm 0.00$ & $20.77 \pm 6.49$ & $14.92 \pm 6.49$ & $\begin{array}{c}\text { Min (Door } \\
\text { Openings): } \\
2.58^{\circ} \mathrm{C}\left(36.64^{\circ} \mathrm{F}\right) \\
\end{array}$ \\
\hline Evaporator Fan & $0.24 \pm 0.01$ & $0.17 \pm 0.01$ & $24.16 \pm 8.49$ & $17.36 \pm 8.49$ & \\
\hline $\begin{array}{l}\text { Lighting/ } \\
\text { Controller }\end{array}$ & $1.03 \pm 0.00$ & $0.74 \pm 0.00$ & $42.99 \pm 0.09$ & $30.89 \pm 0.09$ & \\
\hline EE Case B & $\begin{array}{c}\text { Daily } \\
\text { Energy } \\
\text { Consump- } \\
\text { tion } \\
\text { (kWh/day) }\end{array}$ & $\begin{array}{l}\text { Energy Corrected to } \\
\text { Time-Between-Defrost } \\
\text { and Normalized to } \\
\text { Internal Volume } \\
\text { (kWh/m } / \mathrm{m}^{3} \text { day) }\end{array}$ & $\begin{array}{c}\text { Mean Power } \\
\text { Consumption } \\
\text { (On-Cycle) (W) }\end{array}$ & $\begin{array}{l}\text { Mean On-Cycle } \\
\text { Power } \\
\text { Normalized to } \\
\text { Internal Volume } \\
\left(\mathrm{W} / \mathrm{m}^{3}\right) \\
\end{array}$ & $\begin{array}{c}\text { Average Product } \\
\text { Simulator } \\
\text { Temperature } \\
\end{array}$ \\
\hline Total & $7.59 \pm 0.04$ & $6.09 \pm 0.02$ & $892.38 \pm 382.47$ & $652.61 \pm 279.71$ & $\begin{array}{c}\text { Max (Defrost): } \\
3.57^{\circ} \mathrm{C}\left(38.43^{\circ} \mathrm{F}\right)\end{array}$ \\
\hline Compressor & $5.87 \pm 0.01$ & $4.71 \pm 0.01$ & $802.13 \pm 369.87$ & $586.61 \pm 270.49$ & $\begin{array}{c}\text { Daily Average: } \\
3.02^{\circ} \mathrm{C}\left(37.44^{\circ} \mathrm{F}\right)\end{array}$ \\
\hline Condenser Fan & $0.45 \pm 0.00$ & $0.36 \pm 0.00$ & $61.95 \pm 28.62$ & $45.30 \pm 20.93$ & $\begin{array}{c}\text { Min (Door } \\
\text { Openings): } \\
2.53^{\circ} \mathrm{C}\left(36.55^{\circ} \mathrm{F}\right)\end{array}$ \\
\hline Evaporator Fans & $0.26 \pm 0.00$ & $0.21 \pm 0.00$ & $28.41 \pm 13.88$ & $20.77 \pm 10.15$ & \\
\hline $\begin{array}{l}\text { Lighting/ } \\
\text { Controller }\end{array}$ & $1.42 \pm 0.01$ & $1.14 \pm 0.01$ & $59.33 \pm 0.17$ & $43.39 \pm 0.12$ & \\
\hline
\end{tabular}

For all cases, both higher chamber dry-bulb and dew-point temperatures caused the compressor to cycle on for a longer duration, which resulted in increased energy use. The product simulator temperatures fluctuated with scheduled door openings and defrost, but were maintained within AHRI/FDA limits. Scheduled door openings caused the compressor to cycle more frequently in response to infiltrated warm air. Scheduled defrost cycles caused product simulator temperatures to slightly increase in the baseline case and EE case B, especially when extended at more humid chamber conditions. Due to EE case A's improved insulation, ice is fully removed between compressor cycles and no defrost cycle was required. 


\section{Table of Contents}

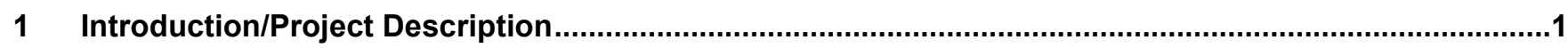

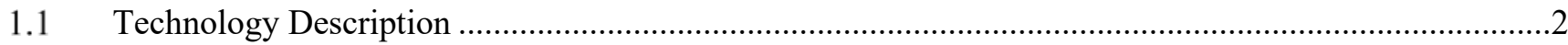

2 Laboratory Assessment Procedure

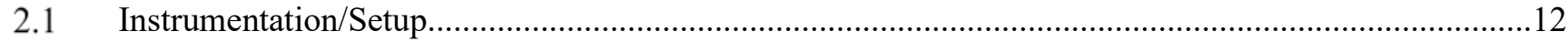

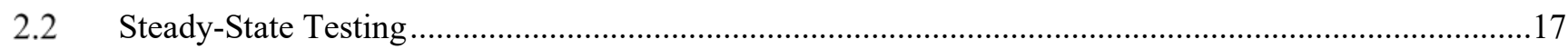

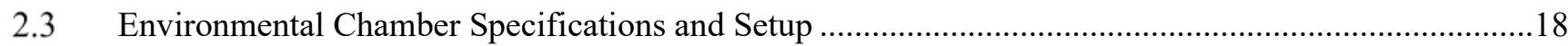

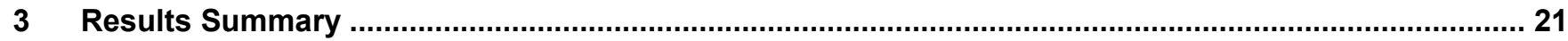

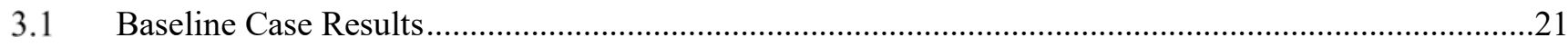

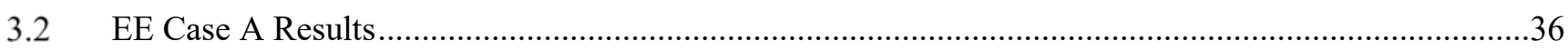

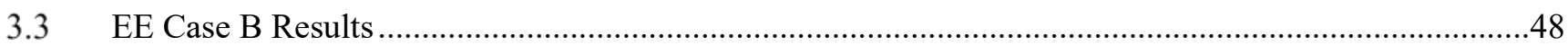

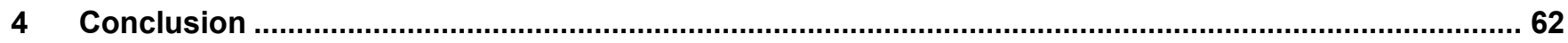

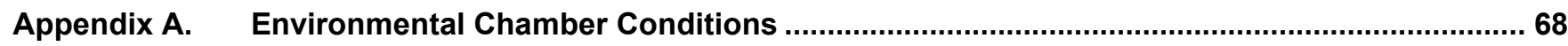

A.1 Baseline Case Environmental Temperatures...........................................................................68

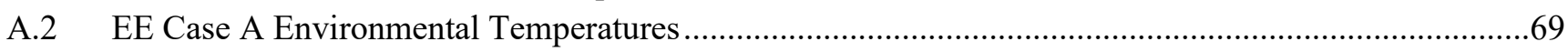

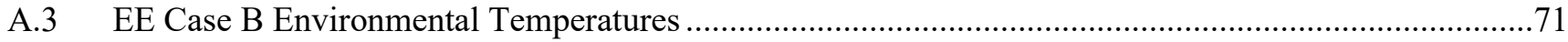

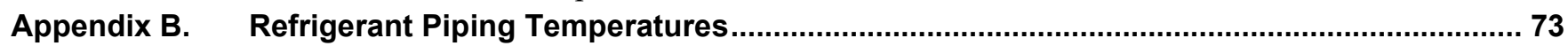

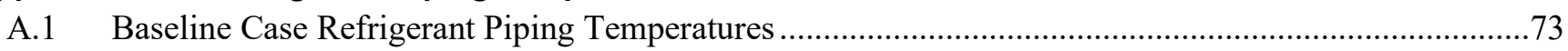

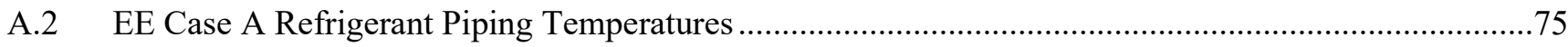

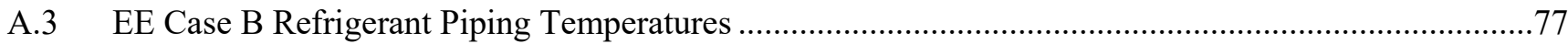




\section{List of Figures}

Figure 1. Diagram of refrigeration vapor-compression cycle components .....................................................

Figure 2. Molecular structure of: (left) 1,1,1,2-Tetrafluoroethane (R134a, $\mathrm{C}_{2} \mathrm{H}_{2} \mathrm{~F}_{4}$ ), (center) propane (R290, $\left.\mathrm{C}_{3} \mathrm{H}_{8}\right)$,

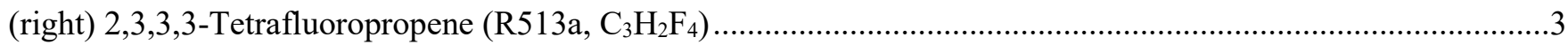

Figure 3. Baseline and EE case B catalogue image (above) and drawing (below) ............................................6

Figure 4. Baseline case condensing unit (top) and evaporator panel (bottom) .................................................

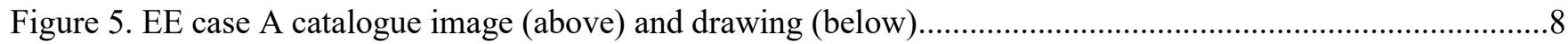

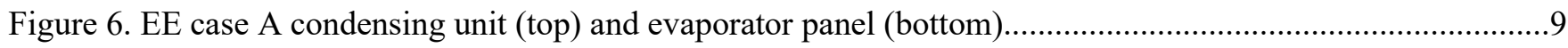

Figure 7. EE case B condensing unit (top) and evaporator panel (bottom) .....................................................10

Figure 8. Schematic of product simulator temperature measurement locations $(A-R)$, and ambient temperature

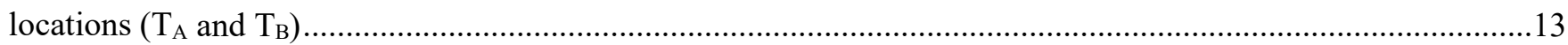

Figure 9. Diagram of filler material (blue) and product simulator (yellow) configuration on an example right-side

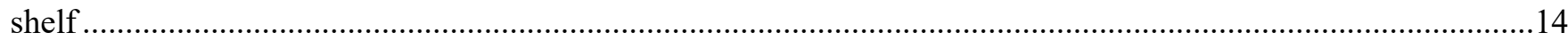

Figure 10. Door actuators mounted to EE case A (top), and the baseline case (bottom) ...................................15

Figure 11. Left: Image of Wattnode "Meter Box" designed for component power consumption metering, Middle: Image of BEDAC data acquisition system terminal panel, Right: Image of BEDAC modbus interface and PXI (Peripheral component interconnect Extension for Instrumentation)...

Figure 12. OCL Building Bay 3 with (from left) EE case B, the baseline case (undergoing steady-state testing),

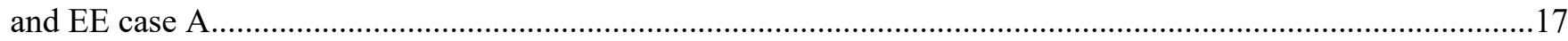

Figure 13. Image of Espec Environmental Control Chamber ................................................................18

Figure 14. Images of cases in environmental chamber. Left: Baseline case from rear of chamber. Right: EE case

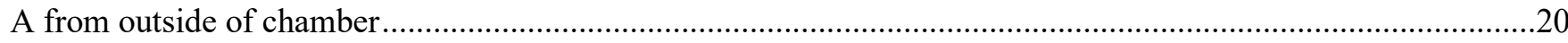

Figure 15. Baseline refrigerator case January condition transient product simulator temperatures (top) and internal air temperatures (middle) over $24 \mathrm{~h}$. Internal air temperatures over $1.5 \mathrm{~h}$ are shown around hour 11 (bottom)......23 Figure 16. Baseline refrigerator case July condition transient product simulator temperatures (top) and internal air

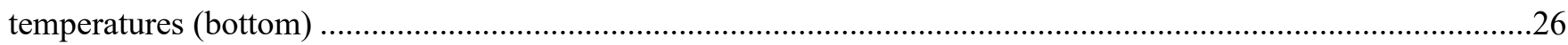

Figure 17. Baseline refrigerator case Upper Target condition transient product simulator temperatures (top) and

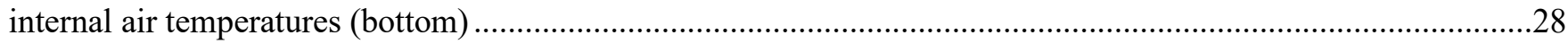

Figure 18. Baseline refrigerator case condensate mass generated at each environmental condition .....................29

Figure 19. Baseline case total energy consumption (left) and mean on-cycle power consumption (right) at each

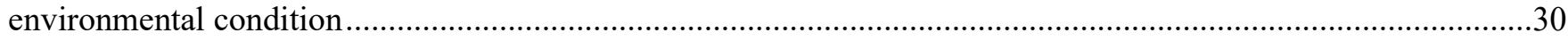

Figure 20. Baseline case component daily energy ( $\mathrm{kWh} /$ day, top) and mean on-cycle power consumption (W,

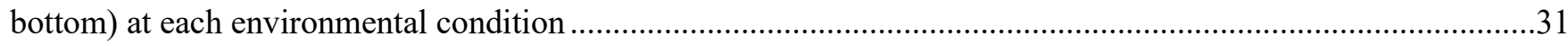

Figure 21. Baseline case total and component power consumption under January environmental conditions (top:

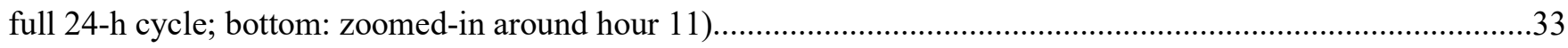

Figure 22. Baseline case total and component power consumption under July environmental conditions (full 24-h

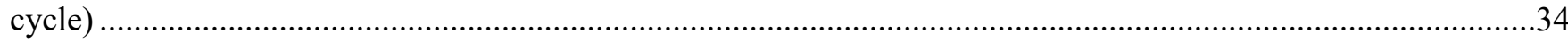

Figure 23. Baseline case total and component power consumption under Upper Target environmental conditions

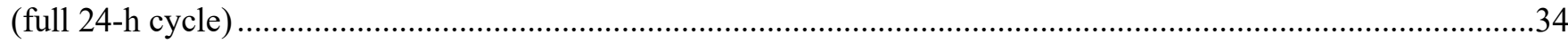

Figure 24. Baseline case component daily energy normalized to time-between-defrost and internal volumetric capacity ( $\mathrm{kWh} / \mathrm{m}^{3}$ day, top) and mean on-cycle power consumption normalized to internal volumetric capacity

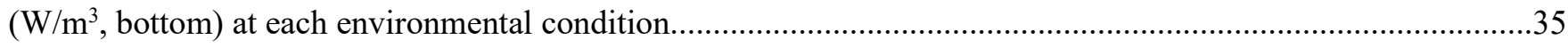

Figure 25. EE case A January condition transient product simulator temperatures (top) and internal air temperatures (middle) over $24 \mathrm{~h}$. Internal air temperatures over $1.5 \mathrm{~h}$ are shown around hour 11 (bottom)..... 
Figure 26. EE case A July condition transient product simulator temperatures (top) and internal air temperatures (bottom)

Figure 27. EE case A Upper Target condition transient product simulator temperatures (top) and internal air

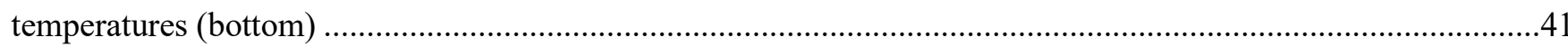

Figure 28. EE case A condensate mass generated at each environmental condition.......................................43

Figure 29. EE case A total energy consumption (left) and mean on-cycle power consumption (right) at each

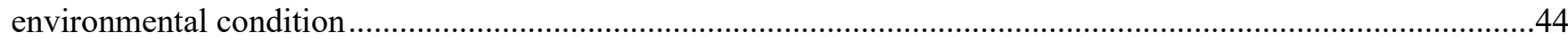

Figure 30. EE case A component daily energy (kWh/day, top) and mean on-cycle power consumption (W, bottom) at each environmental condition.....

Figure 31. EE case A total and component power consumption under January environmental conditions (top: full 24-h cycle; bottom: zoomed-in around hour 11).

Figure 32. EE case A total and component power consumption under July environmental conditions (full 24-h cycle)

Figure 33. EE case A total and component power consumption under Upper Target environmental conditions (full 24-h cycle)

Figure 34. EE case A component daily energy normalized to time-between-defrost and internal volumetric capacity ( $\mathrm{kWh} / \mathrm{m}^{3}$ day, top) and mean on-cycle power consumption normalized to internal volumetric capacity $\left(\mathrm{W} / \mathrm{m}^{3}\right.$, bottom) at each environmental condition.

Figure 35. EE case B January condition transient product simulator temperatures (top) and internal air temperatures (middle) over $24 \mathrm{~h}$. Internal air temperatures over $1.5 \mathrm{~h}$ are shown around hour 11 (bottom) ...........50 Figure 36. EE case B July condition transient product simulator temperatures (top) and internal air temperatures (bottom)

Figure 37. EE case B Upper Target condition transient product simulator temperatures (top) and internal air temperatures (bottom) .55

Figure 38. EE case B condensate mass generated at each environmental condition...........................................56

Figure 39. EE case B total energy consumption (left) and mean on-cycle power consumption (right) at each environmental condition....

Figure 40. EE case B component daily energy (kWh/day, top) and mean on-cycle power consumption (W, bottom) at each environmental condition....

Figure 41. EE case B total and component power consumption under January environmental conditions (top: full

24-h cycle; bottom: zoomed-in around hour 11).

Figure 42. EE case B total and component power consumption under July environmental conditions (full 24-h cycle)

Figure 43. EE case B total and component power consumption under July environmental conditions (full 24-h cycle)

Figure 44. EE case B component daily energy normalized to time-between-defrost and internal volumetric capacity ( $\mathrm{kWh} / \mathrm{m}^{3}$ day, top) and mean on-cycle power consumption normalized to internal volumetric capacity $\left(\mathrm{W} / \mathrm{m}^{3}\right.$, bottom) at each environmental condition.

Figure 45. Chamber dry-bulb temperatures and dew-point temperature during baseline case testing in January environmental conditions

Figure 46. Chamber dry-bulb temperatures and dew-point temperature during baseline case testing in July environmental conditions

Figure 47. Chamber dry-bulb temperatures and dew-point temperature during baseline case testing in Upper Target environmental conditions 
Figure 48. Chamber dry-bulb temperatures and dew-point temperature during EE case A testing in January environmental conditions .70

Figure 49. Chamber dry-bulb temperatures and dew-point temperature during EE case A testing in July environmental conditions .70

Figure 50. Chamber dry-bulb temperatures and dew-point temperature during EE case A testing in Upper Target environmental conditions . .71

Figure 51. Chamber dry-bulb temperatures and dew-point temperature during EE case B testing in January environmental conditions .71

Figure 52. Chamber dry-bulb temperatures and dew-point temperature during EE case B testing in July environmental conditions .72

Figure 53. Chamber dry-bulb temperatures and dew-point temperature during EE case B testing in Upper Target environmental conditions . .72

Figure 54. Refrigerant piping temperatures during baseline case testing in January environmental conditions......74

Figure 55. Refrigerant piping temperatures during baseline case testing in July environmental conditions .74 Figure 56. Refrigerant piping temperatures during baseline case testing in Upper Target environmental conditions

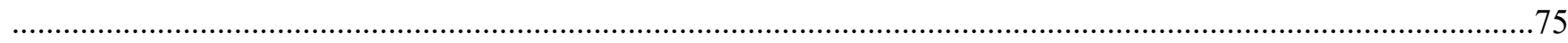

Figure 57. Refrigerant piping temperatures during EE case A testing in January environmental conditions ..........76

Figure 58. Refrigerant piping temperatures during EE case A testing in July environmental conditions...............76

Figure 59. Refrigerant piping temperatures during EE case A testing in Upper Target environmental conditions.77

Figure 60. Refrigerant piping temperatures during EE case B testing in January environmental conditions ..........78

Figure 61. Refrigerant piping temperatures during EE case B testing in July environmental conditions ..............78

Figure 62. Refrigerant piping temperatures during EE case B testing in Upper Target environmental conditions .79 


\section{List of Tables}

Table 1. Properties of Refrigerants Used in the Evaluated Refrigerator Case Technologies [13-15, 19] ...............4

Table 2. General Refrigerator Display Case Key Parameter Specifications …..................................................11

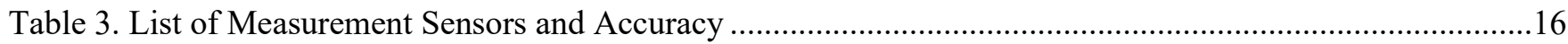

Table 4. Selected Cut-In and Cut-Out Temperatures and Resultant Mean Product Simulator Temperature...........18

Table 5. Environmental Condition Setpoints and Upper and Lower Limits ....................................................19

Table 6. Baseline Refrigerator Case January Condition Average Product Simulator Temperatures ......................24

Table 7. Baseline Refrigerator Case July Condition Average Product Simulator Temperatures ............................26

Table 8. Baseline Refrigerator Case Upper Target Condition Average Product Simulator Temperatures ..............28

Table 9. Baseline Case Energy and Mean On-Cycle Power Consumption Normalized to Time-Between-Defrost

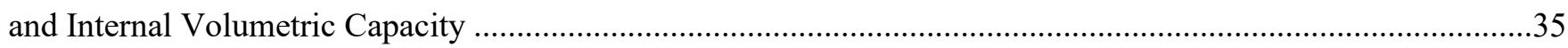

Table 10. EE Case A January Condition Average Product Simulator Temperatures...........................................38

Table 11. EE Case A July Condition Average Product Simulator Temperatures …............................................40

Table 12. EE Case A Upper Target Condition Average Product Simulator Temperatures.....................................42

Table 13. EE Case A Energy and Mean On-Cycle Power Consumption Normalized to Time-Between-Defrost and

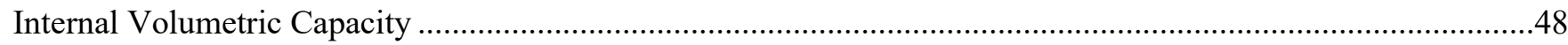

Table 14. EE Case B January Condition Average Product Simulator Temperatures...........................................51

Table 15. EE Case B July Condition Average Product Simulator Temperatures...............................................53

Table 16. EE Case B Upper Target Condition Average Product Simulator Temperatures ....................................55

Table 17. EE Case B Energy and Mean On-Cycle Power Consumption Normalized to Time-Between-Defrost and

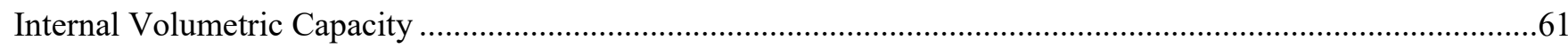




\section{Introduction/Project Description}

In this study, energy consumption and refrigeration performance are compared between three selfcontained, commercial, medium-temperature reach-in refrigerated display case technologies under various indoor conditions. Two cases containing energy-efficient components and/or environmentally friendly refrigerants were compared against a baseline case containing a traditional hydrofluorocarbon. The results of this evaluation will be used by ComEd and CLEAResult to develop new energy efficiency measures for ComEd incentive programs and will be included in the updated Illinois Technical Reference Manual for commercial and industrial energy efficiency measures [1]. Therefore, the environmental conditions used replicate indoor conditions in the climate zone in which ComEd's service territory is contained. Additionally, only test methods relevant to operation of these cases by ComEd customers were used. The following lists the three types of cases that were evaluated:

1. Baseline Case: $6 \frac{1}{2}$, 3 -door unit utilizing a $1 / 2$ horsepower (HP) fixed-speed compressor with the conventional hydrofluorocarbon (HFC) refrigerant, R134a, which exhibits a global warming potential (GWP) of 1,300 [4].

2. Energy-Efficient (EE) Case A: $6 \frac{1}{2}$,, 3 -door unit utilizing a $1 / 2$ HP fixed-speed compressor with the thermodynamically efficient R-290 refrigerant (low-density/high-purity propane) that exhibits a low GWP of 3 [5].

3 Energy-Efficient (EE) Case B: Externally equivalent model to the baseline case but containing upgraded energy-efficient refrigeration components using low-GWP R513a, an R-134a drop-in hydrofluoroolefin (HFO), with GWP of 573 [4].

In January 2020, the U.S. EPA began to enforce a ban of production of hydrofluorocarbon refrigerants due to their high GWP, in compliance with the Kigali Montreal Protocol Amendment [2]. GWP is a ratio of the amount of heat stored by a single metric ton of a substance to the amount of heat stored in a metric ton of carbon dioxide [6]. Thereby, a GWP of 1 corresponds to the heat absorbed by atmospheric $\mathrm{CO}_{2}$. The HFO refrigerant R513a exhibits less than half the GWP of R134a [4], but still exhibits a relatively high GWP. In order to be retrofittable to R134a systems, R513a contains a blend of some HFC refrigerant. Therefore, its thermodynamic performance is expected to be similar to R134a [4]. R290 (propane) refrigerant is a high-purity natural refrigerant with a comparable GWP to $\mathrm{CO}_{2}$ and improved thermodynamic efficiency compared to HFC refrigerants [5]. Refrigeration systems charged with R290 contain a very low density to reduce flammability hazards [7].

Refrigeration technologies have only recently begun adapting R290 refrigerant in more available products. Because of this, various studies have been conducted to assess the energy use of refrigerated display cases using R290 in recent years. However, self-contained medium-temperature cases have not been widely assessed other than to verify compliance with standards. Current studies have primarily focused on remote units or self-contained units for low-temperature applications [8-10].

Self-contained refrigeration is largely used in convenience stores, pharmacies, and smaller supermarkets. The use of self-contained refrigeration in the restaurant sector has also seen a significant increase due to the COVID-19 pandemic. Despite not dominating the large supermarket sector, which primarily uses remote refrigeration, self-contained refrigeration continues to have a presence in large supermarkets. There, self-contained units are commonly used in aisle-ends, checkout lanes, or for store-front novelty items. Due to the higher-than-average population density and large number of these types of markets 
within the ComEd service territory [11], reducing the energy consumption of medium-temperature cases presents significant potential for energy savings across the overall territory.

For the purpose of consistent comparison, selection of the display cases was based on the following attributes:

- Equivalent overall merchandizing configuration

- Discharge air temperatures

- Components wiring

- Number of glass doors

- An equal number of compressors/condensing units

- Internal dimensions.

The refrigerator cases' energy use and product cooling performance were evaluated under indoor conditions measured in supermarkets within the climate zone of ComEd's utility territory, as well as at the "Upper Target" environmental conditions (used in the ASHRAE 72-2018 method of test). Where applicable, the experimentation design for this work was based on AHRI/ASHRAE standard 72-2018 [3]. However, this method was modified from the standard to better address the specific questions investigated in our study. Instrumentation included monitoring the power of evaporator and condenser fans, the compressor, and lighting/controllers. Assessments were conducted over 24 hours to evaluate the effect of compressor cycling on the cases' ability to maintain the temperature of various "product simulators" situated throughout the case interior.

The following section contains a detailed description of the refrigerated case technologies evaluated. This is followed by a detailed overview of the experimentation design, set up, data collection, and analysis.

\subsection{Technology Description}

Self-contained refrigeration is defined as systems containing all components of the vapor-compression cycle (Figure 1) within an individual case. The condenser and compressor are usually mounted above the case or installed in a ventilated enclosure. By contrast, the compressor and condenser in remote refrigeration systems are located outside of a building and connected to the case through a remote refrigerant line. Because one compressor is dedicated to a single case, a self-contained system's controller is also able to respond more readily to that case's cooling demands. Self-contained systems are also cheaper to install and maintain, although they also release heat to the room surrounding the case, which must be compensated for by a building's HVAC system. 


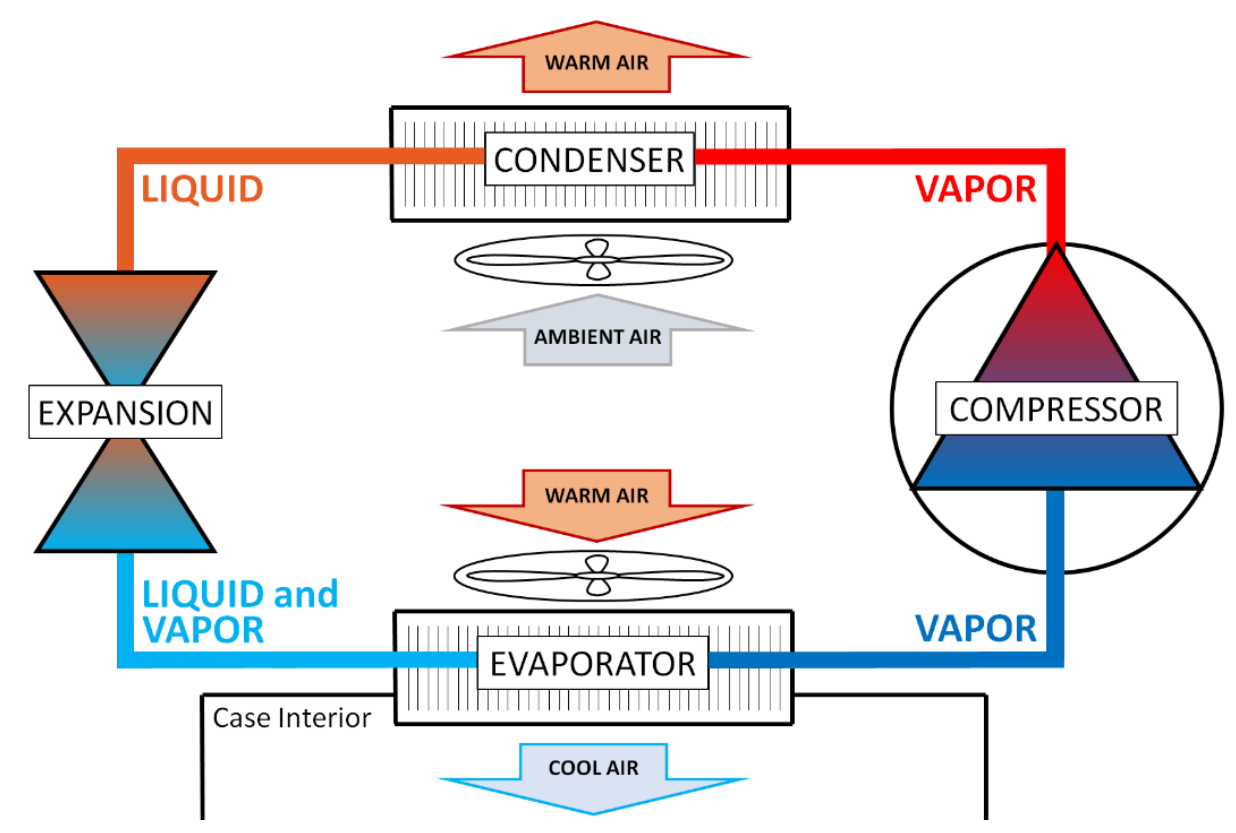

Figure 1. Diagram of refrigeration vapor-compression cycle components

Hydrofluorocarbons (HFCs) emerged as the primary refrigerants used following EPA bans on the sale and manufacture of chlorofluorocarbons (CFCs) in the late 70s through early 90s due to the latter's contribution to ozone depletion [12]. Most medium-temperature applications have since used R134a, or norflurane (1,1,1,2-Tetrafluoroethane: $\left.\mathrm{C}_{2} \mathrm{H}_{2} \mathrm{~F}_{4}\right)$. Despite its impact in reducing atmospheric ozone depletion, the EPA has since banned the sale and manufacture of R134a systems in compliance with the UN Kigali Montreal Protocol Amendment [2]. This ban took effect in January of 2020. The use of $\mathrm{R} 134 \mathrm{a}$ in existing refrigeration systems is, however, still permitted. It is therefore necessary to generate incentive for customers to replace existing R134a systems with low-GWP alternatives.

$\mathrm{R} 134 \mathrm{a}$ has a constant pressure heat coefficient $\left(\mathrm{c}_{\mathrm{p}}\right.$ ) of approximately 1.426 (liquid) $/ 0.851$ (vapor) $\mathrm{kJ} / \mathrm{kgK}$ at $25^{\circ} \mathrm{C}[13,14]$, and an enthalpy of vaporization of $234.7 \pm 15.5 \mathrm{~kJ} / \mathrm{kg}$ [15]. The thermodynamic properties of R134a in comparison to its alternatives suggest that systems could be designed with these alternatives to yield energy savings. The properties of R134a compared to the alternatives evaluated in this study are shown in Table 1. The molecular structure of the three chemicals analyzed here are shown in Figure 2.

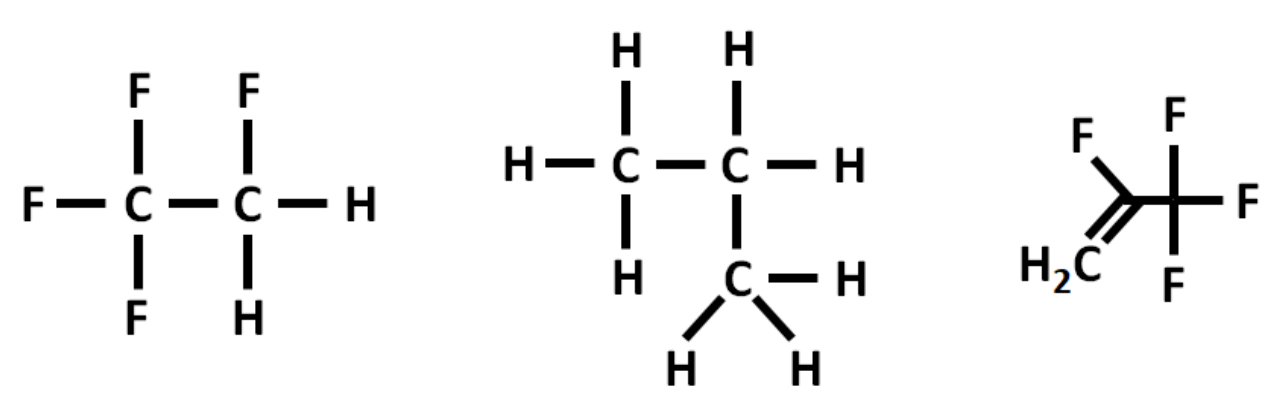

Figure 2. Molecular structure of: (left) 1,1,1,2-Tetrafluoroethane (R134a, $\mathrm{C}_{2} \mathrm{H}_{2} \mathrm{~F}_{4}$ ), (center) propane (R290, $\mathrm{C}_{3} \mathrm{H}_{8}$ ), (right) 2,3,3,3-Tetrafluoropropene (R513a, $\left.\mathrm{C}_{3} \mathrm{H}_{2} \mathrm{~F}_{4}\right)$ 
R290 refrigerant is a high-purity propane $\left(\mathrm{C}_{3} \mathrm{H}_{8}\right)$ charged at very low density that has had a history of use in industrial refrigeration [7]. Due the EPA ban on HFC refrigerants, recent refrigeration and HVAC technologies have begun to implement R290 refrigerant. The GWP of R290 is nearly $1 / 500^{\text {th }}$ that of R134a at around 3 [5]. R290 also exhibits superior thermodynamic properties. Propane has a constant pressure heat coefficient of 2.742 (liquid) $/ 2.036$ (vapor) $\mathrm{kJ} / \mathrm{kgK}$ at $25^{\circ} \mathrm{C} \mathrm{[14]} \mathrm{and} \mathrm{an} \mathrm{enthalpy} \mathrm{of}$ vaporization of $440.1 \pm 23.2 \mathrm{~kJ} / \mathrm{kg}$ [15]. Because of the flammability of propane, IEC standards have capped the allowed charge mass to 150 grams in refrigeration systems [16]. The higher latent heat of vaporization of R290 allows the system to be charged with lower mass without sacrificing thermodynamic performance [7].

R290 refrigerant offers improved thermodynamic properties and reduced greenhouse impact in comparison to R134a. Its properties, however, prevent R290 from being simply retrofit to existing R134a systems. Heat exchangers must be designed with smaller channels to transfer heat to and from the low-density propane [17]. Due to flammability, plastic or aluminum non-spark fans must be used, as well as a compressor that contains overload protectors and safe-startup devices according to IEC 60079$15[18]$.

R513a, or Opteon XP10, is a hydrofluoroolefin (HFO) refrigerant blend containing 2,3,3,3Tetrafluoropropene $\left(\mathrm{C}_{3} \mathrm{H}_{2} \mathrm{~F}_{4}\right)$. The blend contains a small fraction of $\mathrm{R} 134 \mathrm{a}$ that allows it to be implemented into most existing R134a systems due to its similar thermodynamic properties. This provides a cheaper replacement option than R290, which requires an entirely updated refrigeration system. Its thermodynamic properties are slightly deviated from R134a, however, to a degree that is expected to affect energy consumption. R513a exhibits a constant pressure heat coefficient of 1.412 (liquid) $/ 0.881$ (vapor) $\mathrm{kJ} / \mathrm{kgK}$ at $25^{\circ} \mathrm{C}$, and its enthalpy of vaporization is $194.8 \mathrm{~kJ} / \mathrm{kg}$ [19]. Despite this, R513a's GWP of 573 is nearly $1 / 3$ that of R134a [4]. If implementing other environmentally friendly alternatives is not an option, it is therefore critical that customers using R134a are incentivized to transition their equipment to R513a.

Table 1. Properties of Refrigerants Used in the Evaluated Refrigerator Case Technologies [13-15, 19]

\begin{tabular}{|c|c|c|c|c|}
\hline Refrigerant: & $\begin{array}{l}\text { Saturated Liquid } \\
\text { Density, } \rho \\
\text { @ } 25^{\circ} \mathrm{C}\left(\mathrm{kg} / \mathrm{m}^{3}\right)\end{array}$ & $\begin{array}{c}\text { Liquid Constant } \\
\text { Pressure Heat } \\
\text { Coefficient, cp } \\
\text { @ } 25^{\circ} \mathrm{C}(\mathrm{kJ} / \mathrm{kgK})\end{array}$ & $\begin{array}{c}\text { Vapor Constant } \\
\text { Pressure Heat } \\
\text { Coefficient, } \mathrm{c}_{p} \\
@ 25^{\circ} \mathrm{C}(\mathrm{kJ} / \mathrm{kgK})\end{array}$ & $\begin{array}{c}\text { Enthalpy of } \\
\text { Vaporization } \\
(\mathrm{kJ} / \mathrm{kg})\end{array}$ \\
\hline R134a & $1207 \mathrm{~kg} / \mathrm{m}^{3}$ & 1.426 & 0.851 & 234.7 \\
\hline R290 & $492 \mathrm{~kg} / \mathrm{m}^{3}$ & 2.742 & 2.036 & 440.1 \\
\hline R513a & $1134 \mathrm{~kg} / \mathrm{m}^{3}$ & 1.412 & 0.881 & 194.8 \\
\hline
\end{tabular}

We evaluated three different commercially available refrigerator cases containing different system components and refrigerants that each affect energy consumption. The baseline case (containing R134a) and EE case A (containing R290) were selected from a U.S. Department of Energy (DOE) database of commercially available refrigerators that contained the closest specifications. These included 3 doors, 5 decks (4 shelves), the closest internal dimensions, an equal number of compressors/condensing units, and equivalent electrical specifications. Although the closest cases were selected, internal volumes were not exactly identical and so energy consumption was normalized with respect to the cases' internal volumes.

The baseline case was purchased prior to the EPA ban at the end of 2019, and so a second case of the same model fitted with R513a (EE case B) was then purchased after the start of 2020. EE case B was 
updated from its R134a model and also included upgraded energy-efficient refrigeration components. Images and detailed specifications of each case are provided in the following subsections.

\subsubsection{Baseline Case}

The catalogue image and drawing of the baseline refrigerator case and EE case B are shown in Figure 3. This display case was chosen because it was the DOE-listed fixture with the closest specifications to EE case $\mathrm{A}$. The baseline case contains a top-mounted condensing unit within an aluminum enclosure, a plywood ceiling, and a front grille but no rear wall. The case has right-side hinged doors with a whitepainted stainless-steel interior and exterior. The refrigeration components consist of a fixed-speed compressor, a capillary tube, and an evaporator enclosure containing two $14 \mathrm{~cm}$-diameter plastic evaporator fans.

All of the electrical components are wired to a $115 \mathrm{~V} / 60 \mathrm{~Hz} / 1-\mathrm{Ph} 5-20 \mathrm{P}$ NEMA plug. The unit is approximately 78" in length, 37" deep, and 87" tall when placed on 5-inch casters. The interior volumetric capacity is reported as 62.1 cubic feet. However, the volumetric capacity between shelves, product load lines, and below the evaporator is 48.29 cubic feet. The left and right shelves are 22.75 inches wide, and middle shelves are 25 inches wide. All shelves are 21 inches between product load lines, and the bottom deck is 25.25 inches to the product load line. There is 10.5 inches of clearance between each shelf, and below the evaporator. 

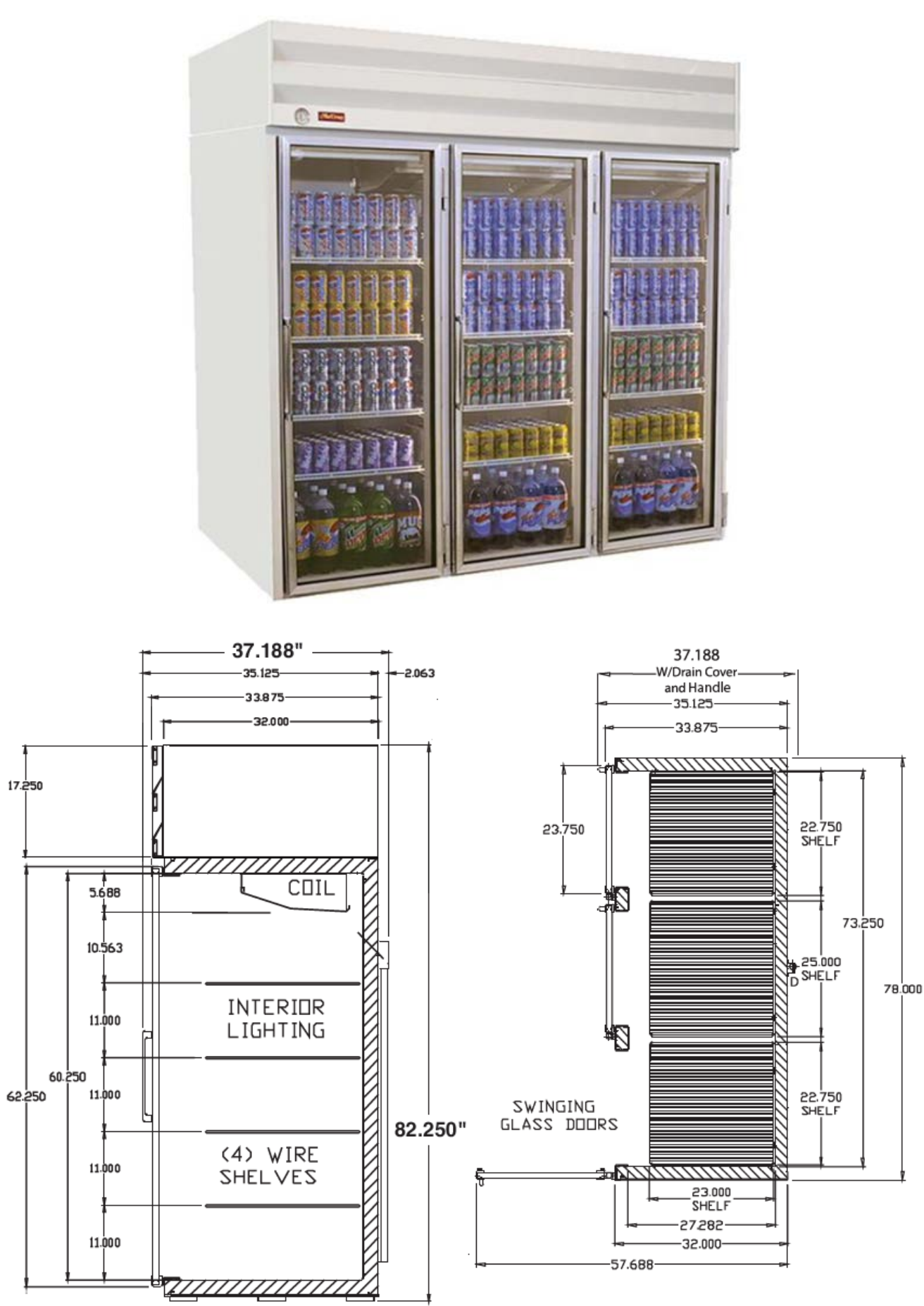

Figure 3. Baseline and EE case B catalogue image (above) and drawing (below)

Figure courtesy of JES Restaurant Equipment Inc. (2019)

Images of the condensing unit and evaporator panel are shown in Figure 4. The baseline case condensing unit contains a $1 / 2$ HP Tecumseh compressor (model AKA4476YXA) and 11.75" diameter aluminum condensing fan mounted to the 13.25 " $\mathrm{x} 12.25$ " face of a 5 " thick condenser heat exchanger. A 15.75 " x 35.25 " evaporator enclosure hanging 5.25" from the case interior's ceiling contains the two plastic $7.5^{\prime \prime}$ diameter draw through fans directed forward at a $17.5^{\circ}$ angle and centered $11.75^{\prime \prime}$ from the 
front of the case and 5.25" from the center. Airflow is directed into the fans and a discharge opening of 2.25 " from the rear of the evaporator enclosure delivers air to the case along the back wall.

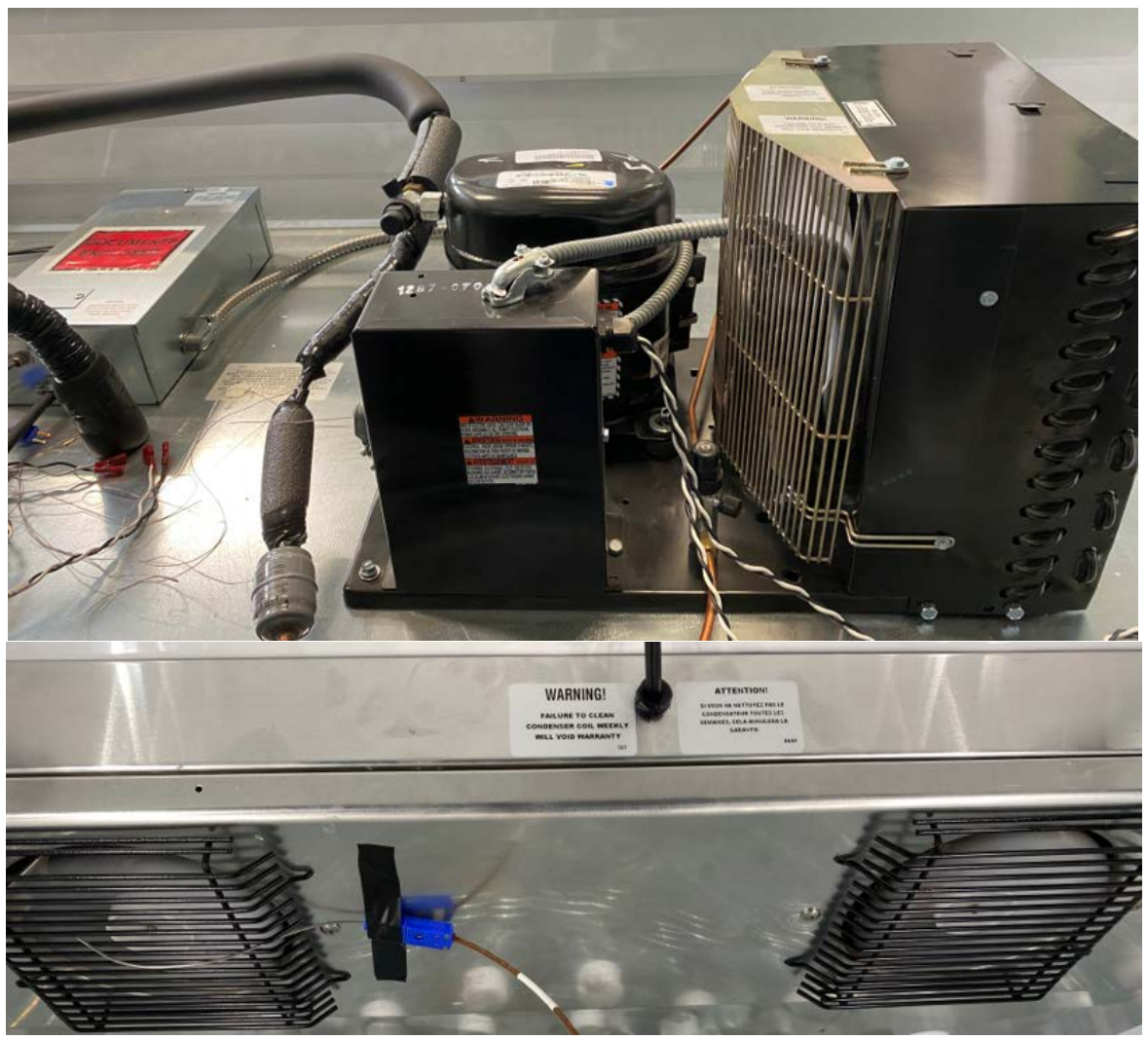

Figure 4. Baseline case condensing unit (top) and evaporator panel (bottom)

Compressor cycling is controlled via internal cut-in and cut-out temperatures set to $\pm 2.22^{\circ} \mathrm{C}\left(4^{\circ} \mathrm{F}\right)$ from a default $2.22^{\circ} \mathrm{C}\left(36^{\circ} \mathrm{F}\right)$ setpoint temperature that can be adjusted on a digital Dixell XR40CX controller interface. The baseline case manual stated that defrost cycles were set to occur by default every 8 hours until the evaporator coil would reach a temperature of $10^{\circ} \mathrm{C}\left(50^{\circ} \mathrm{F}\right)$. Through operation, it was found that defrost cycles instead only occurred once every 24 hours. Like the other cases, this case contained no electrical defrost and instead allowed natural convection to warm the evaporator coil. Because the other cases contained different defrost cycling controls, the total energy consumption was calculated with respect to the time between defrost cycles (and normalized by internal volume). Evaporator fans operated continuously, and the condenser fan cycled concurrently with the compressor.

\subsubsection{EE Case A}

The catalogue image and drawing of the EE case A are shown in Figure 5. This fixture was selected as an optimally rated DOE-listed case using R290 that shared the closest specifications to the baseline case. Unlike the baseline and EE case B, this case contains a bottom-mounted condensing unit within an enclosure containing a front and rear steel-coated grille to allow airflow through the condenser. Also, the far left door hinges from the left and not the right side, whereas the baseline and EE case B doors all hinge from the right. The case contains a stainless steel interior and a powder-coated, black-painted exterior. The refrigeration components consist of a fixed-speed compressor, a capillary tube, and an evaporator enclosure containing a single $21-\mathrm{cm}$ diameter plastic evaporator fan. 
All of the electrical components are wired to a $115 \mathrm{~V} / 60 \mathrm{~Hz} / 1-\mathrm{Ph} 5-15 \mathrm{P}$ NEMA plug. The unit is approximately 78 " in length, 30" deep, and 83" tall when mounted on 4" casters. The interior volumetric capacity is reported as 65.7 cubic feet. However, this includes space that cannot be occupied by product. Not including space between shelves, around the evaporator, or outside of the product load line, the volumetric capacity is 49.15 cubic feet. The shelves are all 21.5 inches deep, 24.25 inches wide, and have 10.5 inches of clearance between them and the above shelf (or evaporator enclosure). The bottom deck is 23 inches deep to the product load line and has 11.5 inches of clearance below the lowest shelf.
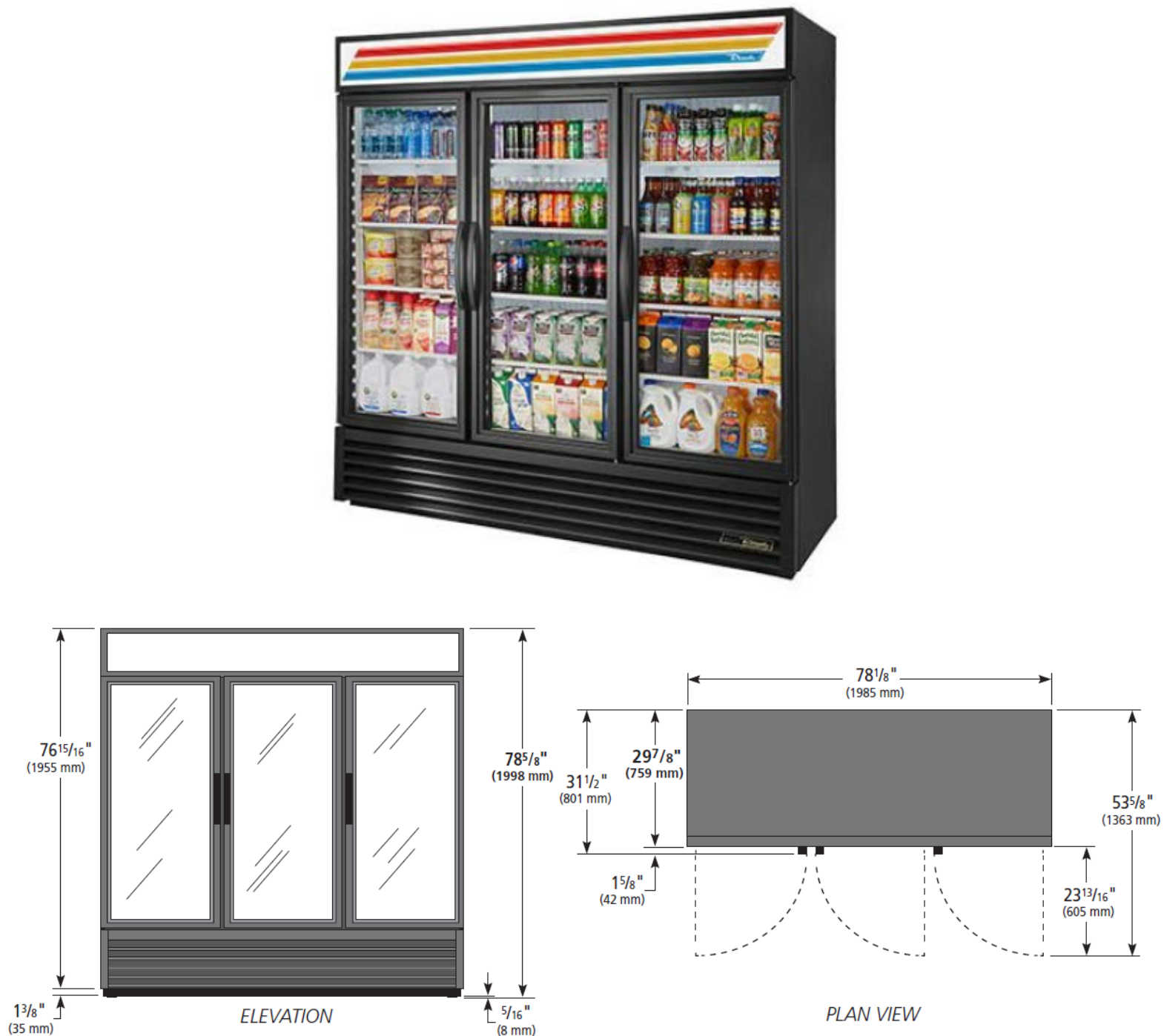

Figure 5. EE case A catalogue image (above) and drawing (below)

Figure courtesy of True Manufacturing Company, Inc. (2019)

Images of the condensing unit and evaporator panel are shown in Figure 6. This fixture's condensing unit contains a SECOP model NLE11MN $1 / 2$ HP compressor and 10.25" diameter aluminum condensing fan mounted to the 11 " $\mathrm{x} 11$ " face of a 5.5" thick condenser heat exchanger. Just as with the other cases, the evaporator uses a draw-through fan that delivers air into the evaporator enclosure and discharges from a grille facing the back wall. The evaporator enclosure is 16.75 " x 33 " and hangs 5.25" from the case interior's ceiling and is flush with the front wall of the case above the doors. The evaporator fan is 
located 11.5" from the front of the case and the discharge grille located on the rear of the evaporator panel 5.75" from the back wall.

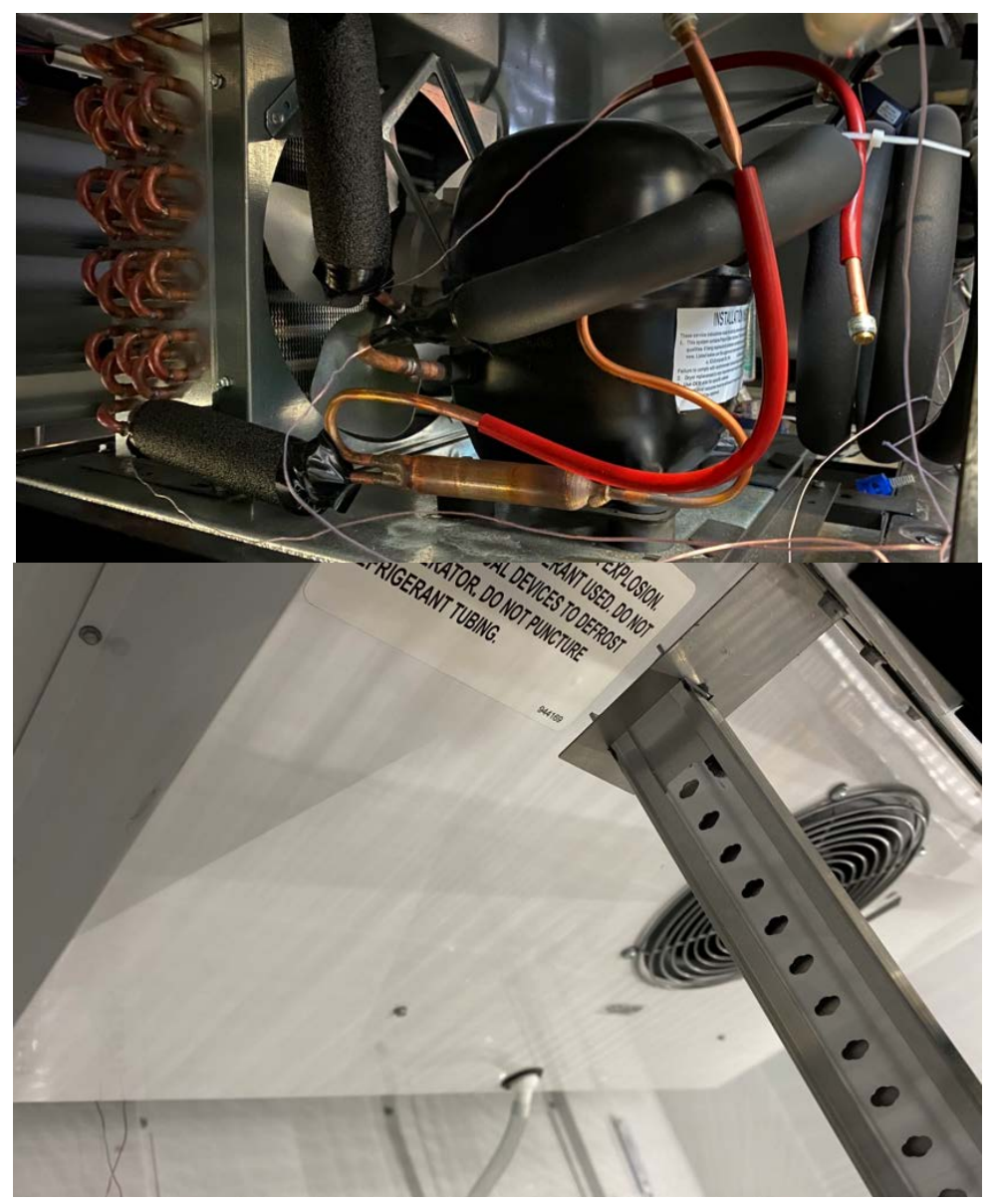

Figure 6. EE case A condensing unit (top) and evaporator panel (bottom)

An analogue Sollatek brand controller regulates compressor cycling via internal cut-in and cut-out temperatures set according to the value specified on a dial. Values on the dial range between 1 and 9 , where a default value of 5 corresponds to cut-out and cut-in internal temperatures of $0.56^{\circ} \mathrm{C}\left(33^{\circ} \mathrm{F}\right)$ and $3.33^{\circ} \mathrm{C}\left(38^{\circ} \mathrm{F}\right)$, respectively. This case evaporator defrosts off-cycle, although the case does not have any scheduled defrost cycle. The case is well insulated, and so compressor cycling occurs infrequently enough that the evaporator coil sufficiently defrosts between compressor cycles. Unlike the other cases, the evaporator fans operate on regular intervals for 1-min cycles every $6 \mathrm{~min}$. The condenser fan is, however, still powered concurrently with compressor cycling.

\subsubsection{EE Case $B$}

Leading up to the EPA ban on hydrofluorocarbons, the manufacturer of the baseline case began to produce their model with an upgraded evaporator and condenser using R513a refrigerant, and lighting. Because these upgrades were expected to reduce case energy consumption, a second model of this case was purchased as EE case B. The refrigeration components consist of a fixed-speed compressor, a capillary tube, and an evaporator enclosure containing two, more robust 8.5 " diameter aluminum evaporator fans than those of the baseline. The R513a model was equipped with a top-mounted condensing unit within an aluminum enclosure with a front grille, but no ceiling or rear wall. The case 
exterior is otherwise equivalent to the baseline case with right-side hinged doors and a white-painted stainless-steel interior and exterior.

All of the electrical components are wired to a $115 \mathrm{~V} / 60 \mathrm{~Hz} / 1-\mathrm{Ph} 5-20 \mathrm{P}$ NEMA plug. The unit's external dimensions (78" in length, 37" deep, and 87" tall when placed on 5" casters) are equivalent to the R134a version of the model. Left and right shelves are 22.75 " wide and middle shelves are 25 " wide. All shelves are 21 " deep up to the product load line, and the bottom deck is 25.25 " deep to the product load line. There is 10.5 " of clearance between each shelf, and below the evaporator. The catalogue image and drawing are shown in Figure 3. The interior volumetric capacity is reported as 62.1 cubic feet. However, the volumetric capacity was calculated only up to the product load lines and between shelves at 48.29 cubic feet.

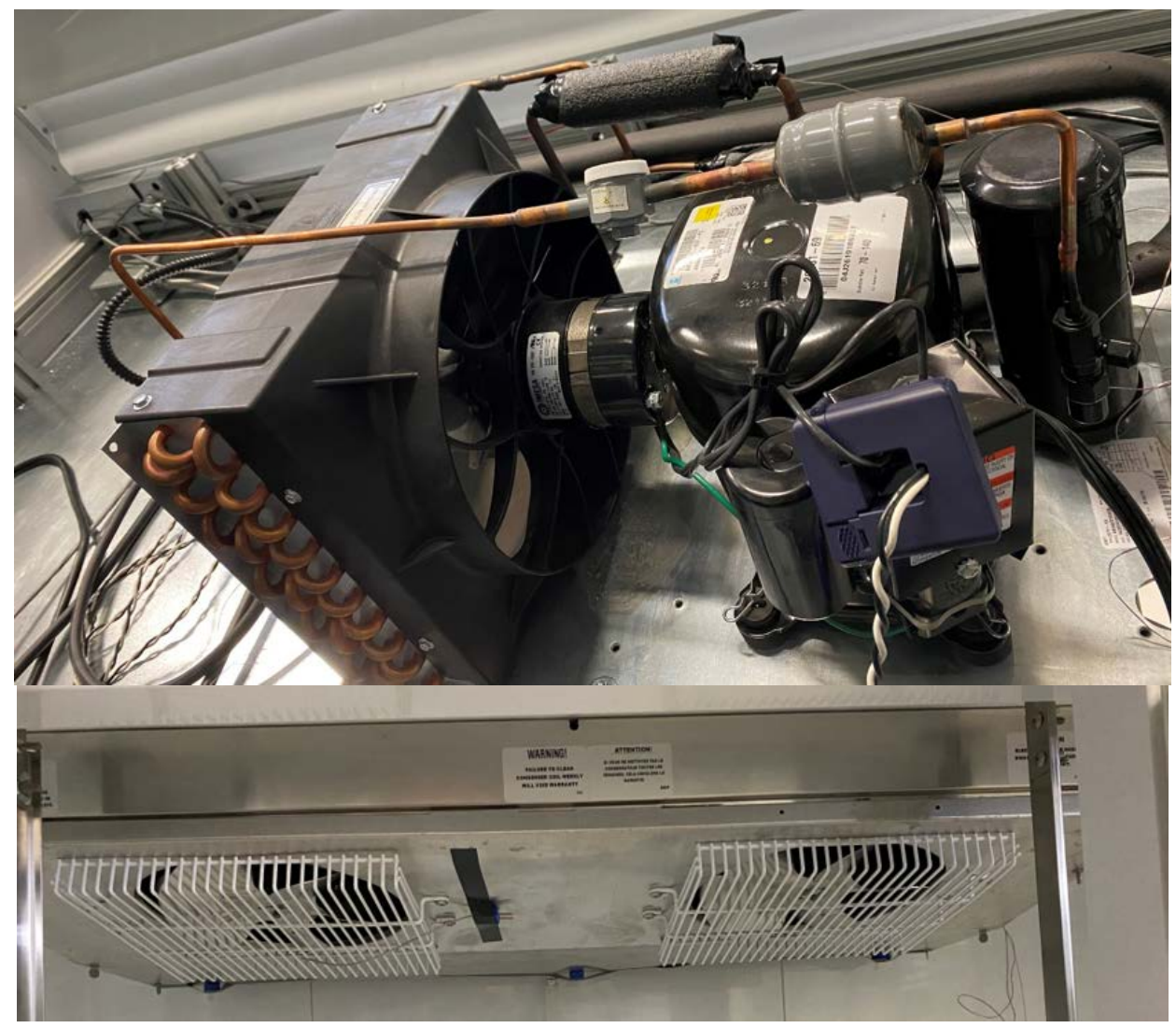

Figure 7. EE case B condensing unit (top) and evaporator panel (bottom)

Images of the condensing unit and evaporator panel are shown in Figure 7. The EE case B condensing unit contains the same $1 / 2$ HP compressor Tecumseh model AKA4476YXA as the baseline version since it is compatible with both refrigerants. A slightly smaller 10.5 " diameter aluminum condensing fan, however, is mounted to the 12 " $\mathrm{x} 11.25$ " face of a 3.5 " thick condenser heat exchanger. A larger 17.5 " $\mathrm{x}$ 36.25 " evaporator enclosure hanging 5 " from the case interior's ceiling contains the two fans directed forward at an $11^{\circ}$ angle and centered 12.5" from the front of the case and 5.5" from the center. As with the other cases, draw through fans discharge air across a 2.25 " opening from the rear of the evaporator enclosure into the case along the back wall. 
Compressor cycling is controlled via a digital Dixell XR40CX controller set to internal cut-in and cutout temperatures $\pm 2.22^{\circ} \mathrm{C}\left( \pm 4^{\circ} \mathrm{F}\right)$ from a $2.22^{\circ} \mathrm{C}\left(36^{\circ} \mathrm{F}\right)$ default setpoint. Defrost cycles are off-cycle, allowing natural convection to warm the evaporator coil without electrical heating. Defrost cycles terminate when a sensor on the evaporator coil reaches $10^{\circ} \mathrm{C}\left(50^{\circ} \mathrm{F}\right)$ like the baseline model. However, cycles are scheduled to occur once every 12 hours as opposed to 24 hours. Again, the total energy consumption was therefore normalized with respect to time between defrost cycles. The evaporator fan operation was also different from the baseline: The evaporator fan was powered concurrently with compressor cycling and during defrost. However, the condenser fan was only powered concurrently with compressor cycling. A table displaying differences in key parameters for each of the three cases is provided in Table 2 .

Table 2. General Refrigerator Display Case Key Parameter Specifications

\begin{tabular}{ll|lllll}
\hline Case & Refrigerant & V/Hz/Ph & $\begin{array}{l}\text { CCMS-Rated } \\
\text { Energy (kWh/day) }\end{array}$ & $\begin{array}{l}\text { Defrost Cycle } \\
\text { Frequency }\end{array}$ & $\begin{array}{l}\text { Rated Cooling } \\
\text { Output (Btu/h) }\end{array}$ & $\begin{array}{l}\text { Rated } \\
\text { Current (A) }\end{array}$ \\
\hline Baseline & R134a & $115 / 60 / 1$ & 6.24 & 24 hours & 2,600 & 13.8 \\
\hline EE Case A & R290 & $115 / 60 / 1$ & 4.90 & none & 4,716 & 9.3 \\
\hline EE Case B & R513a & $115 / 60 / 1$ & Unavailable & 12 hours & Unavailable & Unavailable \\
\hline Refrigerant & GWP & Volumetric & Default Cut-In & Default Cut- & Evaporator Fan Cycling \\
\hline R134a & & Capacity (ft $\left.{ }^{3}\right)$ & Temp ( ${ }^{\circ}$ F) & Out Temp ( ${ }^{\circ}$ F) & Continuous \\
\hline R290 & 1300 & 48.29 & 32 & 40 & 38 & 1 min every 6 min \\
\hline R513a & $<4$ & 49.15 & 33 & 40 & With compressor cycling
\end{tabular}




\section{Laboratory Assessment Procedure}

The laboratory assessment plan (LAP) for this project was developed to capture the performance of selected display cases under representative environmental and operational conditions similar to supermarkets within ComEd's service territory. Because of this, and because of factors present at the National Renewable Energy Laboratory's (NREL's) facility (such as elevation), this project is not intended to replicate any tests performed by rating entities for medium-temperature refrigerated cases. Where applicable, measurement methods were modified from industry-wide standards, including ANSI/ASHRAE 72-2018 and ANSI/AHRI 1200-2013 [3, 20]. These standards were used to maintain consistency between the assessment of each display case. In addition to indoor supermarket conditions, the cases were evaluated at environmental conditions defined in ANSI/ASHRAE 72-2018, denoted as "Upper Target" conditions in this report.

The LAP focused on temperature and electrical measurements. Temperature measurements included air, "product simulator," and refrigerant line locations. Power consumption, current, voltage, and power factor were measured for the total case and for each of the case subcomponents including the compressor, condenser and evaporator fans, and lighting and controls. Total energy was calculated by integrating power measurements across refrigeration cycle, normalized by operation time between defrost cycles and internal volumetric capacity.

Temperature measurements included:

- Product simulators placed at various locations within each case

- Air discharge temperatures leaving the evaporator

- Air inlet temperature to the evaporator

- Case interior air temperature.

To ensure environmental conditions were appropriately maintained, ambient measurements within the environmental chamber were closely monitored and recorded. Condensate mass was also measured after each experimentation to quantify the moisture removal capability of each case.

Following stabilization and steady-state testing in the lab, the cases were evaluated for 24-h cycles within a controlled-environment chamber. Evaluations were conducted repeatedly until approximately equivalent results were obtained between at least two tests under each environmental condition. Details pertaining to the experimental setup, steady state testing, and environmental chamber evaluations are provided in the following sections.

\subsection{Instrumentation/Setup}

Each case was evaluated in NREL's Optimization and Control Laboratory (OCL). The OCL contains "building" bays, which each contain electrical supply to simulate residential and commercial buildings. The environmental chamber would hold one case at a time while the others were set up and stored in building bay 3 . Following setup, the cases were maintained powered on to reduce any irregularities caused by startup and to keep product simulators cooled at target temperature to reduce stabilization time. 
Once the cases were first obtained, they were modified to remove any optional equipment that could increase total energy consumption. Any exterior lighting not connected to interior lights was assumed as optional and shut off. Condensate pans were removed and instead condensate lines were connected to a laboratory condensate pumping system. When in the chamber, the case condensate was pumped to a weigh bucket for analysis of condensate mass.

The AHRI test standard requires the average of product temperatures to be maintained within $38 \pm 2^{\circ} \mathrm{F}$ $\left(3.33 \pm 1.11^{\circ} \mathrm{C}\right)$ for medium-temperature refrigeration applications in order to comply with FDA food code [20]. These product temperatures were monitored using thermocouples placed in multiple "product simulators" situated evenly throughout the interior of the cases. The product simulators specifications (ASHRAE 72) are as follows [3]:

- Product simulators consisted of 3" x 3" (base) x 2.5" (height) plastic containers.

- Simulators were filled with grout sponges soaked in a 50/50 ( $\pm 2 \%)$ mix of food-grade propylene glycol and deionized water.

- Simulators were inserted with Omega brand 1/16" type-T thermocouple probes (model number TMQSS-062U-6) with $\pm 0.9^{\circ} \mathrm{F}$ accuracy.

- Thermocouple probes were inserted through a drillhole in the simulator lid such that the tip of each probe would rest 1.5 " from the bottom.

- Thermocouple pre-calibration was verified using an ice bath.

Eighteen simulators were placed at the left wall, right wall, and geometric center of the cases on the bottom deck, the second shelf from the bottom, and the top shelf. Each of these locations had two simulators placed at both the front and rear product load limit lines on the shelf. Figure 8 shows a schematic diagram of the location of these product simulators throughout the case interior.

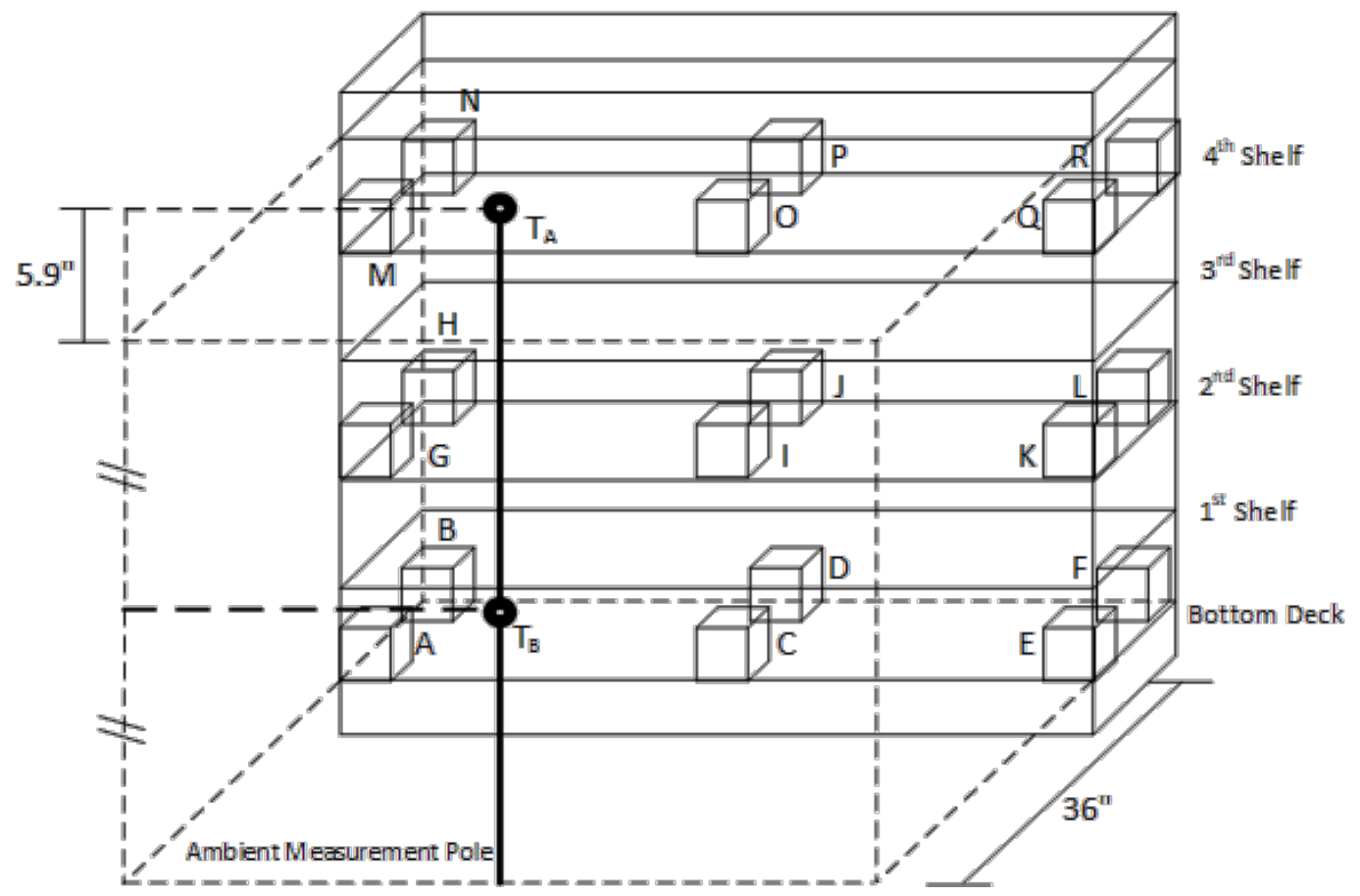

Figure 8. Schematic of product simulator temperature measurement locations (A-R), and ambient temperature locations $\left(T_{A}\right.$ and $\left.T_{B}\right)$ 
The net usable interior volume of the cases was loaded with "filler material" to simulate the thermal mass of food product. The initial lab assessment plan stated that at least $70 \%$ of each case's internal volume would be filled with lumber containing a density above $480 \mathrm{~kg} / \mathrm{m}^{3}$ stacked evenly to the load line of each shelf [3]. This loading procedure was used for the filler material during initial steady-state testing. However, it was found that this loading method blocked airflow within the cases' interior, which prevented product simulators from stabilizing within required temperatures. Therefore, the cases were instead filled with 11" tall, $1 \mathrm{~L}$ water bottles as the filler material. The curved-shape of the cylindrical bottles allowed air to pass between them, which allowed the case to effectively cool the product simulators.

Filler bottles were organized in a $7 \times 7$ pattern on each shelf except those that contained product simulators. This was the maximum number of bottles that fit between the product load lines on each cases' shelves. Since the bottles nearly reached the full height of each shelf, shelves containing product simulators had six bottles removed to fit the simulators at the front and rear of the shelf, as shown in Figure 9. The baseline case and EE case B have a deeper bottom deck, and so an additional row of seven bottles was added to those shelves. Therefore, the baseline and EE case B held a total of 702 bottles $\left(24.8 \mathrm{ft}^{3}\right)$, and EE case A held a total of 681 bottles $\left(24.0 \mathrm{ft}^{3}\right)$. Since each case had a slightly different net usable volume, this accounted for $51.3 \%$ of the volume filled in the baseline case and EE case B, and $48.9 \%$ of the volume filled in EE case A.

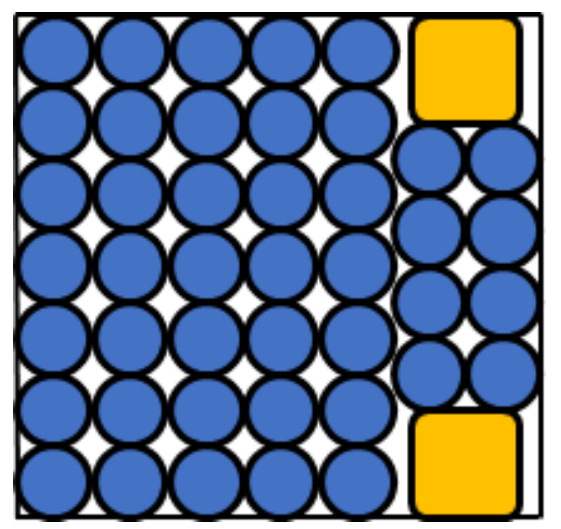

Figure 9. Diagram of filler material (blue) and product simulator (yellow) configuration on an example right-side shelf

To monitor and maintain conditions within the environmental test chamber, an "ambient measurement pole" was mounted 36" from the front of the case as shown in Figure 8. Measurements were collected at different heights along the pole specified by $\mathrm{T}_{\mathrm{A}}$ and $\mathrm{T}_{\mathrm{B}}$. Location $\mathrm{T}_{\mathrm{A}}$ is $5.9^{\prime \prime}$ above the top edge of the case doors, and location $\mathrm{T}_{\mathrm{B}}$ is at the height of the geometric center of the case doors. Location $\mathrm{T}_{\mathrm{A}}$ was fitted with both a thermocouple probe and the measurement end of the dew-point hygrometer hose. Location $\mathrm{T}_{\mathrm{B}}$ was fitted with only a thermocouple probe. The same model 1/16" T-type probes were used as for the product simulators, and an EdgeTech DewTrak II DPS3 model chilled mirror dew-point hygrometer was used with $\pm 0.2^{\circ} \mathrm{C}\left( \pm 0.4^{\circ} \mathrm{F}\right)$ accuracy. The two ambient thermocouples were each inserted into $1 / 2$ "-thick brass slugs with a $3 / 4$ " diameter to measure dry-bulb temperature.

Power, voltage, current, and power factor were each measured through two Continental Control Systems WMC-3Y-208-MB model Wattnode power meters. A "meter box" containing each of the Wattnodes was constructed to allow the case to be plugged directly to the box to monitor total plug power while 
also allowing individual current transformers (CTs) to be connected to monitor component consumption. Five Accu-CT ACTL-0750 model CTs were instrumented to each of the three refrigerated cases' components. Two 20 A CTs were clamped to the wiring to each case's total plug power and compressor, and three other 5 A CTs were clamped to that of the condenser fan, evaporator fan, and lighting and controls. Measurement accuracy for each electrical parameter was $\pm 0.5 \%$. An image of the constructed meter box is shown in the left image of Figure 11.

To simulate door openings by customers in the field, automatic Olide 120B model door actuators were mounted to the cases above each of their three doors as shown in Figure 10. The actuators were positioned at a height of 1.25 " above the case doors to allow the actuator arm to swing freely with no resistance. The actuators were mounted directly to the frame of EE case A, but the actuators at this height covered the baseline and EE case B controller interface. Therefore, the front panel of these cases' condensing units was raised to install an 87"-long 80-20 structure to hold the actuator mounts. Two 35" extrusions were reinforced to the walls of the condensing unit enclosure from the interior to hold the overhanging actuator mounts in place.

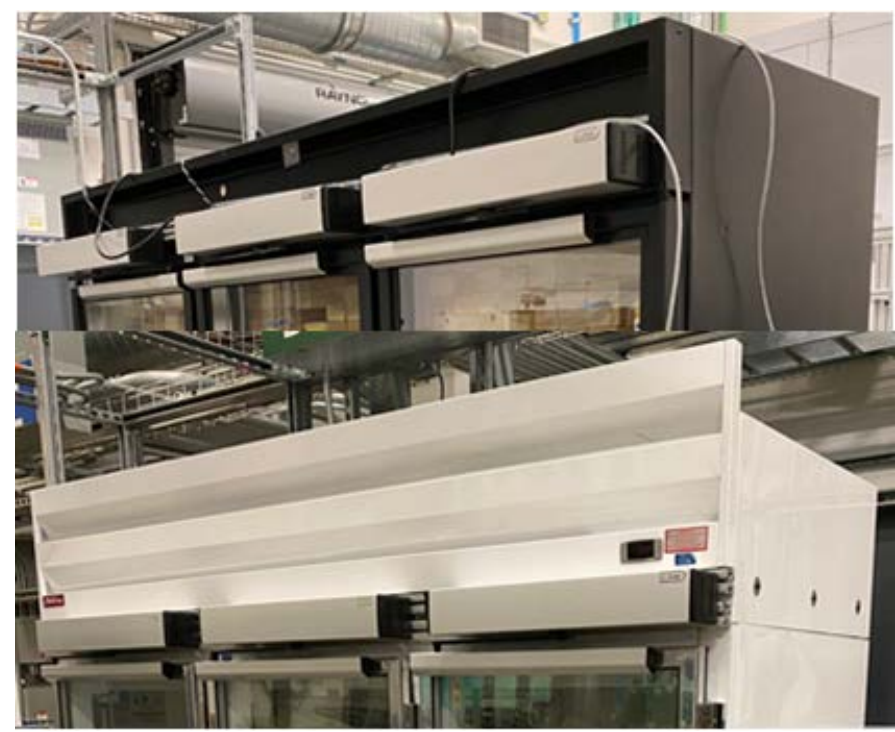

Figure 10. Door actuators mounted to EE case A (top), and the baseline case (bottom)

NREL's in-house data acquisition system, referred to as the Building and Energy Data Acquisition and Control (BEDAC) system, was used to record measurements and control door actuators. BEDAC recorded all measurement data at a sampling rate of $1 \mathrm{~Hz}$. Thermocouples, voltage inputs (e.g., the dewpoint hygrometer), and digital output wiring (e.g., door actuators) were connected to BEDAC terminal panels situated throughout the OCL (Figure 11, middle image). Power measurements from the Wattnode meter box were supplied via Modbus through an RJ50 cable that was connected to a BEDAC Modbus interface (Figure 11, right image). Within the BEDAC software's user interface, separate power, current, voltage, and power factor measurements are selected from different Modbus registers. 

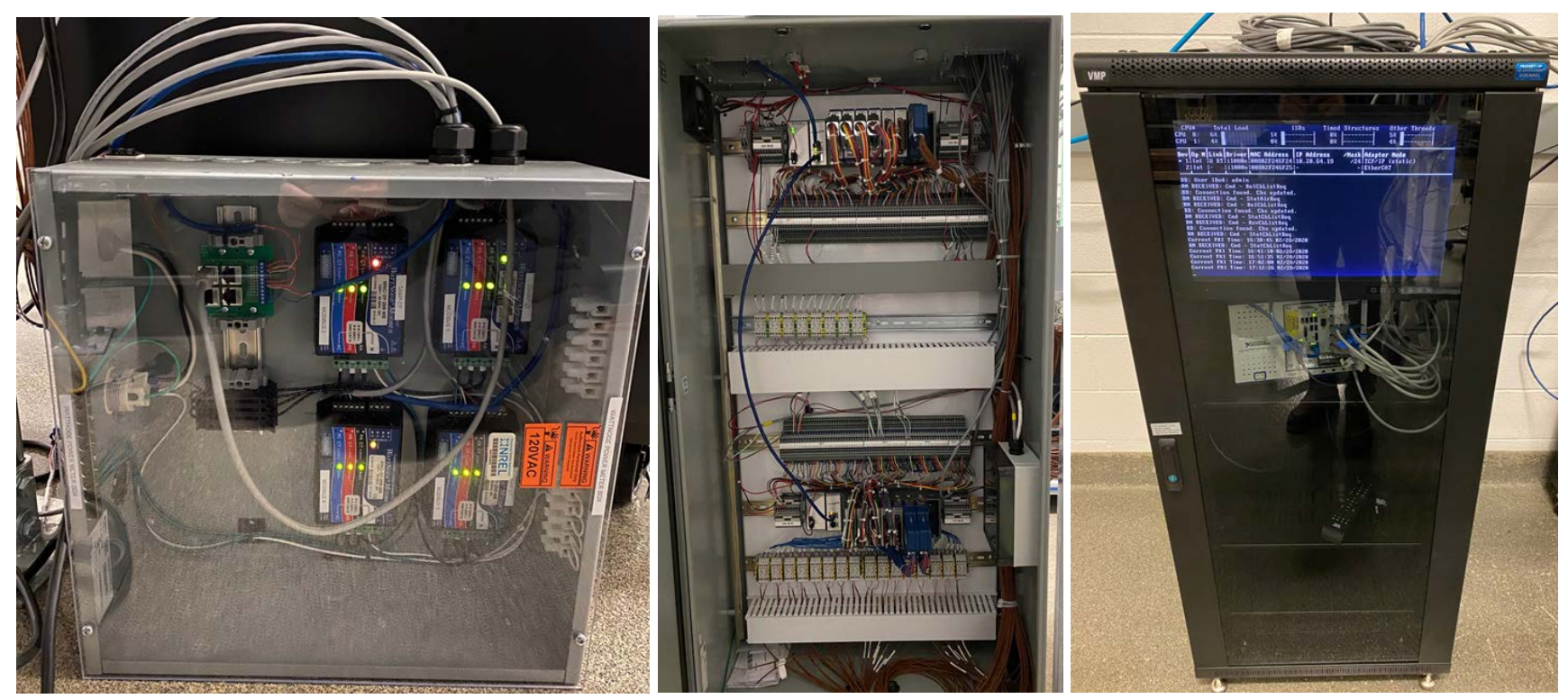

Figure 11. Left: Image of Wattnode "Meter Box" designed for component power consumption metering, Middle: Image of BEDAC data acquisition system terminal panel, Right: Image of BEDAC modbus interface and PXI (Peripheral component interconnect Extension for Instrumentation)

In addition to the product simulator and chamber ambient temperature measurements, five other interior air temperature measurements were recorded. This included evaporator discharge air temperatures at the left, center, and right side of the discharge grille, the evaporator inlet air temperature, and the air temperature at the geometric center of the case interior. These five measurements were recorded using the same model 1/16" T-type thermocouple probes used for the product simulator and ambient measurements. A list of instrument models used for each measurement is listed below in Table 3 . These probes were not, however, inserted into brass slugs as with the chamber ambient thermocouples.

Table 3. List of Measurement Sensors and Accuracy

\begin{tabular}{|c|c|c|c|}
\hline MEASUREMENT: & Brand/Model & Type & Accuracy \\
\hline $\begin{array}{l}\text { Product Simulator, Internal Air, and } \\
\text { Chamber Dry-Bulb Temperatures }\end{array}$ & $\begin{array}{l}\text { Omega/TMQSS- } \\
\text { 062U-6 }\end{array}$ & $\begin{array}{c}\text { 1/16" Type-T } \\
\text { thermocouple probes }\end{array}$ & $\pm 0.5^{\circ} \mathrm{C}\left( \pm 0.9^{\circ} \mathrm{F}\right)$ \\
\hline Chamber Dew-Point Temperature & $\begin{array}{l}\text { EdgeTech/DewTra } \\
\text { k II DPS3 }\end{array}$ & $\begin{array}{l}\text { chilled-mirror dew-point } \\
\text { hygrometer }\end{array}$ & $\pm 0.22^{\circ} \mathrm{C}\left( \pm 0.4^{\circ} \mathrm{F}\right)$ \\
\hline $\begin{array}{l}\text { Refrigerant Piping Surface } \\
\text { Temperatures }\end{array}$ & $\begin{array}{l}\text { Omega/SA1-T- } \\
\text { SRTC }\end{array}$ & $\begin{array}{l}\text { Type-T surface } \\
\text { temperature thermocouple }\end{array}$ & $\pm 0.5^{\circ} \mathrm{C}\left( \pm 0.9^{\circ} \mathrm{F}\right)$ \\
\hline $\begin{array}{l}\text { Case Total Plug and Compressor } \\
\text { Power/Voltage/Current/Power Factor }\end{array}$ & \multirow{2}{*}{$\begin{array}{c}\text { Continental Control } \\
\text { Systems/WMC-3Y- } \\
\text { 208-MB, Accu-CT } \\
\text { ACTL-0750 }\end{array}$} & $\begin{array}{l}\text { Wattnode power meter, } 20 \\
\text { A current transformer }\end{array}$ & \multirow[b]{2}{*}{ $\pm 0.5 \%$} \\
\hline $\begin{array}{l}\text { Condenser Fan, Evaporator Fan(s), } \\
\text { Lighting and Controller } \\
\text { Power/Voltage/Current/Power Factor }\end{array}$ & & $\begin{array}{l}\text { Wattnode power meter, } 5 \\
\text { A current transformer }\end{array}$ & \\
\hline
\end{tabular}

Refrigerant lines' surface temperatures (Appendix B) were recorded to aid NREL engineers in understanding case operation. Only surface temperature thermocouples on the outside of the refrigerant piping wrapped in insulation were used, and not thermocouple taps. Since the purpose of this project was to assess the energy consumption of these technologies as they are provided commercially, it was critical to avoid any instrumentation that would tamper with the refrigeration system in a manner that could affect performance. Due to conductive resistances in the piping, these temperatures cannot be considered an accurate representation of actual refrigerant temperatures. Refrigerant temperatures 
merely provided a general understanding of the temperature relationship between sides of the refrigeration cycle. Omega engineering model SA1-T-SRTC Type-T surface temperature thermocouples with $\pm 0.9^{\circ} \mathrm{F}$ accuracy were used for collecting piping temperatures.

\subsection{Steady-State Testing}

Steady-state testing was initiated in building bay 3 following setup and instrumentation of the three refrigerated cases. Each case was separately filled with product simulators and filler material and allowed to cool to equilibrium. An image of the three cases set up in building bay 3 is shown in Figure 12. From left to right, the cases shown are EE case B, the baseline case, and EE case A. Here, the baseline case is loaded with filler material and undergoing steady state testing. This involved monitoring product simulator until the temperature in each simulator deviated less than $0.4^{\circ} \mathrm{F}\left(0.22^{\circ} \mathrm{C}\right)$ across a 12 -h period. Then, the average of all simulator temperatures was calculated to ensure that it was maintained within AHRI/FDA requirements $\left(3.33 \pm 1.11^{\circ} \mathrm{C} / 38 \pm 2^{\circ} \mathrm{F} /\right)[20,21]$.

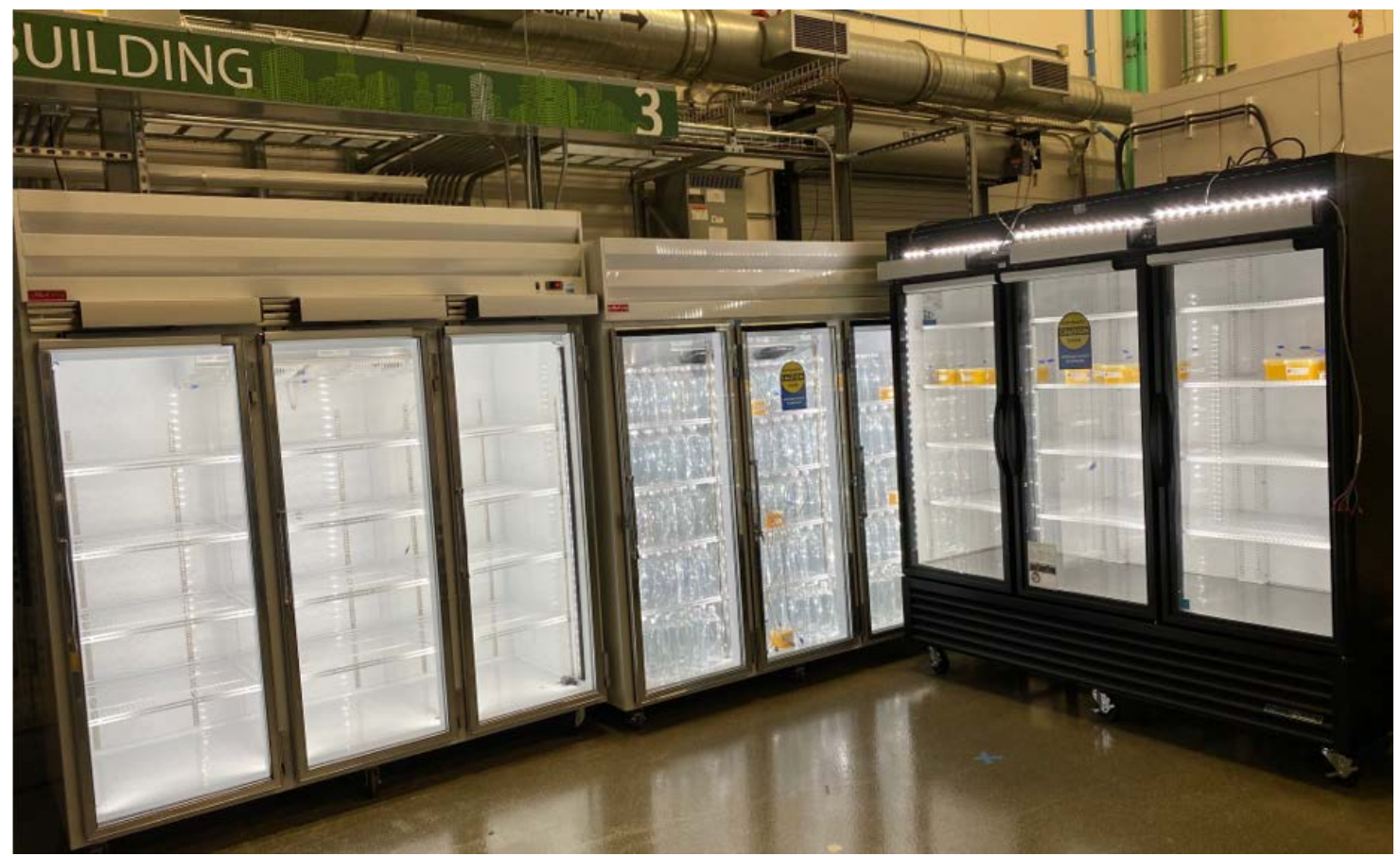

Figure 12. OCL Building Bay 3 with (from left) EE case $B$, the baseline case (undergoing steady-state testing), and EE case A

NREL's OCL is located at high altitude in Golden, Colorado, at 1,773 m. At this altitude, air density is nearly $20 \%$ less than at sea level, which reduces the volumetric flow rate of the evaporator fan, thereby reducing heat transfer through the evaporator. To compensate for the effect of altitude, the cut-in and cut-out temperatures were lowered on each case controller until the average of product simulator temperatures were maintained within AHRI/FDA requirements. This was possible across a range of cutin and cut-out temperatures, so one configuration was selected that generated mean simulator temperatures closest to $3^{\circ} \mathrm{C}\left(37.4^{\circ} \mathrm{F}\right)$. Each time cut-in and cut-out temperatures were readjusted, each case was again stabilized until deviation in all simulator temperatures stayed less than $0.22^{\circ} \mathrm{C}\left(0.4^{\circ} \mathrm{F}\right)$ across a 12-h period. The final cut-in and cut-out temperatures used for each case are listed in Table 4 along with the resultant mean simulator temperature from steady-state testing. 
Table 4. Selected Cut-In and Cut-Out Temperatures and Resultant Mean Product Simulator Temperature

\begin{tabular}{l|c|c|c} 
CASE: & $\begin{array}{c}\text { Cut-In } \\
\text { Temperature } \\
\left({ }^{\circ} \mathrm{C} /{ }^{\circ} \mathrm{F}\right)\end{array}$ & $\begin{array}{c}\text { Cut-Out } \\
\text { Temperature } \\
\left({ }^{\circ} \mathrm{C} /{ }^{\circ} \mathrm{F}\right)\end{array}$ & $\begin{array}{c}\text { Steady-State Mean Product } \\
\text { Simulator Temperature } \\
\left({ }^{\circ} \mathrm{C} /{ }^{\circ} \mathrm{F}\right)\end{array}$ \\
\hline Baseline & $3.33 / 38$ & $-1.11 / 30$ & $3.00 \pm 0.02 / 37.40 \pm 0.04$ \\
EE Case A & $1.67 / 35$ & $-1.11 / 30$ & $2.90 \pm 0.03 / 37.22 \pm 0.05$ \\
EE Case B & $3.89 / 39$ & $-0.56 / 31$ & $3.02 \pm 0.03 / 37.44 \pm 0.05$
\end{tabular}

Following 12-h stabilization at the final controller settings, steady-state testing was continued for another $24 \mathrm{~h}$. Measurements were collected throughout this period to check for any erroneous or unusual conditions and to ensure that the cases were operating as expected before conducting the final evaluation within the environmental chamber. During this 24-h period, door actuators were controlled using the same operation schedule that would be used in the environmental chamber to ensure they functioned as expected. The operation schedule is described in detail in the following section.

\subsection{Environmental Chamber Specifications and Setup}

Following steady-state testing, each case was transferred into the Espec walk-in environmental control chamber shown in Figure 13. The interior of the chamber is 85" wide x 142.5" in length, with a 144"high ceiling. The cases were aligned parallel to the long end of the chamber facing away from the chamber's steam exhaust vent. The cases were oriented exactly 12 " from the back wall according to ASHRAE 72 [3], and centered in the chamber 36" from each side wall and 36" behind the ambient measurement pole. There was 57" of clearance above the top of the tallest case, and no floor perforations around the perimeter of the case.

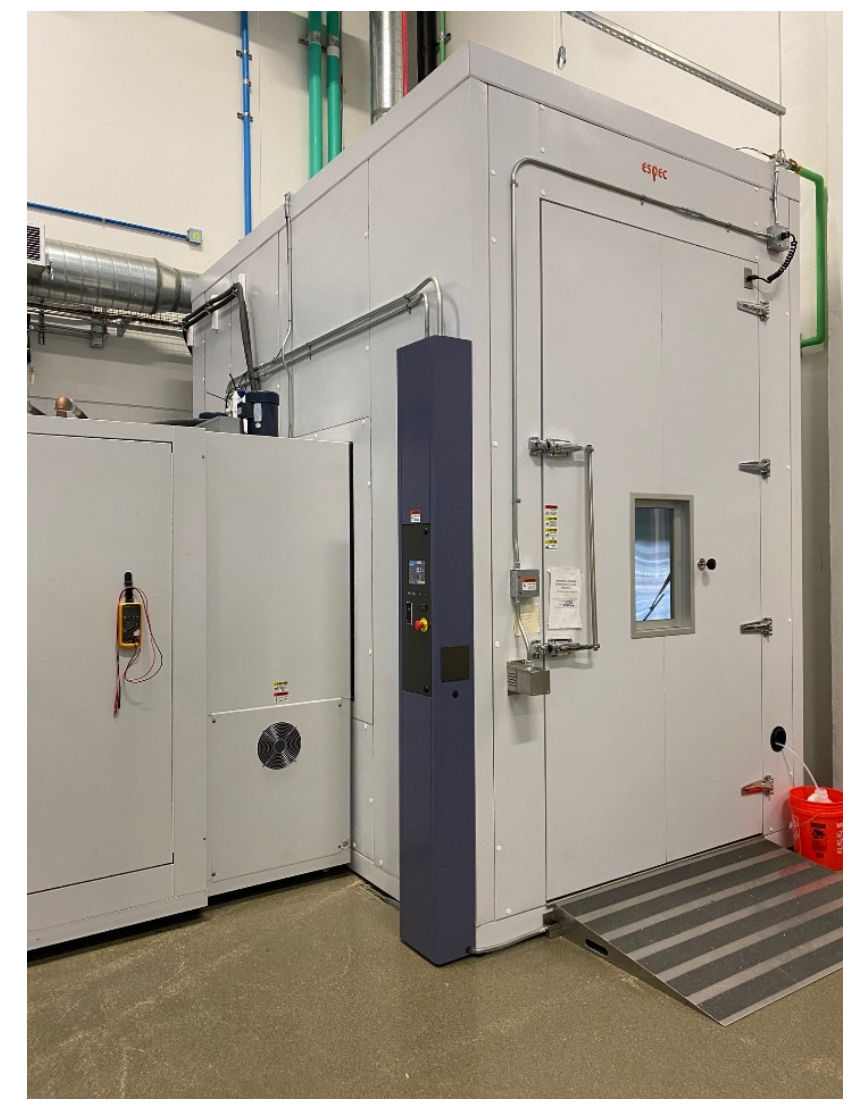

Figure 13. Image of Espec Environmental Control Chamber 
Each case was powered off to transfer into the chamber, which would cause a slight increase in simulator and filler temperatures. Therefore, each case was stabilized for 12 hours following this transfer using the same methods used during steady-state testing. After stabilization, the environmental conditions were established and controlled using the digital interface built into the Espec chamber shown in Figure 13. The chamber's interface controlled the temperature and humidity to an internal thermostat. However, the chamber conditions were altered according to the thermocouple and hygrometer readings at location $\mathrm{T}_{\mathrm{A}}$ on the ambient measurement pole shown in Figure 8.

Each case was evaluated at three different environmental conditions. Two of these conditions are indoor environmental conditions reported in supermarkets within the climate zone comprising ComEd's utility territory. NREL conducted a literature review of yearly indoor supermarket conditions and selected data collected from supermarkets in Minneapolis, Minnesota [22]. The first condition reported in January included the indoor dry-bulb temperature (DBT) and relative humidity $(\mathrm{RH})$ of $21.24^{\circ} \mathrm{C}\left(70.23^{\circ} \mathrm{F}\right)$ and $11.33 \% \mathrm{RH}$, respectively. With the case load in the chamber, the RH could not stabilize below $23 \% \mathrm{RH}$, and so this was used for the winter humidity $\left(9.60^{\circ} \mathrm{C}\right.$ wet-bulb temperature, or WBT). The second environmental condition was from June's data, which consisted of a $21.34^{\circ} \mathrm{C}\left(70.41^{\circ} \mathrm{F}\right) \mathrm{DBT}$ and $52.81 \% \mathrm{RH}\left(14.81^{\circ} \mathrm{C} \mathrm{WBT}\right)$. The third environmental condition evaluated was the "Upper Target" condition, or the upper extreme of conditions that rated commercial refrigerators are required to be able to operate at (defined by ASHRAE 72-2018) [3]. This condition specifies a dry-bulb of $24^{\circ} \mathrm{C}\left(75.2^{\circ} \mathrm{F}\right)$ and wet-bulb of $18^{\circ} \mathrm{C}\left(64.4^{\circ} \mathrm{F}\right)$, as opposed to a relative humidity.

Prior to conducting the performance evaluation, $\mathrm{T}_{\mathrm{A}}$ dry-bulb temperatures were maintained at their setpoint within $\pm 1^{\circ} \mathrm{C}\left( \pm 1.8^{\circ} \mathrm{F}\right)$ for at least 12 hours. The DBT was then recorded continuously throughout the performance evaluation to ensure continued stability within these limits according to ASHRAE 72 [3]. The same was done for the DBT at location $\mathrm{T}_{\mathrm{B}}$ to ensure a temperature gradient between the two locations on the ambient measurement pole was less than $0.56^{\circ} \mathrm{C} / \mathrm{ft}\left(1^{\circ} \mathrm{F} / \mathrm{ft}\right)$. The dewpoint temperature (DPT) recorded by the hygrometer at $\mathrm{T}_{\mathrm{A}}$ was also maintained at the value corresponding to the setpoint RH or WBT, depending on the setpoint DBT. The upper and lower limits for the DPT were calculated according to $\mathrm{a} \pm 1^{\circ} \mathrm{C}\left( \pm 1.8^{\circ} \mathrm{F}\right)$ variation in WBT, also depending on the setpoint DBT. Like the DBTs, the DPT was recorded continuously throughout the performance evaluation to ensure stability within the prescribed limits. The upper and lower limits for each of these three ambient measurements is listed below in Table 5 for the three environmental conditions evaluated.

Table 5. Environmental Condition Setpoints and Upper and Lower Limits

\begin{tabular}{|c|c|c|c|c|c|c|c|c|}
\hline CONDITION & $\mathrm{T}_{\mathrm{A}} \mathrm{DBT}$ & $\begin{array}{c}\mathrm{T}_{\mathrm{A}} \mathrm{DBT} \\
\text { Upper }\end{array}$ & $\begin{array}{l}\mathrm{T}_{\mathrm{A}} \mathrm{DBT} \\
\text { Lower }\end{array}$ & $\mathrm{T}_{\mathrm{A}} \mathrm{DPT}$ & $\begin{array}{c}\mathrm{T}_{\mathrm{A}} \text { DPT } \\
\text { Upper }\end{array}$ & $\begin{array}{l}\mathrm{T}_{\mathrm{A}} \mathrm{DPT} \\
\text { Lower }\end{array}$ & $\begin{array}{c}T_{B} \text { DBT } \\
\text { Upper }\end{array}$ & $\begin{array}{l}T_{B} \text { DBT } \\
\text { Lower }\end{array}$ \\
\hline January & $\begin{array}{c}21.24^{\circ} \mathrm{C} \\
\left(70.23^{\circ} \mathrm{F}\right)\end{array}$ & $\begin{array}{c}22.24^{\circ} \mathrm{C} \\
\left(72.03^{\circ} \mathrm{F}\right)\end{array}$ & $\begin{array}{c}20.24^{\circ} \mathrm{C} \\
\left(68.43^{\circ} \mathrm{F}\right)\end{array}$ & $\begin{array}{c}-0.57^{\circ} \mathrm{C} \\
\left(30.94^{\circ} \mathrm{F}\right)\end{array}$ & $\begin{array}{c}3.24^{\circ} \mathrm{C} \\
\left(30.94^{\circ} \mathrm{F}\right)\end{array}$ & $\begin{array}{c}-5.05^{\circ} \mathrm{C} \\
\left(30.94^{\circ} \mathrm{F}\right)\end{array}$ & $\begin{array}{c}23.91^{\circ} \mathrm{C} \\
\left(75.03^{\circ} \mathrm{F}\right)\end{array}$ & $\begin{array}{c}18.57^{\circ} \mathrm{C} \\
\left(65.43^{\circ} \mathrm{F}\right)\end{array}$ \\
\hline July & $\begin{array}{c}21.34^{\circ} \mathrm{C} \\
\left(70.41^{\circ} \mathrm{F}\right)\end{array}$ & $\begin{array}{l}22.34^{\circ} \mathrm{C} \\
\left(72.21^{\circ} \mathrm{F}\right)\end{array}$ & $\begin{array}{l}20.34^{\circ} \mathrm{C} \\
\left(68.61^{\circ} \mathrm{F}\right)\end{array}$ & $\begin{array}{c}11.35^{\circ} \mathrm{C} \\
\left(52.43^{\circ} \mathrm{F}\right)\end{array}$ & $\begin{array}{c}13.63^{\circ} \mathrm{C} \\
\left(30.94^{\circ} \mathrm{F}\right)\end{array}$ & $\begin{array}{c}8.80^{\circ} \mathrm{C} \\
\left(47.84^{\circ} \mathrm{F}\right)\end{array}$ & $\begin{array}{l}34.01^{\circ} \mathrm{C} \\
\left(75.21^{\circ} \mathrm{F}\right)\end{array}$ & $\begin{array}{c}18.67^{\circ} \mathrm{C} \\
\left(65.61^{\circ} \mathrm{F}\right)\end{array}$ \\
\hline $\begin{array}{l}\text { Upper } \\
\text { Target }\end{array}$ & $\begin{array}{c}24^{\circ} \mathrm{C} \\
\left(75.2^{\circ} \mathrm{F}\right)\end{array}$ & $\begin{array}{l}25^{\circ} \mathrm{C} \\
\left(77^{\circ} \mathrm{F}\right)\end{array}$ & $\begin{array}{c}23^{\circ} \mathrm{C} \\
\left(73.4^{\circ} \mathrm{F}\right)\end{array}$ & $\begin{array}{c}15.42^{\circ} \mathrm{C} \\
\left(59.76^{\circ} \mathrm{F}\right)\end{array}$ & $\begin{array}{c}17.42^{\circ} \mathrm{C} \\
\left(30.94^{\circ} \mathrm{F}\right)\end{array}$ & $\begin{array}{c}13.23^{\circ} \mathrm{C} \\
\left(55.81^{\circ} \mathrm{F}\right)\end{array}$ & $\begin{array}{c}26.67^{\circ} \mathrm{C} \\
\left(80^{\circ} \mathrm{F}\right)\end{array}$ & $\begin{array}{l}21.33^{\circ} \mathrm{C} \\
\left(70.4^{\circ} \mathrm{F}\right)\end{array}$ \\
\hline
\end{tabular}

The cases were each evaluated across at least two 24-h periods at each environmental condition to ensure consistency in results between assessments. Inside the chamber, condensate was removed from 
each case to a weigh bucket and measured following each 24-h evaluation. The case door actuators were operated based on the schedule described in ASHRAE standard 72-2018 [3]. Approximately 3 hours following the start of each assessment, the left case door was set to open for 6 seconds. Exactly 10 minutes after the left door opened (9:54 after closure), the middle door then opens for 6 seconds, followed by the right-side door after another 10 minutes. This process then repeats with the left door for another 8 hours. The case doors then remained closed for the latter 13 hours of each assessment. Because EE case A had no scheduled defrost cycle, door actuators were not scheduled to coordinate with defrost per ASHRAE 72. Because the baseline case had only one defrost cycles per 24 hours, door actuators were scheduled such that defrost would not occur during the 8-h period of scheduled case opening.

A webcam was set up inside the environmental chamber to monitor door openings to ensure they occurred on schedule for each 24-h assessment. Images of the cases inside the chamber are shown in Figure 14 from the rear of the chamber and from outside the chamber with the door open. The left image shows the baseline case from the rear of the chamber. The right image shows EE case A from outside the front door of the chamber.

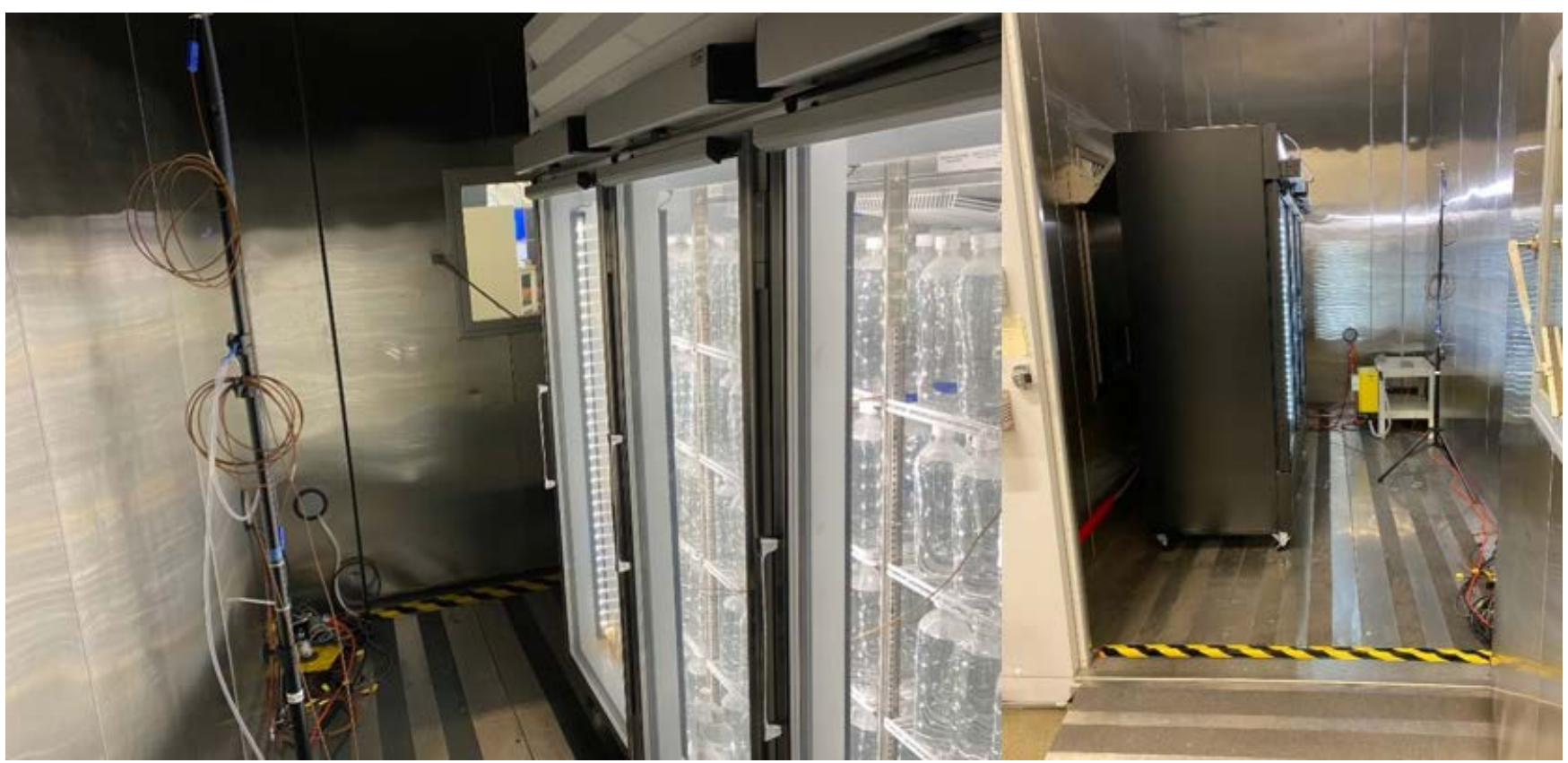

Figure 14. Images of cases in environmental chamber. Left: Baseline case from rear of chamber. Right: EE case A from outside of chamber 


\section{Results Summary}

The cooling performance and power/energy consumed by each of the three refrigerated display case technologies is provided in the following sections. As stated in the laboratory assessment plan, the average product simulator temperature, warmest and coldest average, and warmest and coldest peak simulator temperatures are reported across every 24-h cycle assessed at each environmental condition. The average of all simulator temperatures over the $24-\mathrm{h}$ cycle are also provided. Additionally, internal air temperatures including the evaporator discharge and inlet temperatures and the interior ambient temperature at the case geometric center are reported across the 24-h cycle. Evaporator discharge temperatures are reported as an average across three thermocouples located at the left, center, and right side of the discharge grille.

The total and component power consumptions are also reported across the 24-h cycle in the following sections at each environmental condition. Total and component daily energy consumption is reported as an average of each individual assessment conducted at equal environmental conditions. Experiments were conducted repeatedly at each environmental condition until equivalent results were obtained across at least two 24-h assessment cycles. Results were approximately equivalent at the same environmental conditions for all cases, therefore transient results are only provided for the most recent assessment.

Chamber conditions were maintained within the required temperature limits according to Table 5 for each refrigerated display case assessment at each environmental condition. Transient chamber DBT, DPT, and RH data for each assessment is provided in Appendix A with an associated discussion. Transient refrigerant piping temperatures can also be found in Appendix B with an associated discussion.

\subsection{Baseline Case Results}

The baseline refrigerator case consumed $10.50 \pm 0.01 \mathrm{kWh} /$ day under January's indoor environmental conditions, $10.34 \pm 0.06 \mathrm{kWh}$ /day under July's conditions, and $11.26 \pm 0.01 \mathrm{kWh} /$ day under Upper Target environmental conditions. As expected, energy consumption was highest in Upper Target conditions due to the higher chamber DBT. More heat transfer into the case caused the compressor to cycle more frequently than under January and July conditions. At higher ambient temperatures, the ability of the compressor to reject the heat of compression and refrigeration decreases. This results in the refrigeration cycle operating at higher condensing temperatures. At higher condensing temperatures, the ability of the refrigerant (per mass) to absorb heat at the evaporator diminishes. Therefore, the compressor must work harder and for a longer duration to meet the thermostatic setpoint.

The different chamber DPT/humidity between January and July conditions had little impact on daily energy consumption. Higher water vapor content in the air caused more frost to accumulate on the evaporator, which forced defrost cycles to last longer to reach their termination temperature. The energy consumption was normalized to the time between defrost cycles, as well as the internal volumetric capacity. The baseline refrigerator consumed $8.04 \pm 0.02 \mathrm{kWh} / \mathrm{m}^{3}$ day under January conditions, $7.95 \pm$ $0.02 \mathrm{kWh} / \mathrm{m}^{3}$ day under July conditions, and $8.64 \pm 0.02 \mathrm{kWh} / \mathrm{m}^{3}$ day under Upper Target conditions. Energy consumption was still less under July conditions, however, even when corrected to defrost. This difference in consumption was within the case manufacturers' reported variability in daily energy consumption when operating at the same environmental conditions $( \pm 10 \%)$. Because mean energy consumption was evaluated from only two repeated 24-h cycles at each condition, the daily energy variability observed here was much less than observed by the manufacturer. Therefore, additional cycles 
likely would have shifted mean energy consumption under January conditions below that of July conditions.

The product simulators were maintained at a mean temperature of $2.99^{\circ} \mathrm{C}\left(37.38^{\circ} \mathrm{F}\right)$ in January conditions, $2.97^{\circ} \mathrm{C}\left(37.35^{\circ} \mathrm{F}\right)$ in July conditions, and $3.01^{\circ} \mathrm{C}\left(37.42^{\circ} \mathrm{F}\right)$ in Upper Target conditions. Simulator temperatures fluctuated, but were always within their required limits. During the 8 -h period in which doors opened regularly, the compressor cycled more frequently, causing product temperatures to drop. The average simulator temperature was reduced to a minimum of $2.51^{\circ} \mathrm{C}\left(36.52^{\circ} \mathrm{F}\right)$ in January conditions, $2.42^{\circ} \mathrm{C}\left(36.36^{\circ} \mathrm{F}\right)$ in July conditions, and $2.33^{\circ} \mathrm{C}\left(36.19^{\circ} \mathrm{F}\right)$ in Upper Target conditions during door openings. A single defrost cycle caused product temperatures to increase to a maximum value. The maximum of the simulator average was $3.70^{\circ} \mathrm{C}\left(38.66^{\circ} \mathrm{F}\right)$ in January conditions, $3.61^{\circ} \mathrm{C}$ $\left(38.49^{\circ} \mathrm{F}\right)$ in July conditions, and $3.70^{\circ} \mathrm{C}\left(38.66^{\circ} \mathrm{F}\right)$ in Upper Target conditions.

\subsubsection{Baseline Case Cooling Performance}

The baseline refrigerator display case product simulator and internal air temperatures during the January condition assessment are provided in Figure 15. The average of all product simulator temperatures was maintained within AHRI/FDA limits throughout operation [20,21] as shown. Only the average, and not individual simulator temperatures, are required to be maintained within this specified range. The middle shelf/center-rear product simulator exhibited both the coldest average and coldest peak temperatures. The bottom shelf/front-right product simulator exhibited both the warmest average and warmest peak temperatures. Mean product simulator temperatures across the operation period are provided in Table 6 , color-coded based on temperature differential beyond the AHRI/FDA limits.

Evaporator outlet air temperatures were averaged from three thermocouple measurements located at the left, center, and right side of the evaporator discharge grille. The interior ambient temperature was measured at the geometric center of the case interior. These internal air temperatures are also shown in Figure 15 across a 1.5-h segment around the end of the door opening period (hour 11). 


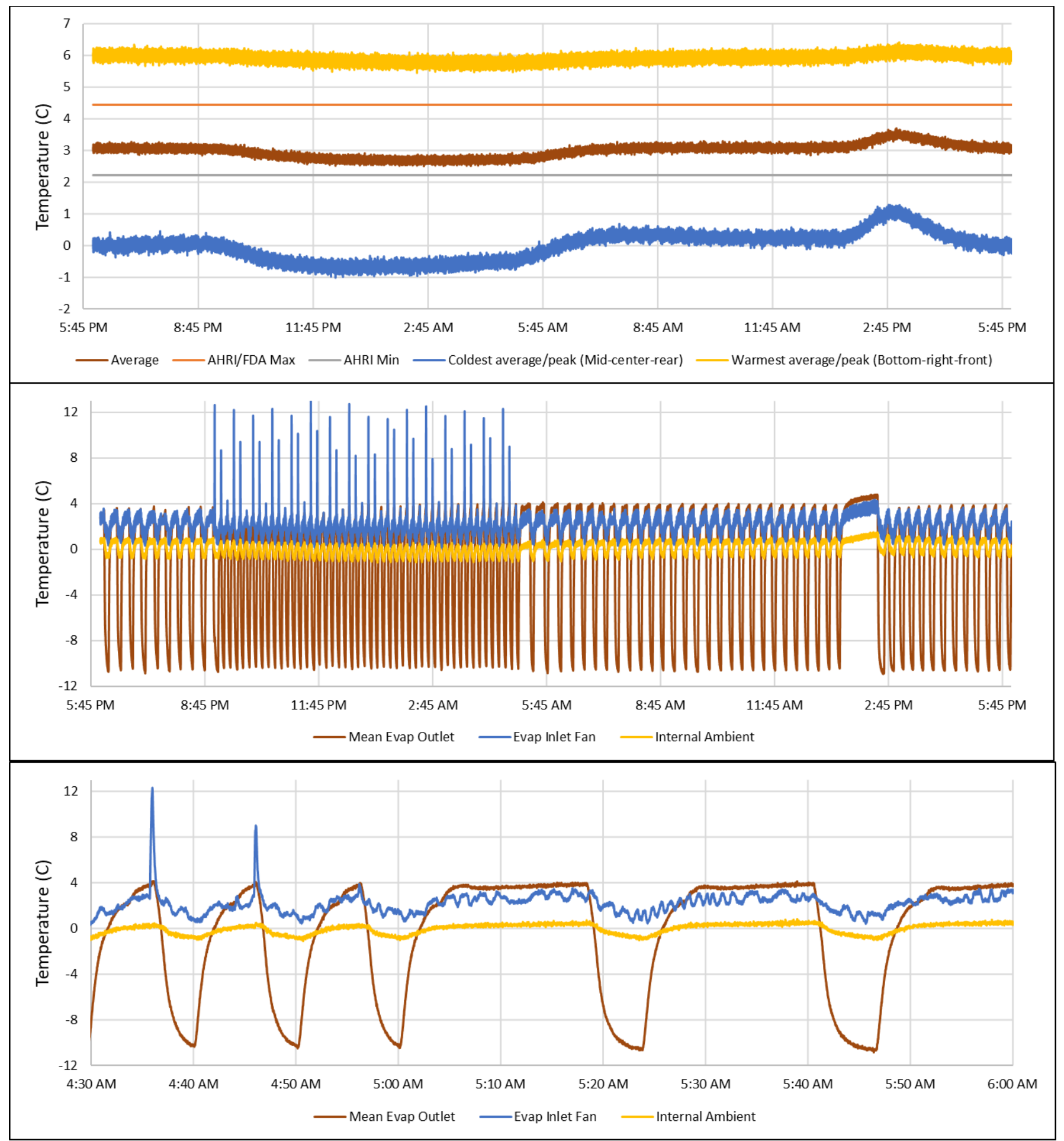

Figure 15. Baseline refrigerator case January condition transient product simulator temperatures (top) and internal air temperatures (middle) over $24 \mathrm{~h}$. Internal air temperatures over $1.5 \mathrm{~h}$ are shown around hour 11 (bottom) 
Table 6. Baseline refrigerator case January condition average product simulator temperatures as a function of position. Color-coding is based on temperature differential beyond the AHRI/FDA limits (required only for the average).

\begin{tabular}{|c|c|c|c|c|}
\cline { 3 - 5 } \multicolumn{2}{c|}{} & \multicolumn{3}{c|}{ x-position } \\
\hline Shelf & y-position & Left & Center & Right \\
\hline \multirow{2}{*}{ Top } & Rear & $2.92^{\circ} \mathrm{C}$ & $0.10^{\circ} \mathrm{C}$ & $3.94^{\circ} \mathrm{C}$ \\
& Front & $4.80^{\circ} \mathrm{C}$ & $2.44^{\circ} \mathrm{C}$ & $5.75^{\circ} \mathrm{C}$ \\
\hline \multirow{2}{*}{ Middle } & Rear & $1.63^{\circ} \mathrm{C}$ & $-0.02^{\circ} \mathrm{C}$ & $2.34^{\circ} \mathrm{C}$ \\
& Front & $2.94^{\circ} \mathrm{C}$ & $1.36^{\circ} \mathrm{C}$ & $3.88^{\circ} \mathrm{C}$ \\
\hline \multirow{2}{*}{ Bottom } & Rear & $2.31^{\circ} \mathrm{C}$ & $1.81^{\circ} \mathrm{C}$ & $3.44^{\circ} \mathrm{C}$ \\
& Front & $4.87^{\circ} \mathrm{C}$ & $3.43^{\circ} \mathrm{C}$ & $5.92^{\circ} \mathrm{C}$ \\
\hline
\end{tabular}

The average product simulator temperature was $2.99^{\circ} \mathrm{C}\left(37.38^{\circ} \mathrm{F}\right)$. Recall that due to the effect of altitude, cut-in and cut-out temperatures were lowered to $3.33^{\circ} \mathrm{C}\left(38^{\circ} \mathrm{F}\right)$ and $-1.11^{\circ} \mathrm{C}\left(30^{\circ} \mathrm{F}\right)$, respectively, to achieve this average simulator temperature. Door openings and defrost significantly affected product simulator temperatures. Door openings (between 8:45 p.m. and 4:45 a.m.) caused warm air to regularly enter the case. The case responded by cycling the compressor on more frequently, which caused the product temperature to drop to a minimum of $2.51^{\circ} \mathrm{C}\left(36.52^{\circ} \mathrm{F}\right)$. Defrost occurred for $1 \mathrm{~h}$ (around approximately 1:45 p.m.), which resulted in the average product temperature rising to a maximum $3.70^{\circ} \mathrm{C}\left(38.66^{\circ} \mathrm{F}\right)$.

The warmest average simulator was the bottom shelf/front-right simulator, which exhibited an average temperature of $5.92^{\circ} \mathrm{C}\left(42.66^{\circ} \mathrm{F}\right)$. The maximum peak temperature also occurred in this simulator during defrost, which was $6.41^{\circ} \mathrm{C}\left(43.54^{\circ} \mathrm{F}\right)$. The coldest average simulator was the middle shelf/center-rear simulator which exhibited an average temperature of $-0.02^{\circ} \mathrm{C}\left(31.96^{\circ} \mathrm{F}\right)$. The minimum peak temperature also occurred in this simulator during the period in which doors were opening, since this caused the compressor to cycle more frequently. This simulator achieved a minimum temperature of $-1.01^{\circ} \mathrm{C}$ $\left(30.18^{\circ} \mathrm{F}\right)$ during that period.

The simulators located on the shelves behind the side doors were much warmer than the simulators on the center shelves. Similarly, the simulators on the front of each shelf were much warmer than the rear simulators. This is due to the location of the evaporator in the case and the induced direction of airflow. The evaporator sits directly behind the center door centered in the middle of the case interior. Cold air discharged from the evaporator is ejected downward, first dissipating through products located behind the center door. Heat is rejected from the product to the air as it returns upward behind the side doors to the evaporator. Likewise, the evaporator discharge grille is located on the back of the evaporator facing the rear wall of the case. Cold air thereby first travels downward along the rear wall of the case, absorbing more heat from the rear simulators than the front simulators as warmer air returns upward behind the doors. For this reason, rear simulator temperatures respond more rapidly to compressor cycling.

It is unclear why product simulators behind the right-side doors were warmer than left-side product simulators. Temperatures on both sides responded similarly to door openings and defrost as can be seen in Appendix A. It was not evident that one side was affected differently by either of these events. It is likely that minor differences in the internal geometry of the case or within the evaporator cause more 
cool air to be directed toward the left side of the case. However, a more robust analysis of internal airflow patterns would be required to fully ascertain the cause of this temperature discrepancy.

Evaporator and internal air temperatures (Figure 15) varied with compressor cycling. The effect of January environmental conditions on compressor cycling is described in the following section. When the compressor cycled on, the mean evaporator discharge temperature dropped to a minimum of $-10.92^{\circ} \mathrm{C}$ $\left(12.34^{\circ} \mathrm{F}\right)$. This induced an air temperature of $-1.15^{\circ} \mathrm{C}\left(29.93^{\circ} \mathrm{F}\right)$ at the geometric center of the case, and return air to the evaporator was warmed to $0.14^{\circ} \mathrm{C}\left(32.25^{\circ} \mathrm{F}\right)$. The maximum internal air temperature occurred during defrost $(\sim 1: 45$ p.m. in Figure 15$)$, which was as high as $1.50^{\circ} \mathrm{C}\left(34.70^{\circ} \mathrm{F}\right)$. Since the evaporator inlet fans sit directly behind the middle door, these temperatures spiked each time doors opened starting 3 hours into the test $(8: 45$ p.m. in Figure 15$)$ to a $\max$ of $13.31^{\circ} \mathrm{C}\left(55.96^{\circ} \mathrm{F}\right)$.

Product simulator and internal air temperatures during the July condition assessment are provided in Figure 16. Overall, product temperatures were generally the same as seen in January conditions. Internal air temperatures were relatively equivalent in magnitude, but they varied slightly less due to reduced compressor cycling frequency. Again, the average of product simulator temperatures was maintained within AHRI/FDA limits. The middle shelf/center-rear, and bottom shelf/front-right product simulators were again both the coldest average and warmest average (and peak) product simulator temperatures, respectively. Mean product simulator temperatures across the operation period are provided in Table 7 , color-coded based on temperature differential beyond the AHRI/FDA limits. 


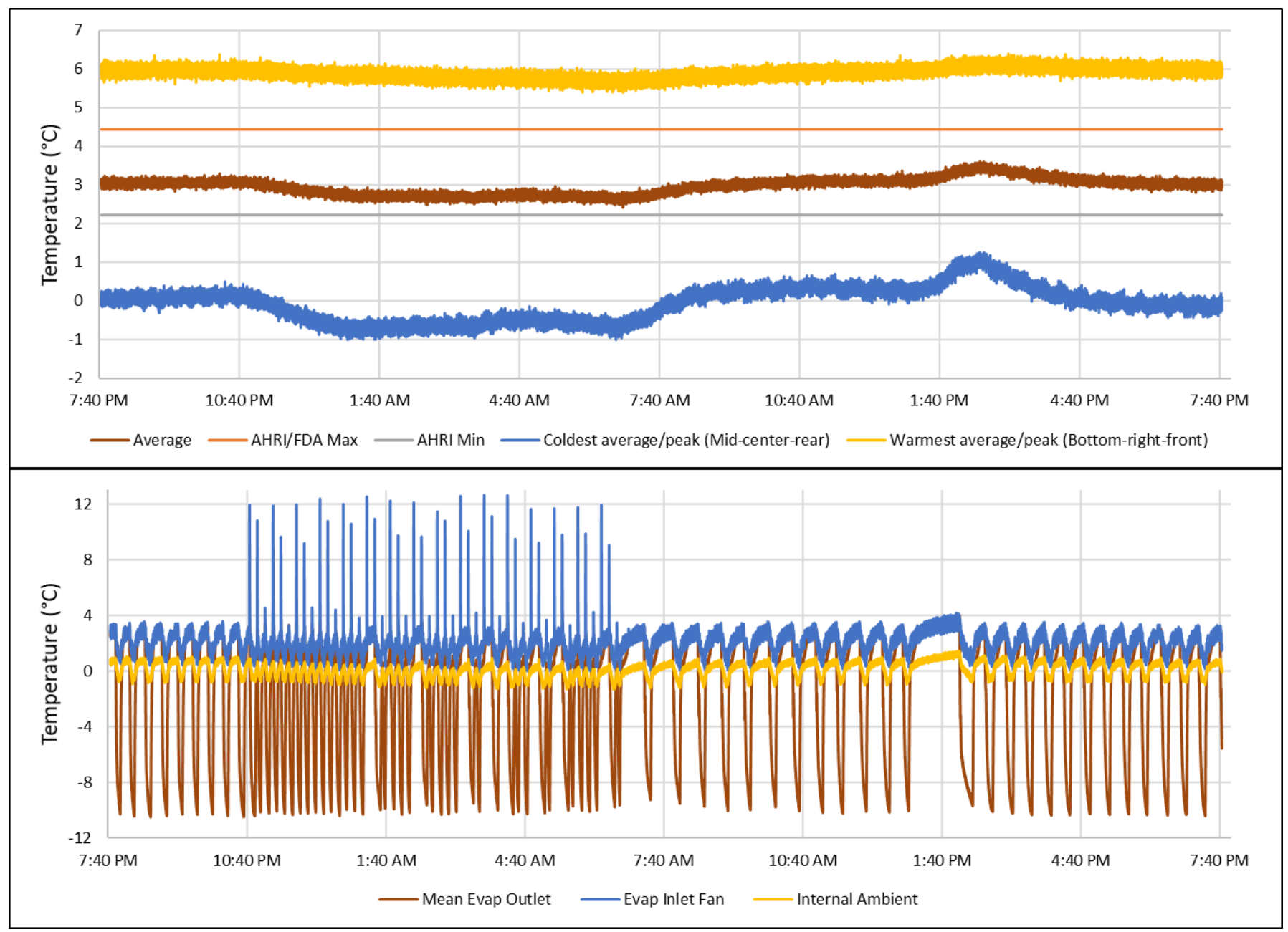

Figure 16. Baseline refrigerator case July condition transient product simulator temperatures (top) and internal air temperatures (bottom)

Table 7. Baseline refrigerator case July condition average product simulator temperatures as a function of position. Color-coding is based on temperature differential beyond the AHRI/FDA limits (required only for the average).

\begin{tabular}{|c|c|c|c|c|}
\cline { 3 - 5 } \multicolumn{2}{c|}{} & \multicolumn{3}{c|}{ x-position } \\
\hline Shelf & y-position & Left & Center & Right \\
\hline \multirow{2}{*}{ Top } & Rear & $2.91^{\circ} \mathrm{C}$ & $0.05^{\circ} \mathrm{C}$ & $3.94^{\circ} \mathrm{C}$ \\
& Front & $4.81^{\circ} \mathrm{C}$ & $2.42^{\circ} \mathrm{C}$ & $5.73^{\circ} \mathrm{C}$ \\
\hline \multirow{2}{*}{ Middle } & Rear & $1.59^{\circ} \mathrm{C}$ & $-0.06^{\circ} \mathrm{C}$ & $2.38^{\circ} \mathrm{C}$ \\
& Front & $2.93^{\circ} \mathrm{C}$ & $1.30^{\circ} \mathrm{C}$ & $3.91^{\circ} \mathrm{C}$ \\
\hline \multirow{2}{*}{ Bottom } & Rear & $2.33^{\circ} \mathrm{C}$ & $1.63^{\circ} \mathrm{C}$ & $3.44^{\circ} \mathrm{C}$ \\
& Front & $4.86^{\circ} \mathrm{C}$ & $3.41^{\circ} \mathrm{C}$ & $5.90^{\circ} \mathrm{C}$ \\
\hline
\end{tabular}

The average product simulator temperature was $2.97^{\circ} \mathrm{C}\left(37.35^{\circ} \mathrm{F}\right)$ in July conditions. The effect of door openings and defrost were relatively the same as in January conditions. Door openings caused the product temperature to drop to a minimum of $2.42^{\circ} \mathrm{C}\left(36.36^{\circ} \mathrm{F}\right)$, and defrost caused the temperature to rise to a maximum $3.61^{\circ} \mathrm{C}\left(38.49^{\circ} \mathrm{F}\right)$. The bottom shelf/front-right simulator average temperature was 
$5.90^{\circ} \mathrm{C}\left(42.62^{\circ} \mathrm{F}\right)$, and the middle shelf/center-rear average temperature was $-0.06^{\circ} \mathrm{C}\left(31.89^{\circ} \mathrm{F}\right)$. The maximum peak temperature during defrost was $6.39^{\circ} \mathrm{C}\left(43.50^{\circ} \mathrm{F}\right)$ in the bottom shelf/front-right simulator and the minimum peak temperature during door openings was $-1.01^{\circ} \mathrm{C}\left(30.18^{\circ} \mathrm{F}\right)$ in the middle shelf/center-rear simulator.

Although compressor cycling was less frequent in July conditions compared to January conditions, the magnitude of internal air temperatures were largely similar. The mean evaporator discharge temperature dropped to a minimum of $-10.51^{\circ} \mathrm{C}\left(13.08^{\circ} \mathrm{F}\right)$ when the compressor cycled on. This induced an air temperature of $-1.32^{\circ} \mathrm{C}\left(29.62^{\circ} \mathrm{F}\right)$ at the geometric center of the case, and a return air temperature of $-0.08^{\circ} \mathrm{C}\left(31.86^{\circ} \mathrm{F}\right)$ to the evaporator. The maximum internal air temperature during defrost $(\sim 1: 40 \mathrm{p} . \mathrm{m}$. in Figure 16) was $1.43^{\circ} \mathrm{C}\left(34.57^{\circ} \mathrm{F}\right)$. The evaporator inlet fan temperature spiked to a maximum $12.63^{\circ} \mathrm{C}$ $\left(54.73^{\circ} \mathrm{F}\right)$ when doors were opened (starting at 10:40 p.m. in Figure 16).

Product simulator and internal air temperatures under Upper Target environmental conditions are provided in Figure 17. Overall, the average of product temperatures was similar to January and July conditions. Product simulators that exhibited more extreme temperatures were, however, higher or lower, respectively. The frequency of compressor cycling and magnitude of internal air temperatures were relatively similar to July and January conditions, except internal temperatures reached slightly higher values between compressor cycles. This was due to greater heat transfer into the case caused by the higher chamber temperature in Upper Target conditions. Compressor cycles were also slightly longer due to the higher chamber temperature, and so internal temperatures were held at lower values for a longer duration. The effect of the chamber temperature on compressor cycling is explained in further detail in the following section.

The mean product simulator temperatures continued to be maintained within AHRI/FDA limits, despite varying to a greater degree during door openings and defrost. The middle shelf/center-rear, and bottom shelf/front-right product simulators were again both the coldest average and warmest average product simulator temperatures, respectively. The bottom shelf/front-right simulator was also the warmest peak simulator, but the top shelf/center-rear had the lowest peak temperature. Mean product simulator temperatures across the operation period are provided in Table 8, color-coded based on temperature differential beyond the AHRI/FDA limits. 


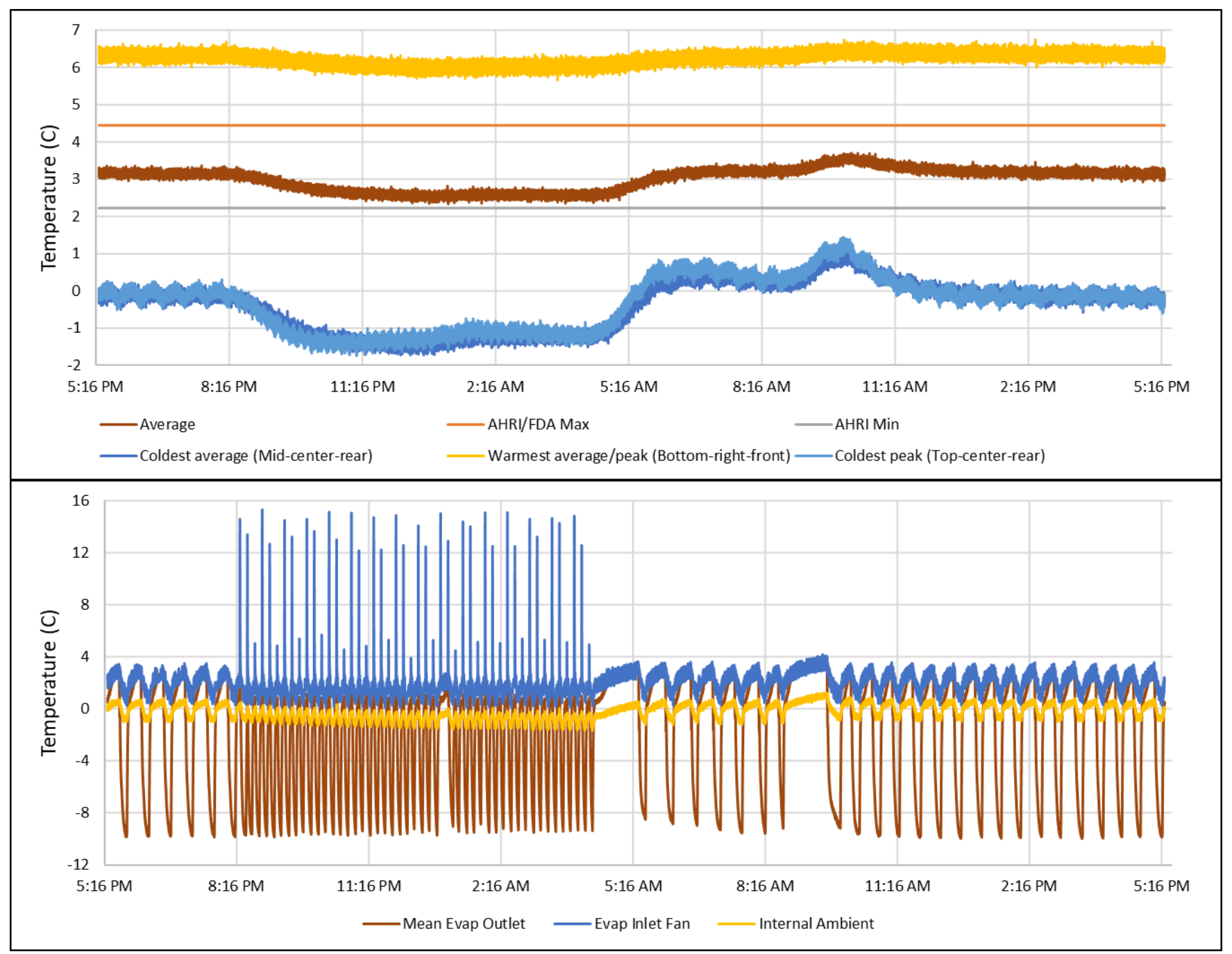

Figure 17. Baseline refrigerator case Upper Target condition transient product simulator temperatures (top) and internal air temperatures (bottom)

Table 8. Baseline refrigerator case Upper Target condition average product simulator temperatures as a function of position. Color-coding is based on temperature differential beyond the AHRI/FDA limits (required only for the average).

\begin{tabular}{|c|c|c|c|c|}
\cline { 3 - 5 } \multicolumn{2}{c|}{} & \multicolumn{3}{c|}{ x-position } \\
\hline Shelf & y-position & Left & Center & Right \\
\hline \multirow{2}{*}{ Top } & Rear & $2.98^{\circ} \mathrm{C}$ & $-0.31^{\circ} \mathrm{C}$ & $4.11^{\circ} \mathrm{C}$ \\
& Front & $4.97^{\circ} \mathrm{C}$ & $2.37^{\circ} \mathrm{C}$ & $5.98^{\circ} \mathrm{C}$ \\
\hline \multirow{2}{*}{ Middle } & Rear & $1.56^{\circ} \mathrm{C}$ & $-0.38^{\circ} \mathrm{C}$ & $2.40^{\circ} \mathrm{C}$ \\
& Front & $2.97^{\circ} \mathrm{C}$ & $1.12^{\circ} \mathrm{C}$ & $4.07^{\circ} \mathrm{C}$ \\
\hline \multirow{2}{*}{ Bottom } & Rear & $2.33^{\circ} \mathrm{C}$ & $1.53^{\circ} \mathrm{C}$ & $3.66^{\circ} \mathrm{C}$ \\
& Front & $5.02^{\circ} \mathrm{C}$ & $3.52^{\circ} \mathrm{C}$ & $6.23^{\circ} \mathrm{C}$ \\
\hline
\end{tabular}

The average product simulator temperature was $3.01^{\circ} \mathrm{C}\left(37.42^{\circ} \mathrm{F}\right)$ in the Upper Target environmental conditions. During January and July conditions, the chamber DBT was relatively unchanged; however, 
the Upper Target DBT was relatively warmer than at these conditions. The simulator temperatures were thereby affected by door openings and defrost more significantly. Since door openings caused warmer air to enter the case interior, the compressor responded by more rapid cycling, further cooling simulators below the evaporator discharge grille. Door openings caused the average product temperature to drop to a minimum of $2.33^{\circ} \mathrm{C}\left(36.19^{\circ} \mathrm{F}\right)$ and generated a minimum peak temperature of $-1.74^{\circ} \mathrm{C}\left(28.87^{\circ} \mathrm{F}\right)$ in the top shelf/center-rear simulator. Similarly, simulators closer to the door and sides were warmed to higher temperatures by conduction and radiative heat transfer during defrost (occurring around 9:16 a.m.). Defrost caused the mean simulator temperature to rise to a maximum $3.70^{\circ} \mathrm{C}\left(38.66^{\circ} \mathrm{F}\right)$ and induced a maximum peak temperature of $6.74^{\circ} \mathrm{C}\left(44.13^{\circ} \mathrm{F}\right)$ in the bottom shelf/front-right simulator. The bottom shelf/front-right simulator average temperature was $6.23^{\circ} \mathrm{C}\left(43.21^{\circ} \mathrm{F}\right)$, and the middle shelf/center-rear average temperature was $-0.38^{\circ} \mathrm{C}\left(31.32^{\circ} \mathrm{F}\right)$.

Again, the magnitude of internal air temperatures were largely similar to those seen in January and July conditions. The mean evaporator discharge temperature dropped to a minimum of $-10.00^{\circ} \mathrm{C}\left(14.00^{\circ} \mathrm{F}\right)$ when the compressor cycled on. This induced an air temperature of $-1.67^{\circ} \mathrm{C}\left(28.99^{\circ} \mathrm{F}\right)$ at the geometric center of the case, and a return air temperature of $0.08^{\circ} \mathrm{C}\left(32.14^{\circ} \mathrm{F}\right)$ to the evaporator. The maximum internal air temperature during defrost $(\sim 9: 16 \mathrm{a} . \mathrm{m}$. in Figure 17$)$ was $1.24^{\circ} \mathrm{C}\left(34.23^{\circ} \mathrm{F}\right)$. The evaporator inlet fan temperature spiked to a much higher maximum value of $15.32^{\circ} \mathrm{C}\left(59.58^{\circ} \mathrm{F}\right)$ when doors were opening (starting at 8:16 p.m. in Figure 17). This was due to the higher chamber DBT in Upper Target environmental conditions causing warmer air to enter the refrigerator case.

As low-temperature refrigerant is forced through the evaporator during compressor cycling, water vapor condenses around the evaporator coils. Often, customers use electric pumps to remove condensate to a floor drain. In these circumstances, the electric pump can contribute to total energy consumption if forced to remove water. Therefore, the mass of condensate produced was evaluated. The condensate mass generated by the baseline case over $24 \mathrm{~h}$ at each environmental condition is shown below in Figure 18.

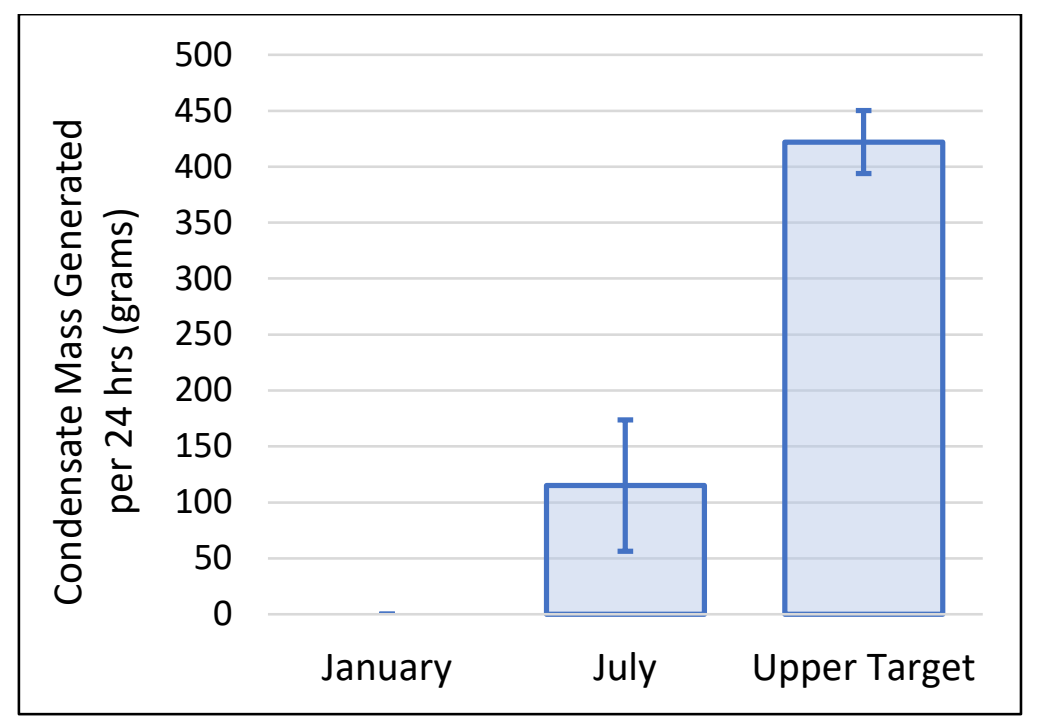

Figure 18. Baseline refrigerator case condensate mass generated at each environmental condition

Doored refrigerator cases can generate a relatively small amount of condensate. If this condensate must be pumped to a floor drain, pumping energy is expected to contribute little to total energy consumption. Here, the maximum condensate mass produced in Upper Target environmental conditions was not 
enough to fill the reservoir of a typical condensate pump over $24 \mathrm{~h}$. In January conditions, no condensate was produced due to relatively low humidity. It should be noted that due to the low condensate mass collected, a significant fraction of this total condensate may have remained in the evaporator or drain line by surface tension.

\subsubsection{Baseline Case Power/Energy Consumption}

The total daily energy consumption, and the mean power consumption (when cycling on), of the baseline case at each environmental condition is shown in Figure 19. Energy consumption error bars indicate standard deviation across separate 24-h assessments. Power consumption error bars indicate standard deviation across total operation time. The case performed best in July conditions, consuming $10.34 \pm 0.06 \mathrm{kWh} /$ day and an average $920.9 \pm 356.8 \mathrm{~W}$ during compressor cycling. As expected, the Upper Target environmental conditions induced the greatest energy consumption due to the higher chamber temperature. The case consumed $11.26 \pm 0.01 \mathrm{kWh} /$ day and an average $930.7 \pm 371.5 \mathrm{~W}$ during compressor cycling at these conditions. In January environmental conditions, the case consumed $10.50 \pm 0.01 \mathrm{kWh} /$ day and an average $909.3 \pm 355.1 \mathrm{~W}$ during compressor cycling. The energy consumed by the case components breaks down the source of these differences in total consumption. Part-daily component energy and mean on-cycle power consumption at each environmental condition are shown in Figure 20. Differences between total energy/power consumption and the sum of components can be attributed to the Wattnode meters' uncertainty.
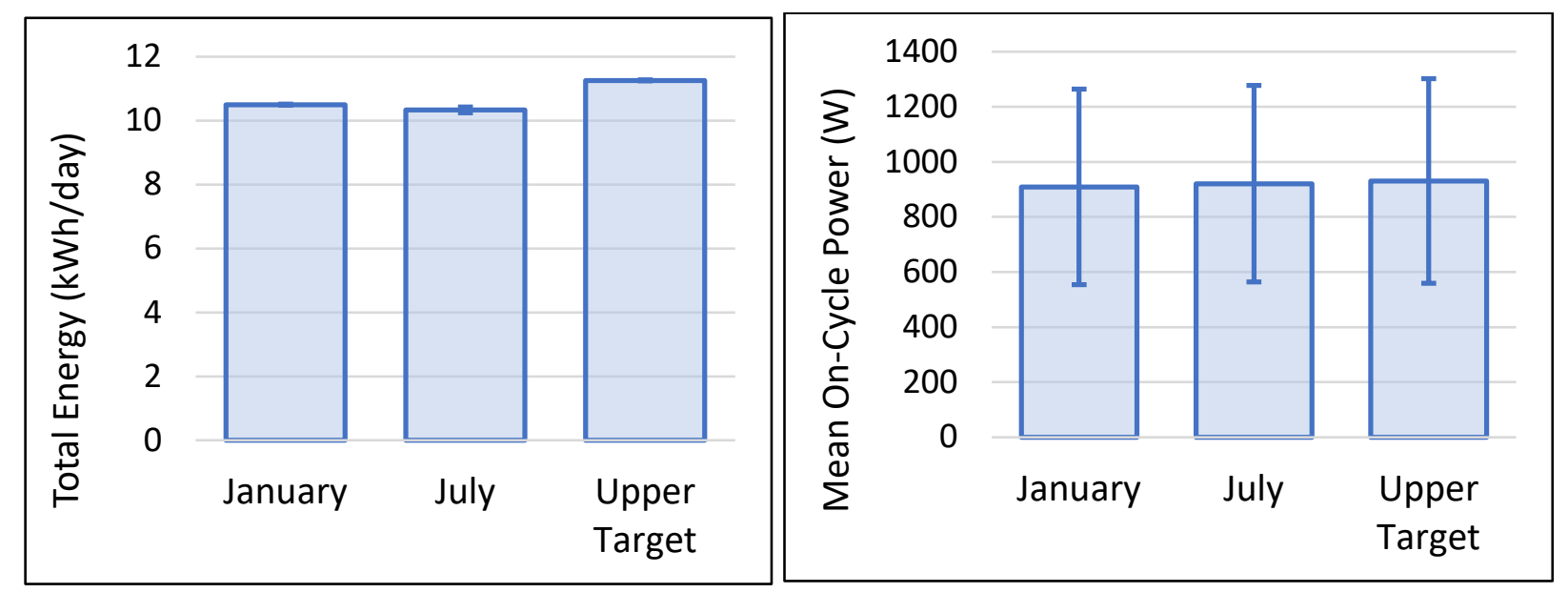

Figure 19. Baseline case total energy consumption (left) and mean on-cycle power consumption (right) at each environmental condition 

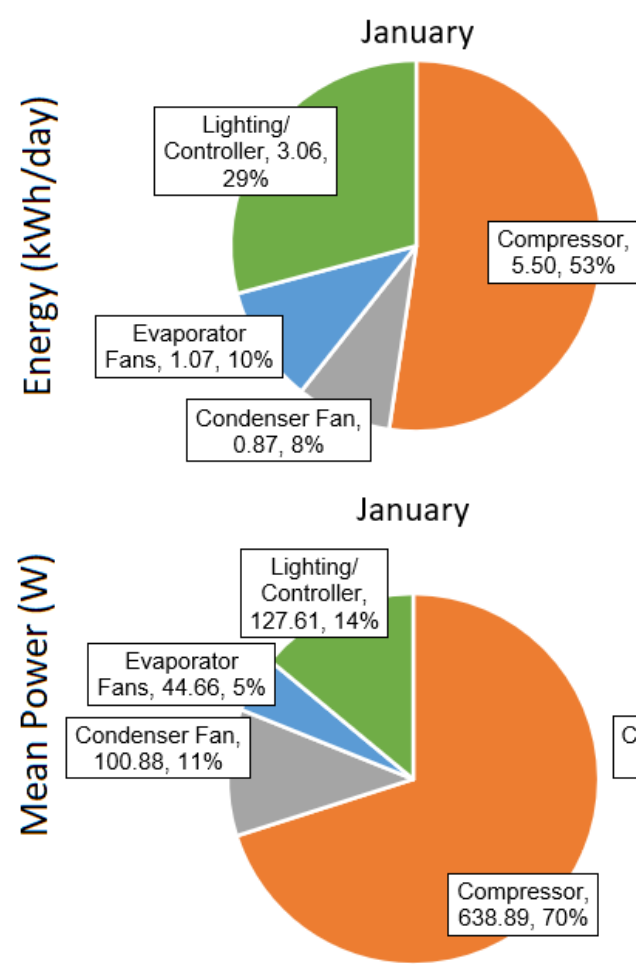

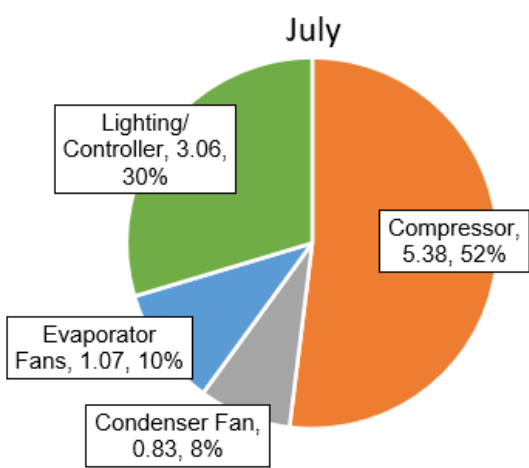

July

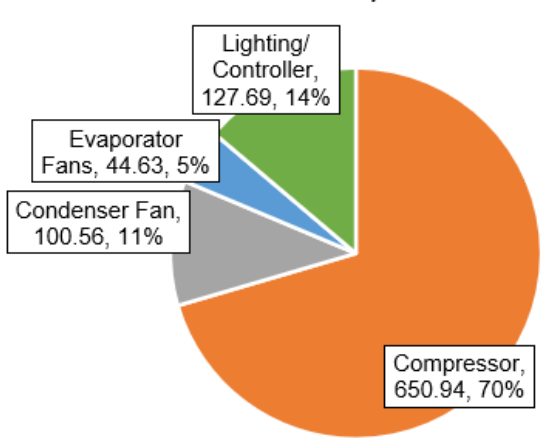

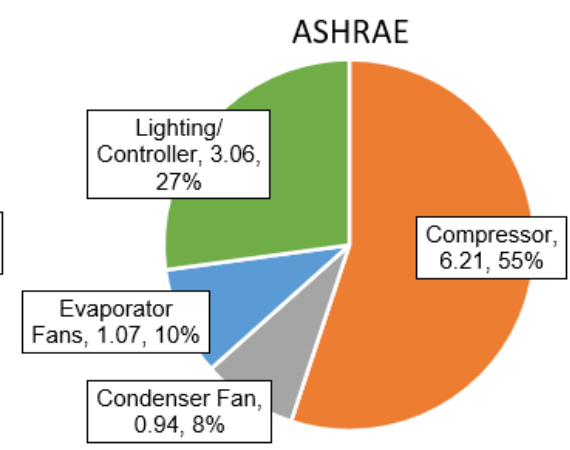

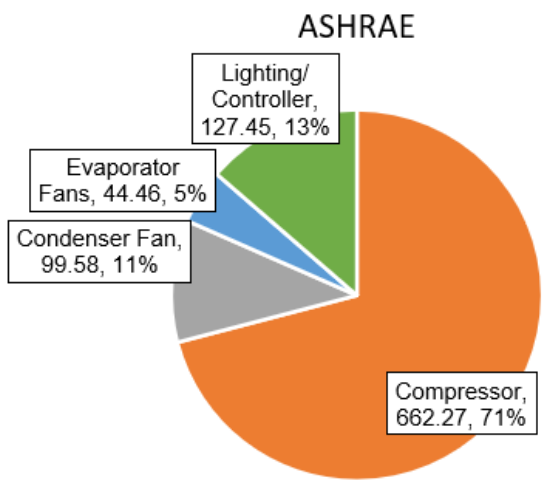

Figure 20. Baseline case component daily energy (kWh/day, top) and mean on-cycle power consumption (W, bottom) at each environmental condition

The compressor consumed the majority of the baseline case energy, ranging between $52 \%$ and $55 \%$ across environmental conditions. The lighting and controller also consumed a significant fraction of the total energy: between $27 \%$ and $30 \%$. As expected, the energy consumed by the lighting and controller was not affected by the environmental conditions, consuming a constant $3.06 \mathrm{kWh} /$ day. Likewise, the fixed-speed evaporator fans were powered on continuously. Therefore, they consumed a constant 1.07 $\mathrm{kWh}$ /day regardless of environmental conditions.

The compressor energy contributed to the greatest overall change in total case energy consumption. This was due to the effect of environmental conditions on the frequency and duration of compressor cycling. At higher room dry-bulb temperatures, the condensing temperature of the refrigerant increases. This requires the compressor to cycle on longer to adequately pressurize the refrigerant to this higher temperature [23]. Additionally, higher room temperatures induce greater heat transfer into the case through its walls and door as well as a displacement of warmer air during door openings. This causes the interior temperature to reach the cut-in temperature more frequently. Because the chamber temperature was $24^{\circ} \mathrm{C}\left(75.2^{\circ} \mathrm{F}\right)$ in Upper Target environmental conditions, the baseline compressor operated for a longer duration which consumed $6.21 \mathrm{kWh} /$ day. Since the DBT in January and July conditions was approximately $2.75^{\circ} \mathrm{C}\left(5^{\circ} \mathrm{F}\right)$ less than Upper Target conditions, compressor power consumption was only 5.50 and $5.38 \mathrm{kWh} /$ day, respectively.

Because the difference in chamber DBT between January and July conditions was relatively negligible, we would expect the difference in compressor energy here to be attributed to the different chamber DPT/humidity. Studies have shown that higher relative humidity causes a modest increase in the energy consumption of household refrigerators [24, 25]. Air with higher water vapor content will generate a greater accumulation of ice around the evaporator coils. This reduces airflow through the evaporator, 
which forces the compressor to cycle on longer to reach the internal cut-out temperature, but also causes defrost cycles to take a longer time to reach termination temperature. If a case contains an electrical defrost heater or anti-condensate door heater, this can also increase energy consumption.

Here, the baseline case contained no electrical defrost heater or anti-condensate door heater. Therefore, longer defrost cycles reduced total energy consumption since the compressor remained off for a longer duration. The defrost cycles under July conditions lasted a few minutes longer during January conditions, but the total compressor cycling time was still reduced compared to January. Although the reduction in compressor cycling time under July conditions was not reflective of these environmental changes, the variability between tests performed at the same conditions was nearly the same as the variability between tests performed under January versus July conditions. These variabilities were both far less than that reported by the case manufacturer, meaning that additional tests would have likely resulted in mean energy consumption in January shifting below that in July, with standard deviation plateauing near the manufacturer-reported value $(\sim 10 \%)$. Since the condenser fan was powered on concurrently with the compressor, its energy consumption was proportionally affected by environmental conditions. The effect of these conditions on compressor cycling frequency was different than its effect on the overall compressor run time. In January conditions, the compressor cycled on 47 times ( $\sim$ every $10 \mathrm{~min}$ ) during the 8 -h door opening period, and 98 times total ( every 18 min outside this period). The total and component power consumption across the 24-h cycle are shown in Figure 21. Also shown is a 1.5 -h segment at the end of the door opening period. Each time the compressor and condenser fan are cycled on, there is an initial spike in power followed by a plateau. This plateau is gradual for the compressor but immediate for the condenser fan. 


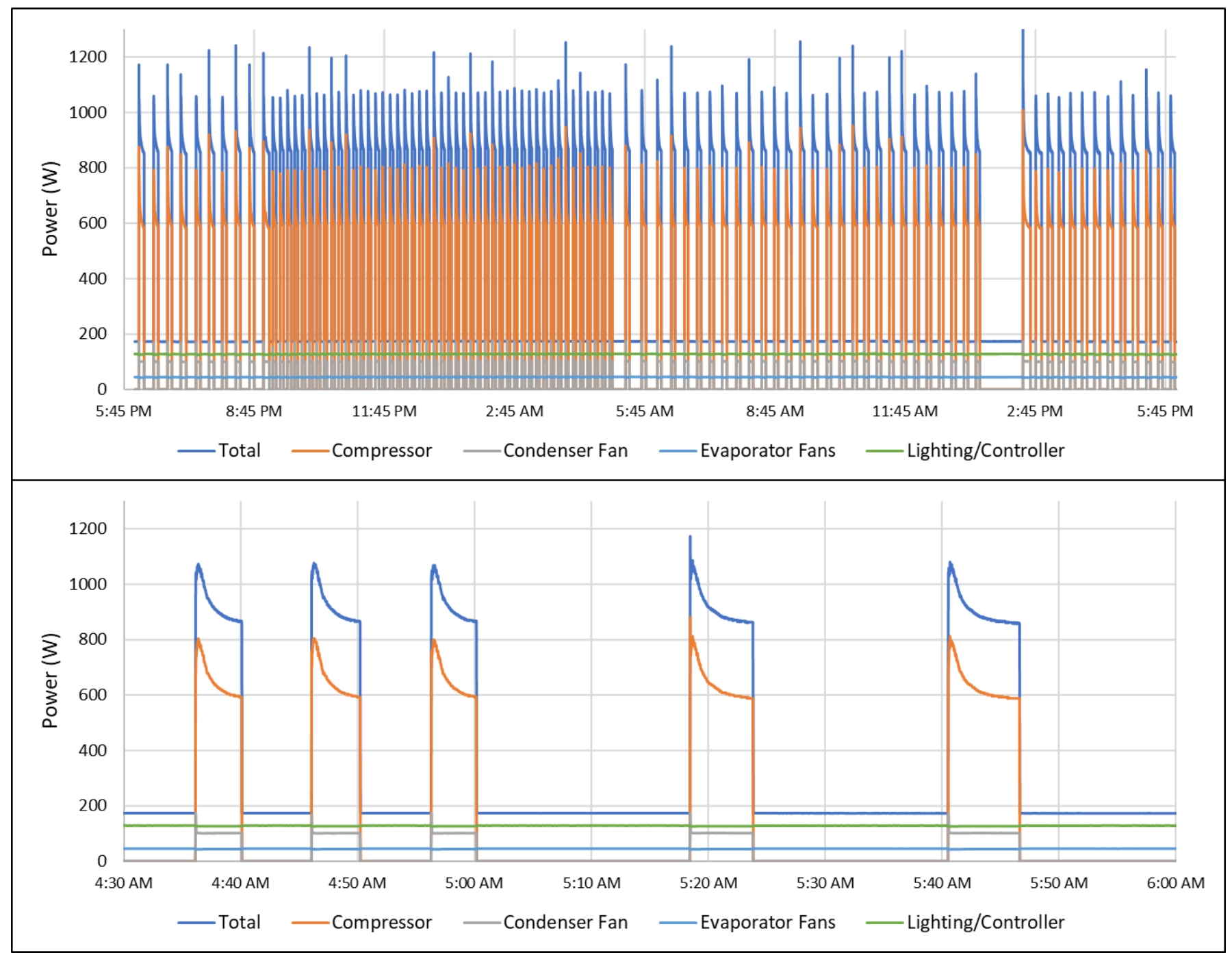

Figure 21. Baseline case total and component power consumption under January environmental conditions (top: full 24-h cycle; bottom: zoomed-in around hour 11)

The total and component power consumption during July conditions across the 24-h cycle are shown in Figure 22. The compressor cycled on 40 times ( every $12 \mathrm{~min}$ ) during the 8-h door opening period and 75 times total ( $\sim$ every 26 min outside this period). Power consumption was slightly greater than under January conditions, which was expected due to the higher latent load. Greater energy consumption under January conditions was solely due to exhibiting a greater total compressor on-cycle time compared to July. Outside of the door opening period, compressor cycles were around 6 min long under July conditions, but around 6.5 min long under January conditions. Based on discussion with the manufacturer, this discrepancy was likely associated with the case compressor's reported 24-h cycle time variability under constant environmental conditions. 


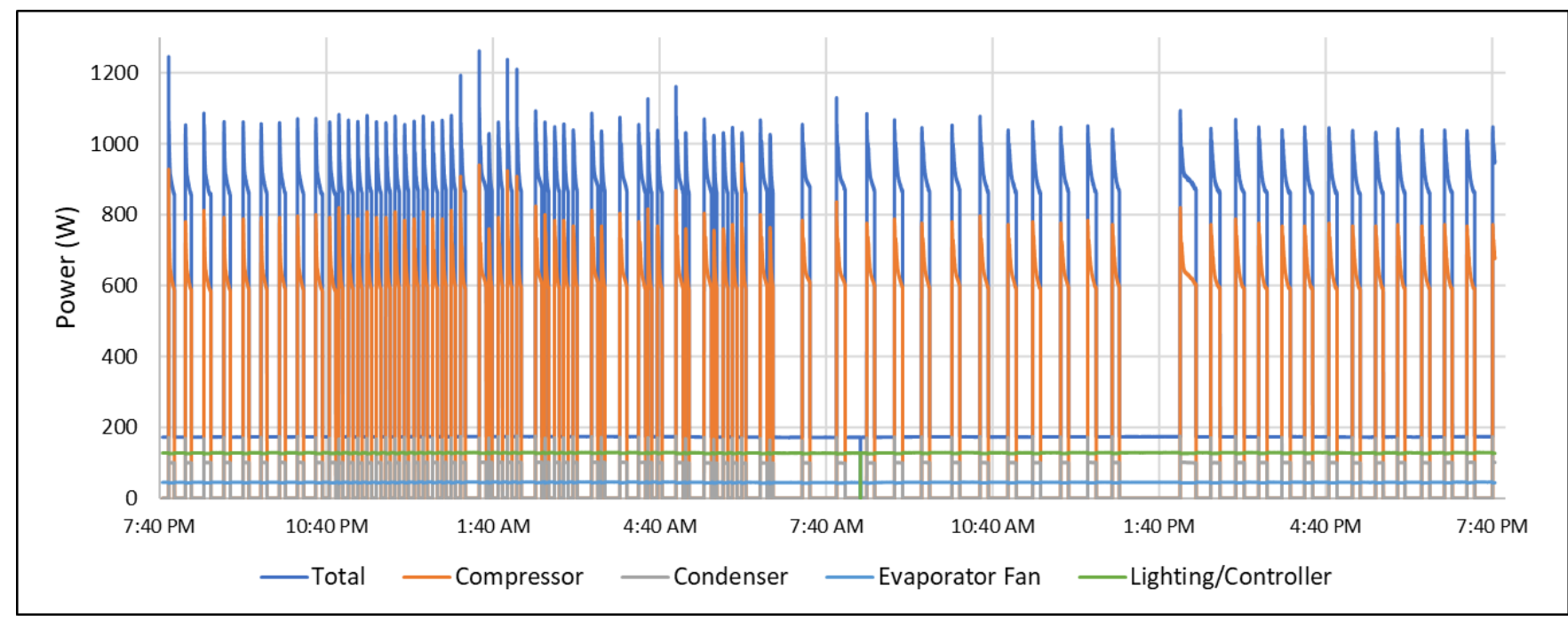

Figure 22. Baseline case total and component power consumption under July environmental conditions (full 24-h cycle)

The total and component power consumption under Upper Target environmental conditions across the 24-h cycle are shown in Figure 23. The compressor cycled on 47 times ( every $10 \mathrm{~min}$ ) during the 8-h door opening period and 77 times total ( every $30 \mathrm{~min}$ outside this period). This cycling frequency was comparable to July conditions. However, the compressor cycle on-time was longer than under the latter two conditions, which resulted in the higher overall energy consumption. Outside of door openings, the mean compressor on-time was over 10 min. During door openings, the cycling frequency was similar to January conditions. Here, the internal temperatures however reached cut-in quicker due to mixing with the higher chamber air temperature during door openings.

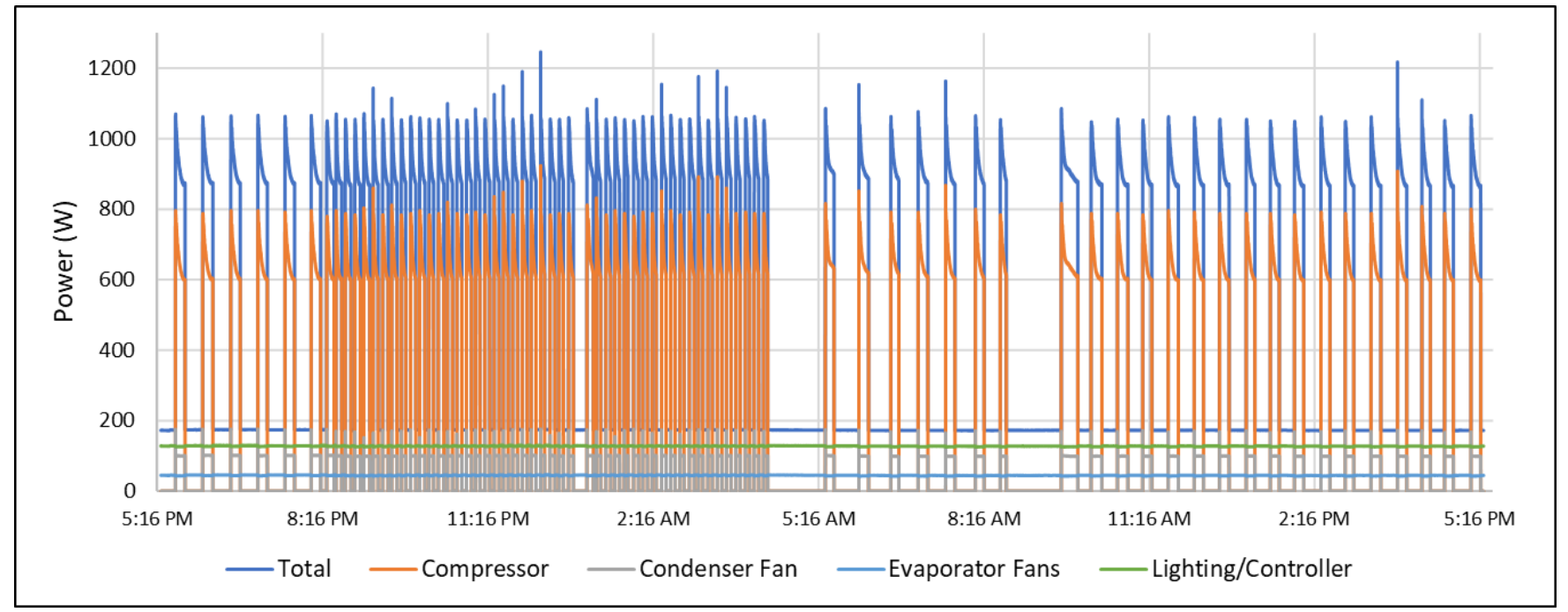

Figure 23. Baseline case total and component power consumption under Upper Target environmental conditions (full 24-h cycle)

As discussed, chamber humidity had a modest effect on total defrost time. The average defrost time was 1:05 \pm 0:05 under January conditions, 1:11 \pm 0:04 under July conditions, and 1:08 \pm 0:08 under Upper Target conditions. The total energy consumption of the baseline case was adjusted to correct for the total time between defrost cycles. The energy and mean on-cycle power consumption were also evaluated as 
a fraction of the internal volumetric capacity of the case. These values are provided in Table 9. The energy standard deviation is across individual 24-h cycles and the power standard deviation is across the total compressor run time. The corrected and normalized energy consumption and normalized mean oncycle power consumption of the case components are also provided in Figure 24. The difference between the sum of the component and total energy can be attributed to the cumulative error in measurement by the Wattnode power meters.

\section{Table 9. Baseline Case Energy and Mean On-Cycle Power Consumption Normalized to Time-Between-} Defrost and Internal Volumetric Capacity

\begin{tabular}{l|c|c|c|c|c|c} 
CONDITION & $\begin{array}{c}\text { Total } \\
\text { Energy } \\
\text { Consump- } \\
\text { tion } \\
(\mathrm{kWh} / \mathrm{day})\end{array}$ & $\begin{array}{c}\text { Total Energy } \\
\text { Consumption } \\
\text { Corrected to } \\
\text { Time-Between- } \\
\text { Defrost } \\
(\mathrm{kWh} / \text { day })\end{array}$ & $\begin{array}{c}\text { Total Energy } \\
\text { Consumption } \\
\text { Normalized } \\
\text { to Internal } \\
\text { Volume } \\
\left(\mathrm{kWh} / \mathrm{m}^{3} \text { day }\right)\end{array}$ & $\begin{array}{c}\text { Total Energy } \\
\text { Consumption } \\
\text { Corrected to } \\
\text { Time-Between- } \\
\text { Defrost and } \\
\text { Normalized to } \\
\text { Internal } \\
\text { Volume } \\
\left(\mathrm{kWh} / \mathrm{m}^{3} \text { day }\right)\end{array}$ & $\begin{array}{c}\text { Mean On- } \\
\text { Cycle Power } \\
\text { Consumption } \\
(\mathrm{W})\end{array}$ & $\begin{array}{c}\text { Mean On-Cycle } \\
\text { Power } \\
\begin{array}{c}\text { Consumption } \\
\text { Normalized to } \\
\text { Internal Volume } \\
\left(\mathrm{W} / \mathrm{m}^{3}\right)\end{array}\end{array}$ \\
\hline January & $\begin{array}{c}10.50 \pm \\
0.01\end{array}$ & $10.99 \pm 0.03$ & $7.68 \pm 0.01$ & $8.04 \pm 0.02$ & $\begin{array}{c}909.27 \pm \\
355.08\end{array}$ & $664.96 \pm 259.67$ \\
July & $\begin{array}{c}10.34 \pm \\
0.06\end{array}$ & $10.87 \pm 0.03$ & $7.56 \pm 0.05$ & $7.95 \pm 0.02$ & $\begin{array}{c}920.88 \pm \\
356.80\end{array}$ & $673.46 \pm 260.93$ \\
Upper Target & $\begin{array}{c}11.26 \pm \\
0.01\end{array}$ & $11.82 \pm 0.08$ & $8.23 \pm 0.01$ & $8.64 \pm 0.06$ & $\begin{array}{c}930.71 \pm \\
371.52\end{array}$ & $680.65 \pm 271.70$
\end{tabular}

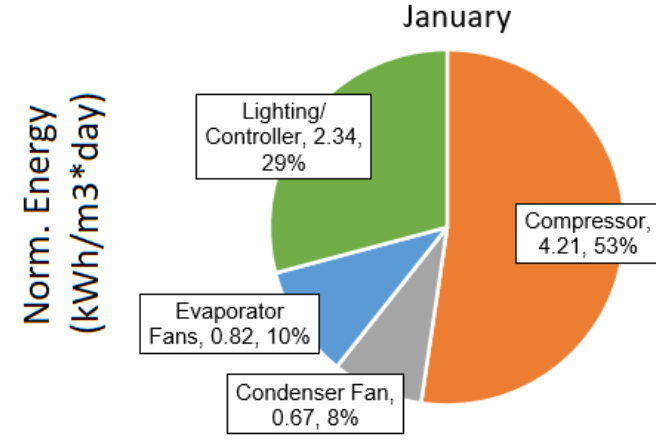

January

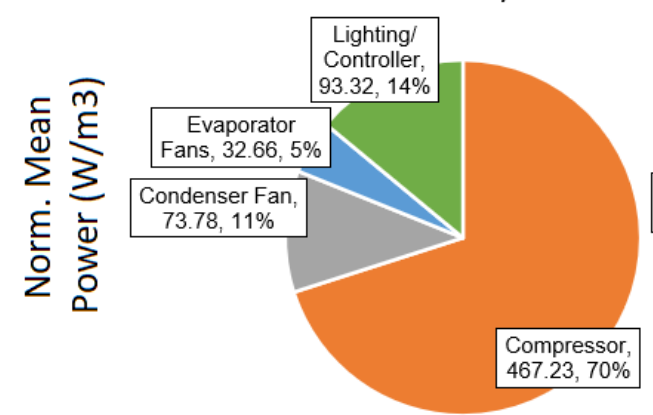

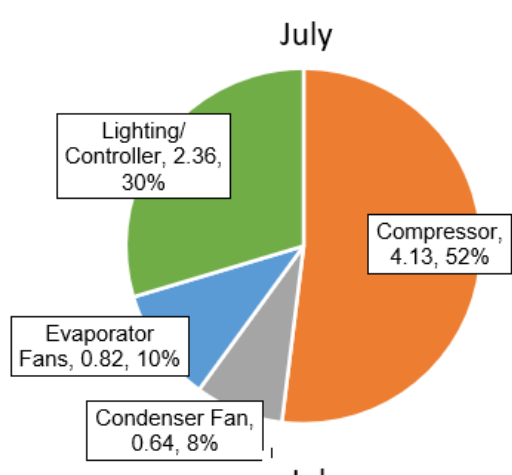

July

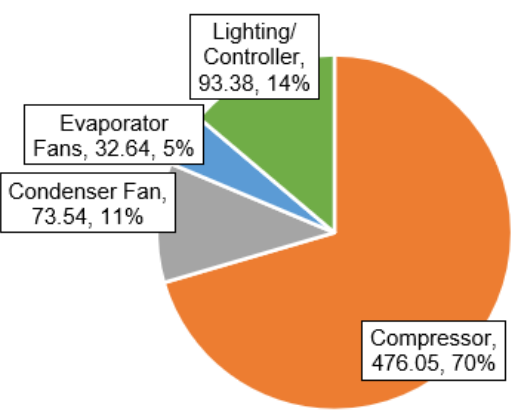

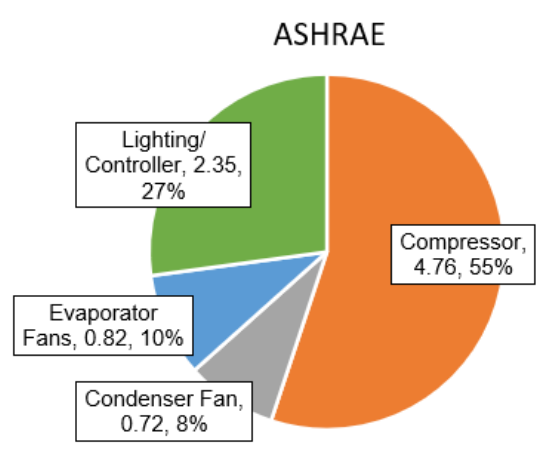

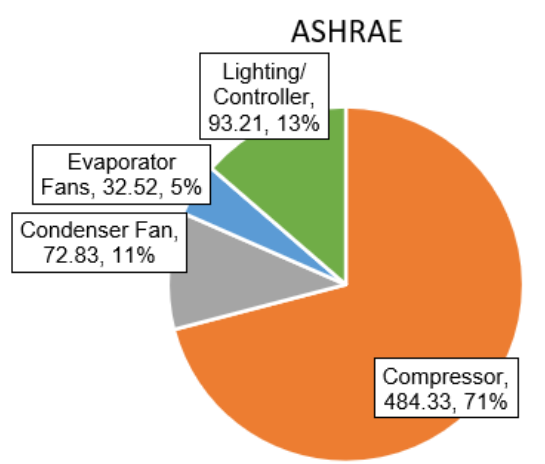

Figure 24. Baseline case component daily energy normalized to time-between-defrost and internal volumetric capacity $\left(\mathrm{kWh} / \mathrm{m}^{3}\right.$ day, top) and mean on-cycle power consumption normalized to internal volumetric capacity $\left(\mathrm{W} / \mathrm{m}^{3}\right.$, bottom) at each environmental condition

When corrected to the time between defrost cycles, we see that the energy consumption under July conditions was still less than the energy consumed under January conditions. If the cause of this 
discrepancy was entirely due to different defrost times, we would expect that this corrected energy consumption would be equivalent. However, under January conditions, the case exhibited a slight increase in compressor cycling frequency and duration which increased total energy consumption compared to July conditions. As discussed, the manufacturer reports a compressor cycle-time variability up to $10 \%$ under constant conditions. Because we were limited to only two repeated experiments at each environmental condition, we observed a much lower variability than reported. Based on this, we expect that the lower energy consumption observed under July conditions compared to January was coincidental, and that more experiments would have shifted mean energy consumption above that observed in January.

\subsection{EE Case A Results}

EE case A consumed $3.53 \pm 0.02 \mathrm{kWh} /$ day under January indoor environmental conditions, $3.63 \pm 0.07$ $\mathrm{kWh}$ /day under July conditions, and $4.30 \pm 0.00 \mathrm{kWh} /$ day under Upper Target environmental conditions. Energy consumption was highest in Upper Target conditions due to the higher chamber DBT. The compressor cycled less frequently, but for a significantly longer total duration compared to January and July conditions. This is because the compressor had to compress the refrigerant to a higher setpoint due to the warmer environment requiring a higher condensing temperature to reject heat.

The chamber DBT was approximately the same between January and July conditions. However, the higher humidity under July conditions increased the compressor energy consumption. This display case is not programmed with a scheduled defrost cycle because frost on the evaporator coil is completely removed between compressor cycles. The greater water vapor content under July conditions, however, resulted in higher frost formation during compressor cycling that hampered coil heat transfer and air circulation. Overall, this caused energy consumption to increase under July conditions.

Because EE case A had no scheduled defrost cycle, energy consumption was only normalized to the calculated interior volumetric capacity of the case. Under January conditions, this was $2.54 \pm 0.01$ $\mathrm{kWh} / \mathrm{m}^{3}$ day; under July conditions this was $2.61 \pm 0.05 \mathrm{kWh} / \mathrm{m}^{3}$ day; and under Upper Target conditions this was $3.09 \pm 0.00 \mathrm{kWh} / \mathrm{m}^{3}$ day.

The product simulators were maintained at a mean temperature of $2.91^{\circ} \mathrm{C}\left(37.24^{\circ} \mathrm{F}\right)$ in January conditions, $2.92^{\circ} \mathrm{C}\left(37.26^{\circ} \mathrm{F}\right)$ in July conditions, and $2.92^{\circ} \mathrm{C}\left(37.26^{\circ} \mathrm{F}\right)$ in Upper Target conditions. Simulator temperatures were considerably stable within their required limits and affected very little by door openings. During the period of door openings, the average simulator temperature lowered to a minimum of $2.59^{\circ} \mathrm{C}\left(36.66^{\circ} \mathrm{F}\right)$ in January conditions, $2.58^{\circ} \mathrm{C}\left(36.64^{\circ} \mathrm{F}\right)$ in July conditions, and $2.56^{\circ} \mathrm{C}$ $\left(36.61^{\circ} \mathrm{F}\right)$ in Upper Target conditions. The average simulator temperature varied to a maximum of only $3.26^{\circ} \mathrm{C}\left(37.87^{\circ} \mathrm{F}\right)$ in January conditions, $3.25^{\circ} \mathrm{C}\left(37.85^{\circ} \mathrm{F}\right)$ in July conditions, and $3.27^{\circ} \mathrm{C}\left(37.89^{\circ} \mathrm{F}\right)$ in Upper Target conditions.

\subsubsection{EE Case A Cooling Performance}

The product simulator and internal air temperatures in EE case A during the January condition assessment are provided in Figure 25. The average of all product simulator temperatures was maintained within AHRI/FDA limits throughout operation [20,21] as shown. Only the average, and not individual simulator temperatures, are required to be maintained within this range. The middle shelf/center-rear product simulator exhibited both the coldest average and coldest peak temperatures. The bottom shelf/front-right product simulator exhibited both the warmest average and warmest peak temperatures. 
Mean product simulator temperatures across the operation period are provided in Table 10, color-coded based on temperature differential beyond the AHRI/FDA limits.

Evaporator outlet air temperatures were averaged from three thermocouple measurements located at the left, center, and right side of the evaporator discharge grille. The interior ambient temperature was measured at the geometric center of the case interior. These internal air temperatures are also shown in Figure 25 across a 1.5-h segment around the end of the door opening period (hour 11).

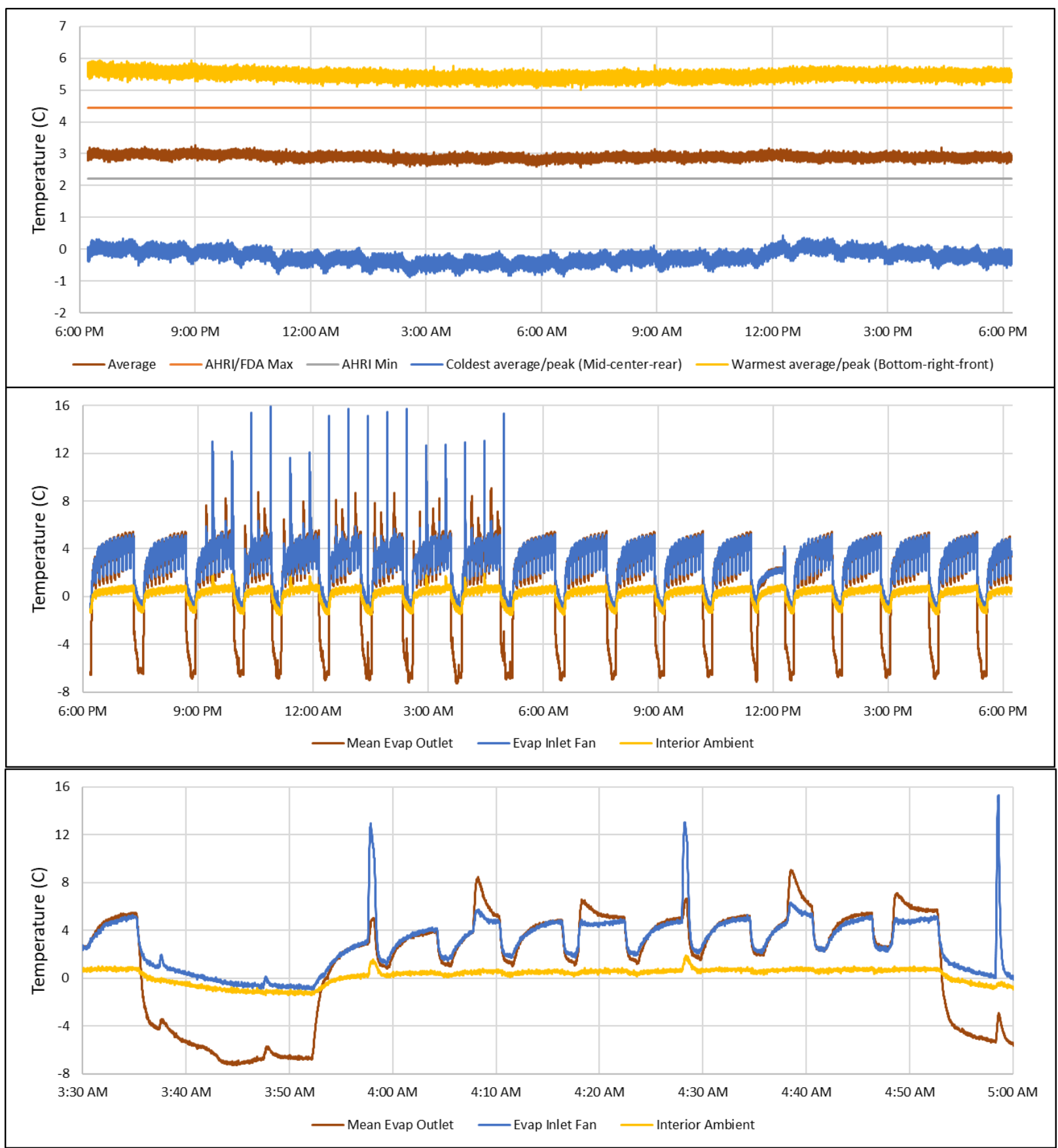

Figure 25. EE case A January condition transient product simulator temperatures (top) and internal air temperatures (middle) over $24 \mathrm{~h}$. Internal air temperatures over $1.5 \mathrm{~h}$ are shown around hour 11 (bottom) 
Table 10. EE Case A January condition average product simulator temperatures as a function of position. Color-coding is based on temperature differential beyond the AHRI/FDA limits (required only for the average).

\begin{tabular}{|c|c|c|c|c|}
\cline { 3 - 5 } \multicolumn{2}{c|}{} & \multicolumn{3}{c|}{ x-position } \\
\hline Shelf & y-position & Left & Center & Right \\
\hline \multirow{2}{*}{ Top } & Rear & $2.06^{\circ} \mathrm{C}$ & $-0.04^{\circ} \mathrm{C}$ & $1.98^{\circ} \mathrm{C}$ \\
& Front & $4.15^{\circ} \mathrm{C}$ & $1.88^{\circ} \mathrm{C}$ & $4.91^{\circ} \mathrm{C}$ \\
\hline \multirow{2}{*}{ Middle } & Rear & $1.68^{\circ} \mathrm{C}$ & $-0.23^{\circ} \mathrm{C}$ & $2.65^{\circ} \mathrm{C}$ \\
& Front & $3.45^{\circ} \mathrm{C}$ & $1.11^{\circ} \mathrm{C}$ & $4.11^{\circ} \mathrm{C}$ \\
\hline \multirow{2}{*}{ Bottom } & Rear & $3.79^{\circ} \mathrm{C}$ & $1.85^{\circ} \mathrm{C}$ & $4.88^{\circ} \mathrm{C}$ \\
& Front & $4.89^{\circ} \mathrm{C}$ & $3.74^{\circ} \mathrm{C}$ & $5.46^{\circ} \mathrm{C}$ \\
\hline
\end{tabular}

The average product simulator temperature was $2.91^{\circ} \mathrm{C}\left(37.24^{\circ} \mathrm{F}\right)$. Recall that due to the effect of altitude, cut-in and cut-out temperatures were lowered to $1.67^{\circ} \mathrm{C}\left(35^{\circ} \mathrm{F}\right)$ and $1.11^{\circ} \mathrm{C}\left(30^{\circ} \mathrm{F}\right)$, respectively, to achieve this average simulator temperature. Door openings and defrost had little noticeable effect on product simulator temperatures. Despite the regular intrusion of warm air during door openings (between 9:00 p.m. and 5:00 a.m.), they induced little change in compressor cycling frequency. This modest increase in cycling caused the coldest product simulators to decrease in temperature slightly during this period. However, these were the only simulators that exhibited any variation throughout the assessment. All other product simulator temperatures were considerably stable. The average simulator temperature varied between only $2.59^{\circ} \mathrm{C}\left(36.66^{\circ} \mathrm{F}\right)$ and $3.26^{\circ} \mathrm{C}\left(37.87^{\circ} \mathrm{F}\right)$.

The warmest average simulator was the bottom shelf/front-right simulator, which exhibited an average temperature of $5.46^{\circ} \mathrm{C}\left(41.83^{\circ} \mathrm{F}\right)$. The maximum peak temperature also occurred in this simulator, which was $5.92^{\circ} \mathrm{C}\left(42.66^{\circ} \mathrm{F}\right)$. The coldest average simulator was the middle shelf/center-rear simulator, which exhibited an average temperature of $-0.23^{\circ} \mathrm{C}\left(31.59^{\circ} \mathrm{F}\right)$. The minimum peak temperature also occurred in this simulator during the period in which doors were opening, which was $-0.85^{\circ} \mathrm{C}\left(30.47^{\circ} \mathrm{F}\right)$.

The product simulators behind the side doors were much warmer than the simulators on the center shelves, and the front-shelf simulators were also warmer than the rear simulators. This was due to the direction of airflow from the evaporator. The evaporator sits directly behind the center door mounted to the case ceiling. Cold air is discharged from the rear of the evaporator and down the back wall. Airflow is directed forward and sideways toward the doors and side walls. Since product simulators at the rear and center of the case are closer to the evaporator outlet and thereby cooled first, they exhibited colder temperatures as expected. Likewise, product simulators closer to the doors and side walls exhibited warmer temperatures.

It is unclear why product simulators behind the right-side doors were warmer than left-side product simulators. Each product simulator temperature was relatively stable throughout the assessment, as can be seen in Appendix A. Therefore, it did not appear that door openings had any effect on the temperature differences between simulators on each side. It is likely that the internal geometry of the case and/or evaporator panel causes slightly more cool air to be directed toward its left side. A more robust analysis of internal airflow patterns would however be required to determine the cause of this discrepancy.

Evaporator and internal air temperatures (Figure 25) varied with compressor cycling. The effect of January environmental conditions on compressor cycling is described in the following section. When the compressor cycled on, the mean evaporator discharge temperature dropped to a minimum of $-7.29^{\circ} \mathrm{C}$ 
$\left(18.88^{\circ} \mathrm{F}\right)$. This induced an air temperature of $-1.54^{\circ} \mathrm{C}\left(29.23^{\circ} \mathrm{F}\right)$ at the geometric center of the case, and return air to the evaporator was warmed to $-1.08^{\circ} \mathrm{C}\left(30.06^{\circ} \mathrm{F}\right)$. The maximum internal air temperature increased to $1.90^{\circ} \mathrm{C}\left(34.70^{\circ} \mathrm{F}\right)$ due to the intrusion of warm air during door openings. Since the evaporator inlet fans sit directly behind the middle door, these temperatures spiked each time doors opened starting 3 hours into the test $(9: 00$ p.m. in Figure 25$)$ to a $\max$ of $15.94^{\circ} \mathrm{C}\left(60.62^{\circ} \mathrm{F}\right)$.

Product simulator and internal air temperatures during the July condition assessment are provided in Figure 26. Overall, product temperatures were relatively the same as seen in January conditions. Door openings triggered a slight increase in the temperature variability of the coldest product simulators, however all other simulators remained stable. Internal air temperatures were relatively equivalent in magnitude. Again, the average of product simulator temperatures was maintained within AHRI/FDA limits. The middle shelf/center-rear product simulator again exhibited the coldest average simulator temperature. The top shelf-center-rear simulator here however exhibited the lowest peak temperature. The bottom shelf/rear-right simulator was the warmest average and peak simulator, which was different from assessments conducted at other environmental conditions. Mean product simulator temperatures across the operation period are provided in Table 11, color-coded based on temperature differential beyond the AHRI/FDA limits.

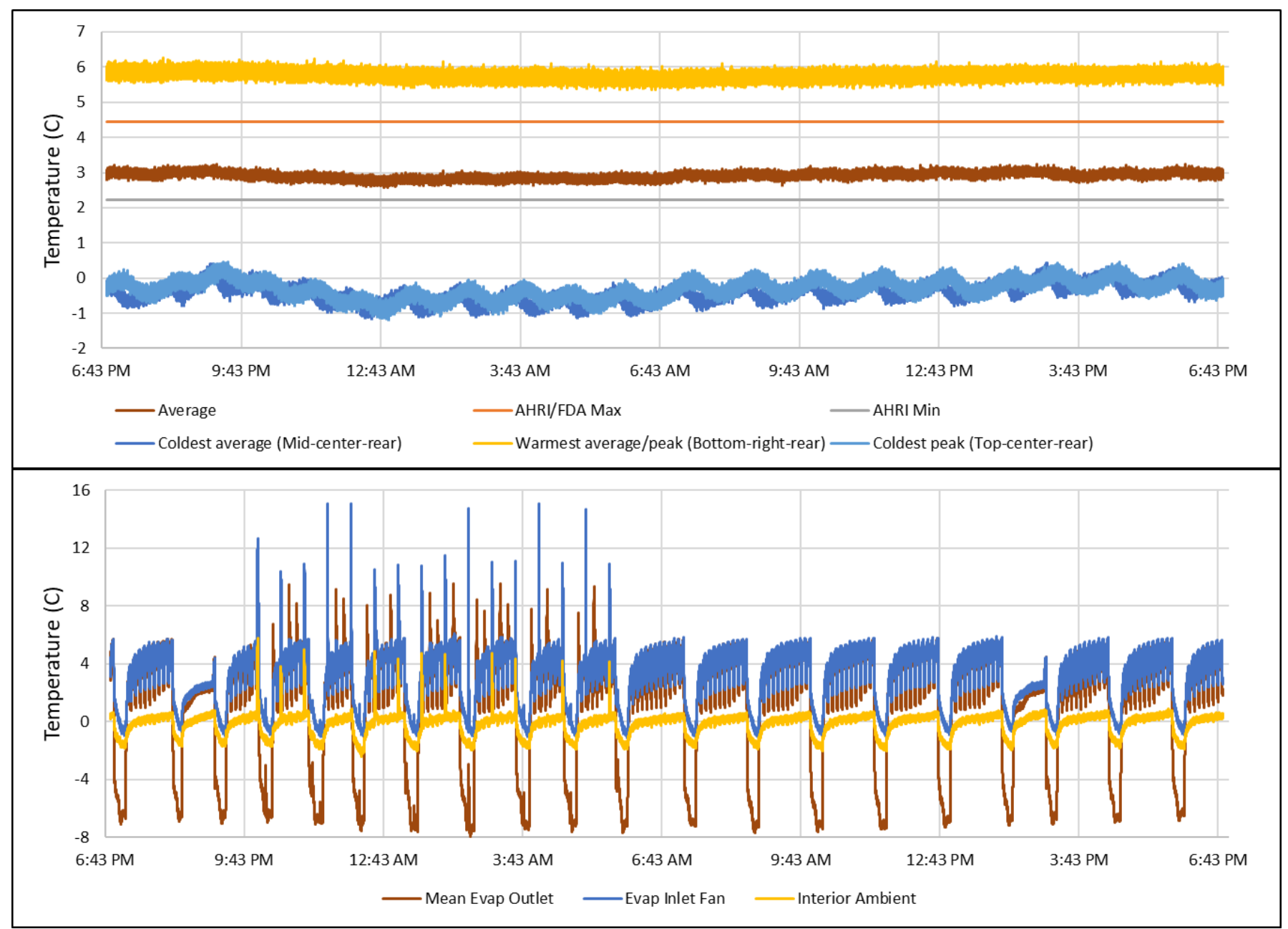

Figure 26. EE case A July condition transient product simulator temperatures (top) and internal air temperatures (bottom) 
Table 11. EE Case A July condition average product simulator temperatures as a function of position. Color-coding is based on temperature differential beyond the AHRI/FDA limits (required only for the average).

\begin{tabular}{|c|c|c|c|c|}
\cline { 3 - 5 } \multicolumn{2}{c|}{} & \multicolumn{3}{c|}{ x-position } \\
\hline Shelf & y-position & Left & Center & Right \\
\hline \multirow{2}{*}{ Top } & Rear & $1.82^{\circ} \mathrm{C}$ & $-0.30^{\circ} \mathrm{C}$ & $1.93^{\circ} \mathrm{C}$ \\
& Front & $4.40^{\circ} \mathrm{C}$ & $2.04^{\circ} \mathrm{C}$ & $4.53^{\circ} \mathrm{C}$ \\
\hline \multirow{2}{*}{ Middle } & Rear & $1.59^{\circ} \mathrm{C}$ & $-0.42^{\circ} \mathrm{C}$ & $2.62^{\circ} \mathrm{C}$ \\
& Front & $3.57^{\circ} \mathrm{C}$ & $1.29^{\circ} \mathrm{C}$ & $3.56^{\circ} \mathrm{C}$ \\
\hline \multirow{2}{*}{ Bottom } & Rear & $4.99^{\circ} \mathrm{C}$ & $1.52^{\circ} \mathrm{C}$ & $5.77^{\circ} \mathrm{C}$ \\
& Front & $4.34^{\circ} \mathrm{C}$ & $4.10^{\circ} \mathrm{C}$ & $5.19^{\circ} \mathrm{C}$ \\
\hline
\end{tabular}

The average product simulator temperature was $2.92^{\circ} \mathrm{C}\left(37.26^{\circ} \mathrm{F}\right)$ in July conditions. Door openings caused the coldest product simulators to decrease slightly in temperature, and by slightly more than under January conditions. Overall, the average product simulator temperature was relatively stable, varying between a minimum and maximum temperature of only $2.58^{\circ} \mathrm{C}\left(36.64^{\circ} \mathrm{F}\right)$ and $3.25^{\circ} \mathrm{C}\left(37.85^{\circ} \mathrm{F}\right)$, respectively. The bottom shelf/rear-right simulator average temperature was $5.77^{\circ} \mathrm{C}\left(42.39^{\circ} \mathrm{F}\right)$, and the middle shelf/center-rear average temperature was $-0.42^{\circ} \mathrm{C}\left(31.24^{\circ} \mathrm{F}\right)$. The warmest peak temperature was $6.25^{\circ} \mathrm{C}\left(43.25^{\circ} \mathrm{F}\right)$ in the bottom shelf/rear-right simulator. During door openings, the minimum peak temperature was reduced to $-1.16^{\circ} \mathrm{C}\left(29.92^{\circ} \mathrm{F}\right)$ in the top shelf/center-rear simulator.

There was an equal number of compressor cycles between July and January conditions, but the compressor cycled for a slightly longer period of time in July conditions. The effect of July environmental conditions on this change is described in the following section. However, this change appeared to have a negligible effect on the relative magnitude of internal air temperatures. The mean evaporator discharge temperature dropped to a minimum of $-7.99^{\circ} \mathrm{C}\left(17.62^{\circ} \mathrm{F}\right)$ when the compressor cycled on. This induced an air temperature of $-1.11^{\circ} \mathrm{C}\left(30.00^{\circ} \mathrm{F}\right)$ at the geometric center of the case, and a return air temperature of $-2.46^{\circ} \mathrm{C}\left(27.57^{\circ} \mathrm{F}\right)$ to the evaporator. The maximum internal air temperature was caused by the infiltration of warm air during door openings (starting at 9:43 p.m. in Figure 26), which reached $5.78^{\circ} \mathrm{C}\left(42.40^{\circ} \mathrm{F}\right)$. The evaporator inlet fan thermocouple probe is situated directly behind the middle door. Therefore, its temperature spiked to a maximum $15.11^{\circ} \mathrm{C}\left(59.20^{\circ} \mathrm{F}\right)$ during this period.

On only the bottom shelf, rear product simulators were slightly warmer than front product simulators. This increase in rear simulator temperatures was not observed at other environmental conditions. It suggests that cool air traveling downward along the back wall was directed forward toward the doors above the bottom shelf. Since filler material and simulators were arranged using the same pattern for each assessment, it is unclear why this occurred. We can speculate that a minor shift in the bottles at the rear of the case may have redirected airflow. However, it is not possible to fully recognize the cause of this change without conducting a robust analysis of internal airflow patterns.

Product simulator and internal air temperatures under Upper Target environmental conditions are provided in Figure 27. Product simulators that exhibited more extreme temperatures were slightly higher, or lower than under January or July conditions. This was due greater heat transfer into the case caused by the higher chamber temperature. Compressor cycles were slightly longer due to the higher chamber temperature, lowering colder simulator temperatures. However, the average temperature was the same. Bottom shelf rear simulators were also no longer warmer than the front simulators. 
The mean product simulator temperatures continued to be maintained within AHRI/FDA limits. The middle shelf/center-rear, and bottom shelf/front-right product simulators were again both the coldest average and warmest average product simulator temperatures, respectively. Both these simulators here exhibited the coldest and warmest peak temperatures as well. Mean product simulator temperatures across the operation period are provided in Table 12, color-coded based on temperature differential beyond the AHRI/FDA limits.

The magnitude of internal air temperatures were relatively similar to July and January conditions. The compressor however cycled less frequently, but for a longer period of time. Internal temperatures therefore varied accordingly. The effect of the chamber temperature on compressor cycling is explained in further detail in the following section.

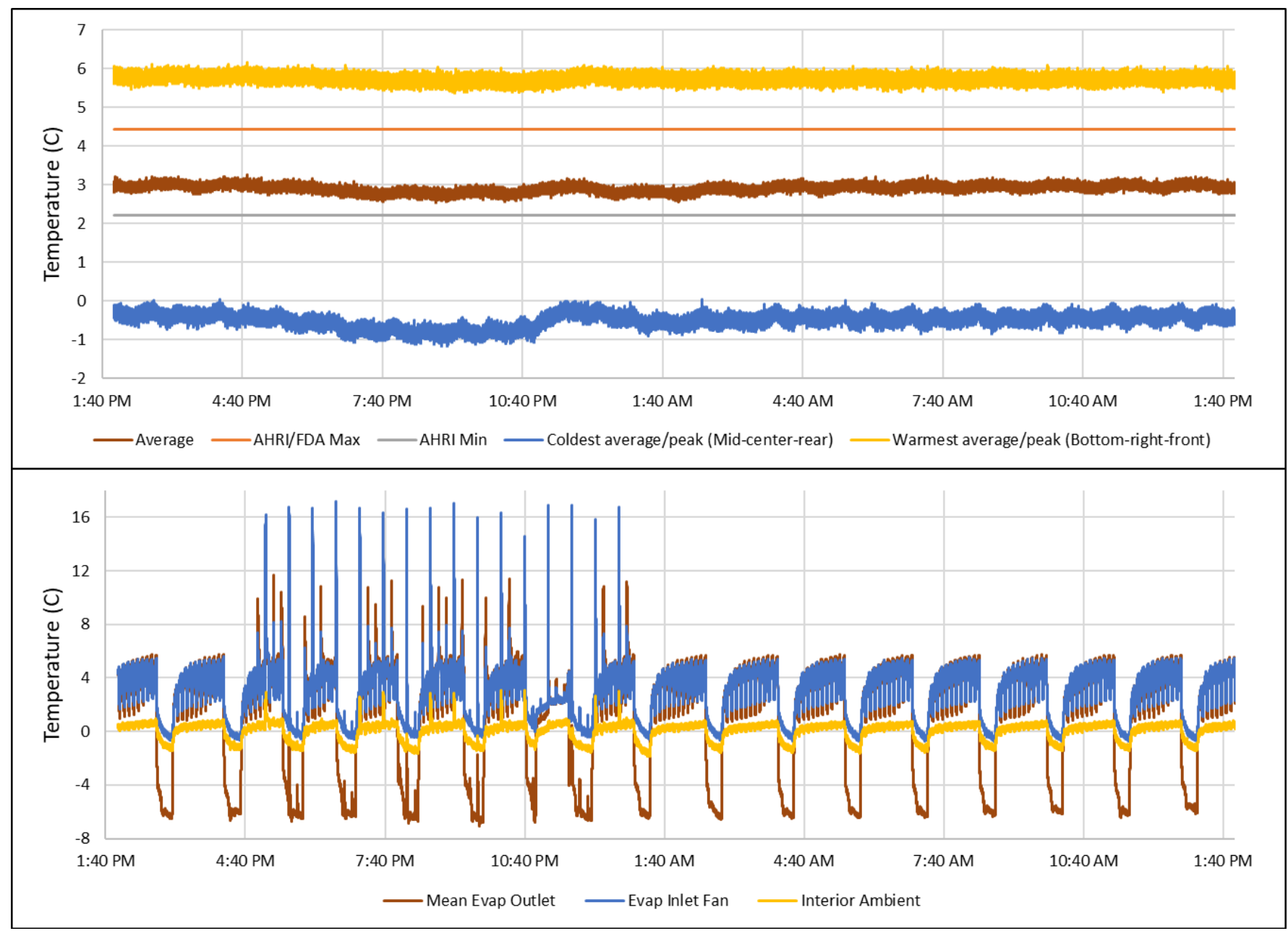

Figure 27. EE case A Upper Target condition transient product simulator temperatures (top) and internal air temperatures (bottom) 
Table 12. EE Case A Upper Target condition average product simulator temperatures as a function of position. Color-coding is based on temperature differential beyond the AHRI/FDA limits (required only for the average).

\begin{tabular}{|c|c|c|c|c|}
\cline { 3 - 5 } \multicolumn{2}{c|}{} & \multicolumn{3}{c|}{ x-position } \\
\hline Shelf & y-position & Left & Center & Right \\
\hline \multirow{2}{*}{ Top } & Rear & $2.07^{\circ} \mathrm{C}$ & $-0.29^{\circ} \mathrm{C}$ & $1.86^{\circ} \mathrm{C}$ \\
& Front & $4.27^{\circ} \mathrm{C}$ & $1.74^{\circ} \mathrm{C}$ & $5.02^{\circ} \mathrm{C}$ \\
\hline \multirow{2}{*}{ Middle } & Rear & $1.54^{\circ} \mathrm{C}$ & $-0.50^{\circ} \mathrm{C}$ & $2.49^{\circ} \mathrm{C}$ \\
& Front & $3.46^{\circ} \mathrm{C}$ & $0.96^{\circ} \mathrm{C}$ & $4.20^{\circ} \mathrm{C}$ \\
\hline \multirow{2}{*}{ Bottom } & Rear & $3.96^{\circ} \mathrm{C}$ & $1.77^{\circ} \mathrm{C}$ & $5.13^{\circ} \mathrm{C}$ \\
& Front & $5.13^{\circ} \mathrm{C}$ & $3.93^{\circ} \mathrm{C}$ & $5.75^{\circ} \mathrm{C}$ \\
\hline
\end{tabular}

The average product simulator temperature was $2.92^{\circ} \mathrm{C}\left(37.26^{\circ} \mathrm{F}\right)$ in the Upper Target environmental conditions. The coldest and warmest product simulators were respectively reduced and increased slightly further from July conditions due to the warmer chamber temperature. The stability in the average product simulator temperature was relatively unchanged from previous conditions, varying between a minimum and maximum of $2.56^{\circ} \mathrm{C}\left(36.61^{\circ} \mathrm{F}\right)$ and $3.27^{\circ} \mathrm{C}\left(37.89^{\circ} \mathrm{F}\right)$. The warmest simulators on the bottom shelf shifted back to the front near the door, similar to January conditions. The bottom shelf/front-right simulator with the average warmest temperature $\left(5.75^{\circ} \mathrm{C}\left(42.35^{\circ} \mathrm{F}\right)\right)$ peaked at around $6.17^{\circ} \mathrm{C}\left(43.11^{\circ} \mathrm{F}\right)$. The coldest simulator was less stable, decreasing during door openings as the compressor cycled on for a longer period of time. During this period, the coldest simulator (averaging $\left.-0.50^{\circ} \mathrm{C}\left(31.10^{\circ} \mathrm{F}\right)\right)$ exhibited a peak minimum temperature of $-1.15^{\circ} \mathrm{C}\left(29.93^{\circ} \mathrm{F}\right)$.

Compressor cycling was less frequent under Upper Target conditions. The compressor was, however, cycled on for a longer period of time than in January and July conditions. Internal air temperatures varied accordingly. Due to the increased chamber temperature in Upper Target conditions, the magnitude of internal air temperatures were slightly greater than in January and July conditions. The mean evaporator discharge temperature dropped to a minimum of $-7.05^{\circ} \mathrm{C}\left(19.31^{\circ} \mathrm{F}\right)$ when the compressor cycled on. This induced an air temperature of $-1.87^{\circ} \mathrm{C}\left(28.63^{\circ} \mathrm{F}\right)$ at the geometric center of the case, and a return air temperature of $-0.78^{\circ} \mathrm{C}\left(30.60^{\circ} \mathrm{F}\right)$ to the evaporator. During the period of door openings (starting at 4:40 p.m. in Figure 27), the interior ambient temperature spiked to $3.08^{\circ} \mathrm{C}$ $\left(37.54^{\circ} \mathrm{F}\right)$. Due to the location of the evaporator inlet fan behind the middle door, it reached a higher maximum value of $17.18^{\circ} \mathrm{C}\left(62.92^{\circ} \mathrm{F}\right)$ during door openings.

Sometimes, customers may be able to remove condensate to a nearby floor drain. Typically, this is not available, and customers will use their own electric pumps to remove condensate. Customers often choose to supply their own condensate pumps, which can contribute to overall energy consumption. Therefore, the mass of condensate produced was evaluated. The condensate mass generated by the baseline case over $24 \mathrm{~h}$ at each environmental conditions is shown below in Figure 28. 


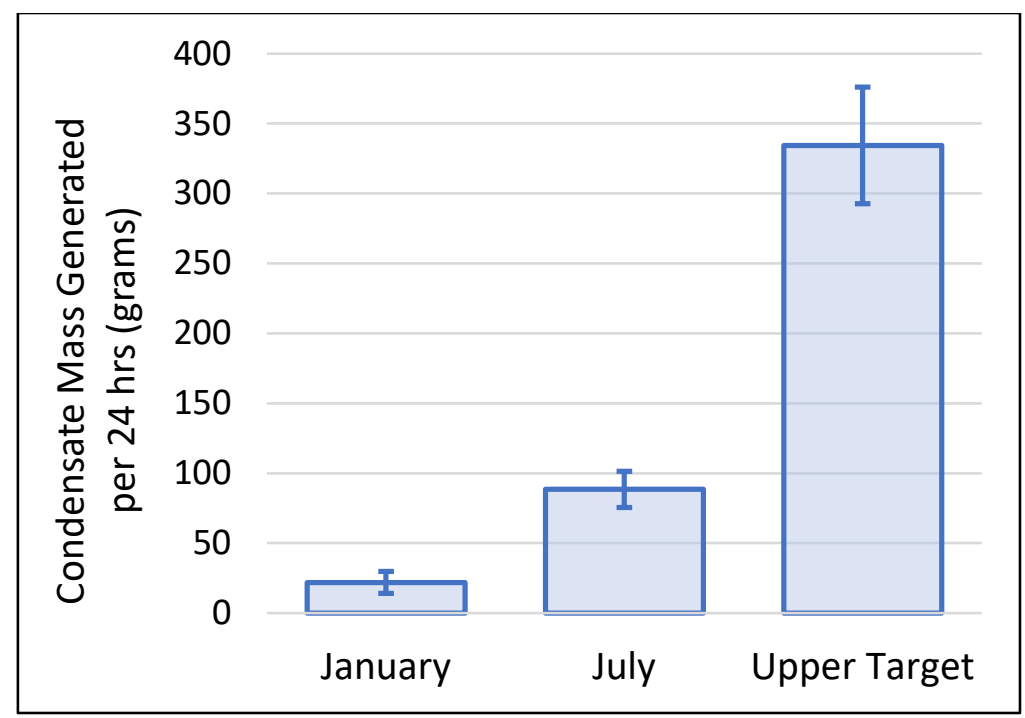

Figure 28. EE case A condensate mass generated at each environmental condition

Like other doored refrigerator cases, EE case A generated a relatively small amount of condensate. Even in Upper Target environmental conditions, not enough condensate was produced to fill a typical condensate pump reservoir. A condensate pump only turns on when the reservoir is filled, and so only small condensate pumps would consume any energy over $24 \mathrm{~h}$ at these conditions. It should be noted that due to the low condensate mass collected in January and July conditions, a significant fraction of the total condensate may have remained in the evaporator or drain line by surface tension.

\subsubsection{EE Case A Power/Energy Consumption}

Figure 29 shows the total power consumption by EE case A at each environmental condition. Error bars indicate standard error across individual 24-h assessments. The case performed best in January conditions, consuming $3.53 \pm 0.02 \mathrm{kWh} /$ day. As expected, the Upper Target environmental conditions induced the greatest energy consumption due to the higher chamber temperature. The case consumed $4.30 \pm 0.004 \mathrm{kWh} /$ day at these conditions. In July environmental conditions, the case consumed $3.63 \pm$ $0.07 \mathrm{kWh} /$ day. Differences in total energy consumption were due to changes in only certain electrical components. These components were affected by environmental conditions differently, as shown in Figure 30. Differences between total energy consumption and the sum of components can be attributed to the Wattnode meters' uncertainty. 

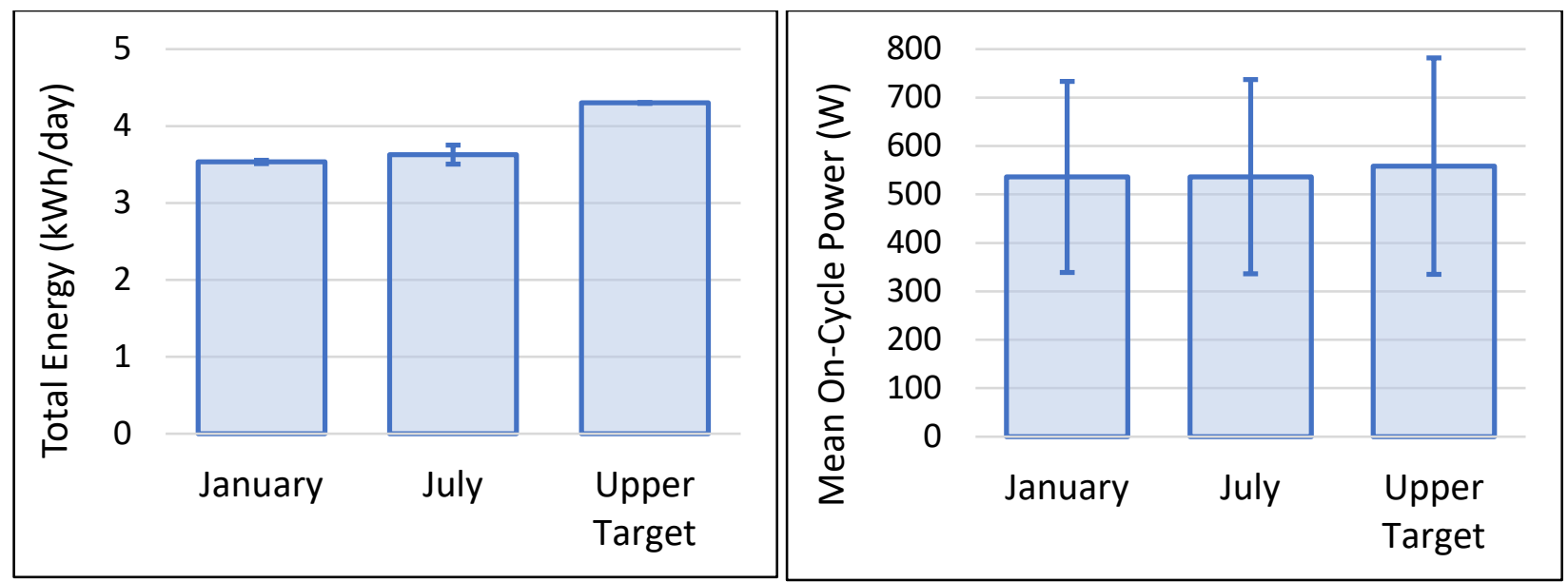

Figure 29. EE case A total energy consumption (left) and mean on-cycle power consumption (right) at each environmental condition
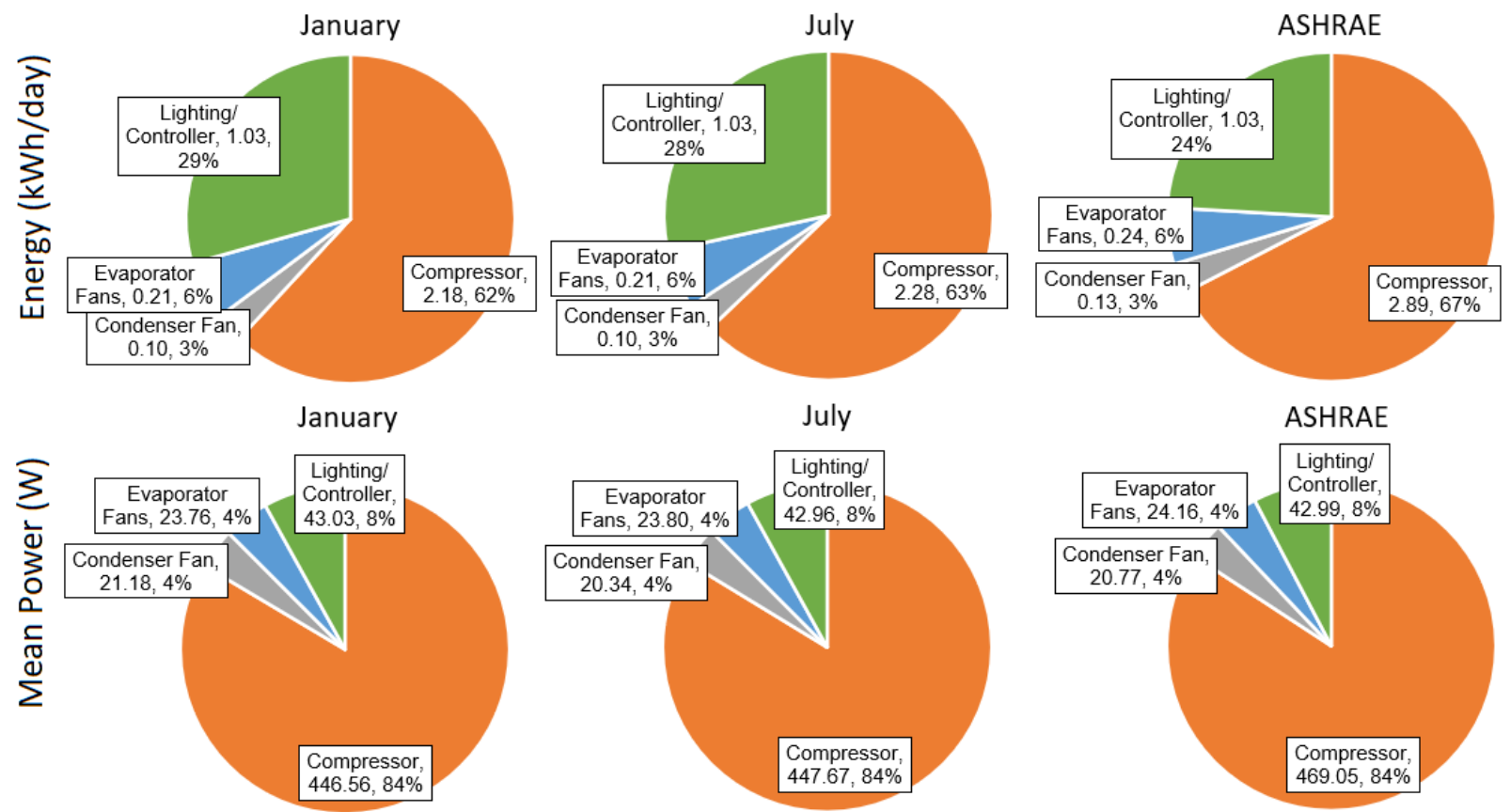

Figure 30. EE case A component daily energy (kWh/day, top) and mean on-cycle power consumption (W, bottom) at each environmental condition

The majority of the energy of EE case A was consumed by the compressor. Its energy constituted between $62 \%$ and $67 \%$ of the total energy consumption, depending on environmental conditions. The lighting and controller also consumed a significant fraction of the total energy: between $24 \%$ and $29 \%$. As expected, environmental conditions had no impact on the lighting and controller energy consumption, which was held at a constant $1.03 \mathrm{kWh} /$ day. The energy of all other components varied with environmental conditions.

The difference in compressor energy between environmental conditions was the largest source of the difference in total energy consumption. This is because the compressor cycling duration and frequency were altered to respond to these conditions. At higher chamber temperatures, a higher condensing temperature requires the refrigerant to be pressurized more to reject heat. This requires the compressor 
to cycle on for a longer duration. The compressor must also cycle on more frequently to compensate for greater heat transfer into the case through the walls and through convection via door openings. Since the chamber temperature was highest in Upper Target environmental conditions, the compressor operated for the longest total duration over $24 \mathrm{~h}$, consuming $2.89 \mathrm{kWh} /$ day. The compressor, however, consumed only 2.18 and $2.28 \mathrm{kWh} /$ day under January and July conditions, respectively.

The difference in DBT between January and July conditions was relatively negligible. Instead, the different chamber DPT/humidity between these conditions affected compressor cycling. In July conditions, the greater humidity causes more ice to accumulate on the evaporator coils, which reduces airflow and increases the time until the case air temperature reaches the compressor cut-out temperature. In cases with defrost, this can also cause the compressor to remain off for a longer duration to reach termination temperature, alternatively reducing energy consumption. However, EE case A did not have a defrost. Instead, ice accumulation only reduced energy efficiency by inhibiting air flow through the evaporator, causing the compressor to cycle on for a longer duration under July conditions and increasing total energy consumption.

The condenser fan was powered on concurrently with the compressor. Therefore, its power consumption was proportionally affected by environmental conditions. The evaporator fan was also powered concurrently with the compressor, and it also cycled on when the compressor was off every 5 minutes for 1 minute. Therefore, its energy consumption was greater than the condenser fan but still increased with greater compressor on-time.

The compressor cycling frequency and duration were affected differently depending on the environmental conditions. During January conditions, the compressor cycled on 7 times ( every hour and $10 \mathrm{~min})$ during the 8-h door opening period, and 20 times total ( every hour and 14 min outside this period). The total and component power consumption across the 24-h cycle are shown in Figure 31. Also shown is a 1.5-h segment at the end of the door opening period. Each time the compressor is cycled on, there is an initial spike in power followed by an immediate plateau. 


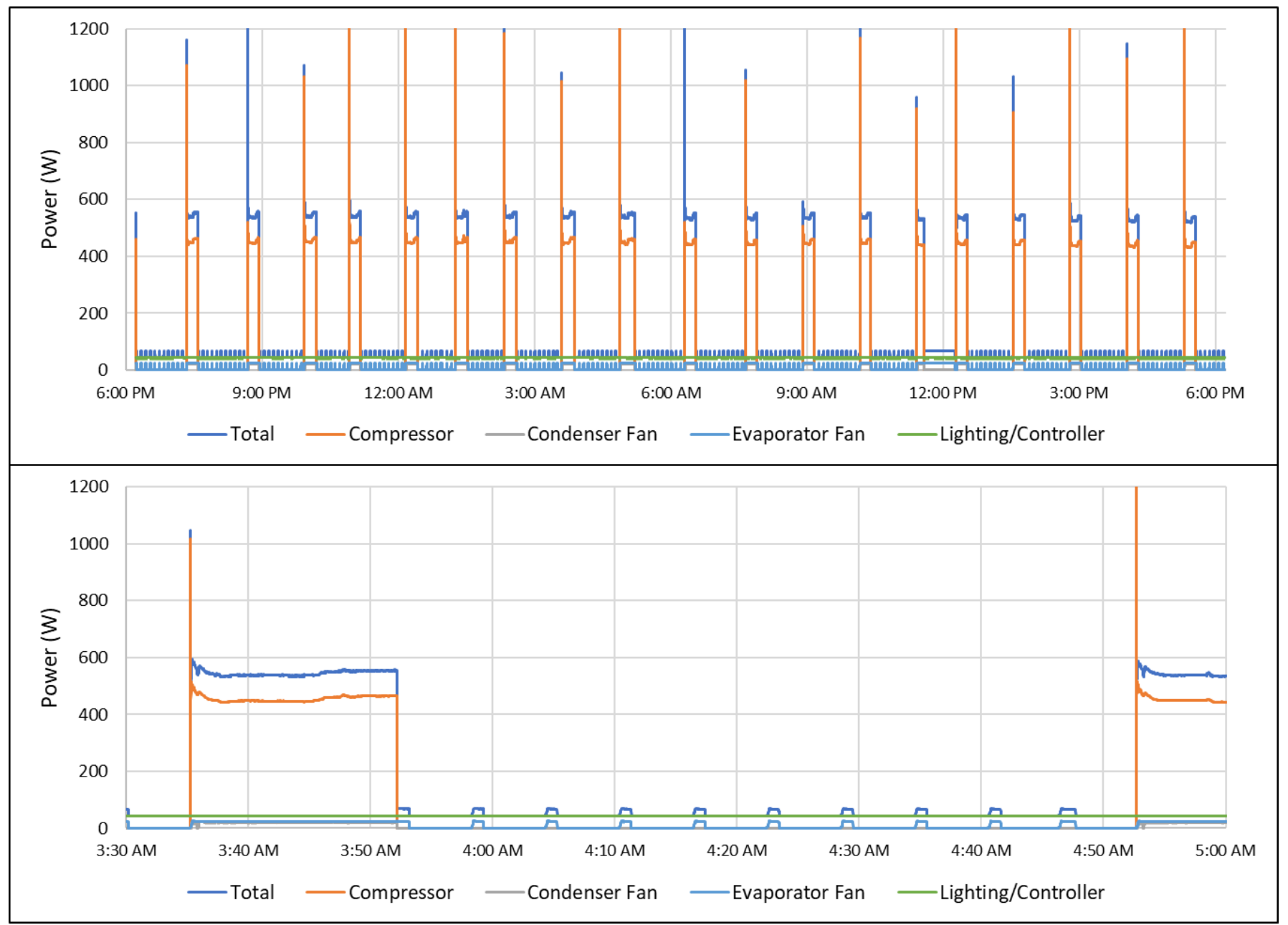

Figure 31. EE case $A$ total and component power consumption under January environmental conditions (top: full 24-h cycle; bottom: zoomed-in around hour 11)

The total and component power consumption during July conditions across the 24-h cycle are shown in Figure 32. The compressor cycled on 7 times ( every hour and $10 \mathrm{~min}$ ) during the 8-h door opening period and 20 times total ( every hour and 14 min outside this period). The frequency of compressor cycling was the same as under January conditions, but the cycling duration was slightly longer due to the increased humidity. This was caused by greater accumulation of ice on the evaporator, which reduced airflow and induced an overall increase in the case's total energy consumption. Outside of the door opening period, compressor cycles were around 15 min long under January conditions, but around 16 min long under July conditions. 


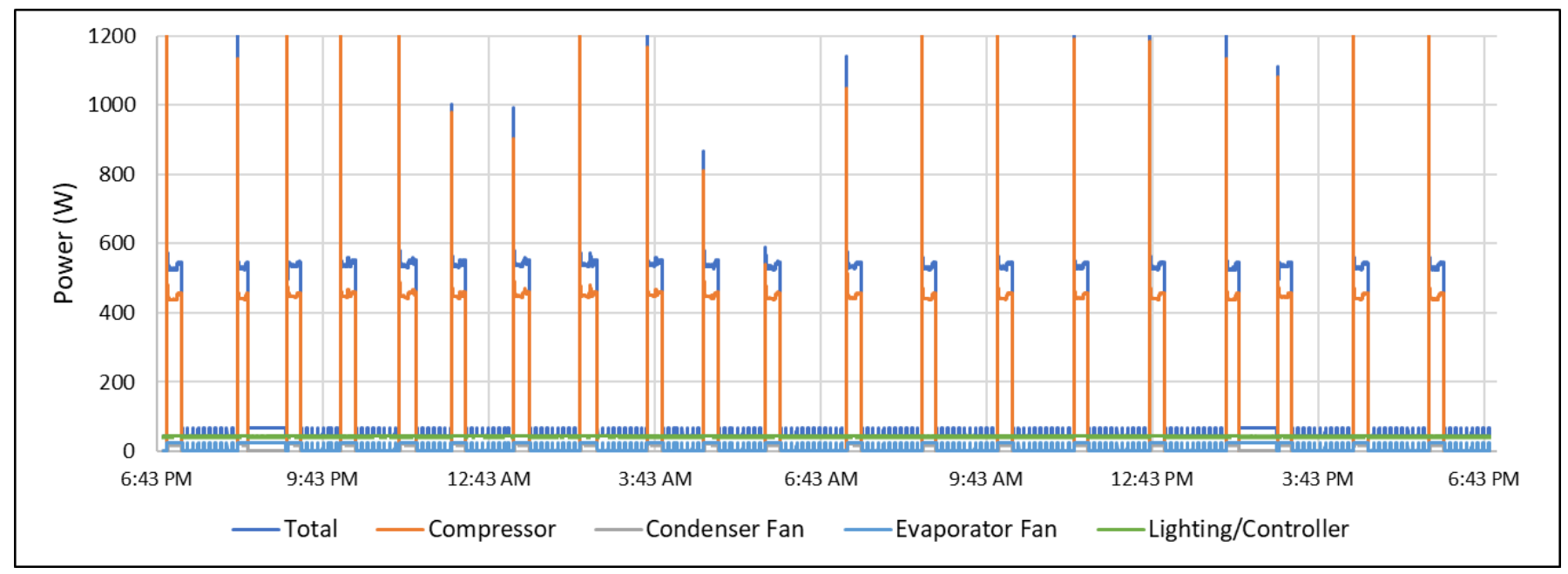

Figure 32. EE case $A$ total and component power consumption under July environmental conditions (full 24-h cycle)

The total and component power consumption under Upper Target environmental conditions are shown in Figure 33 across a 24-h cycle. The compressor cycled on 6 times ( every hour and 20 min) during the 8-h door opening period and 17 times total ( every hour and $27 \mathrm{~min}$ outside this period). This cycling frequency was less than observed under the previous two environmental conditions. However, the compressor cycle on-time was much longer ( $\sim 20 \mathrm{~min})$, resulting in a higher total energy consumption. This was due to the higher chamber air temperature, which required the compressor to cycle on longer due to the higher condensing temperature.

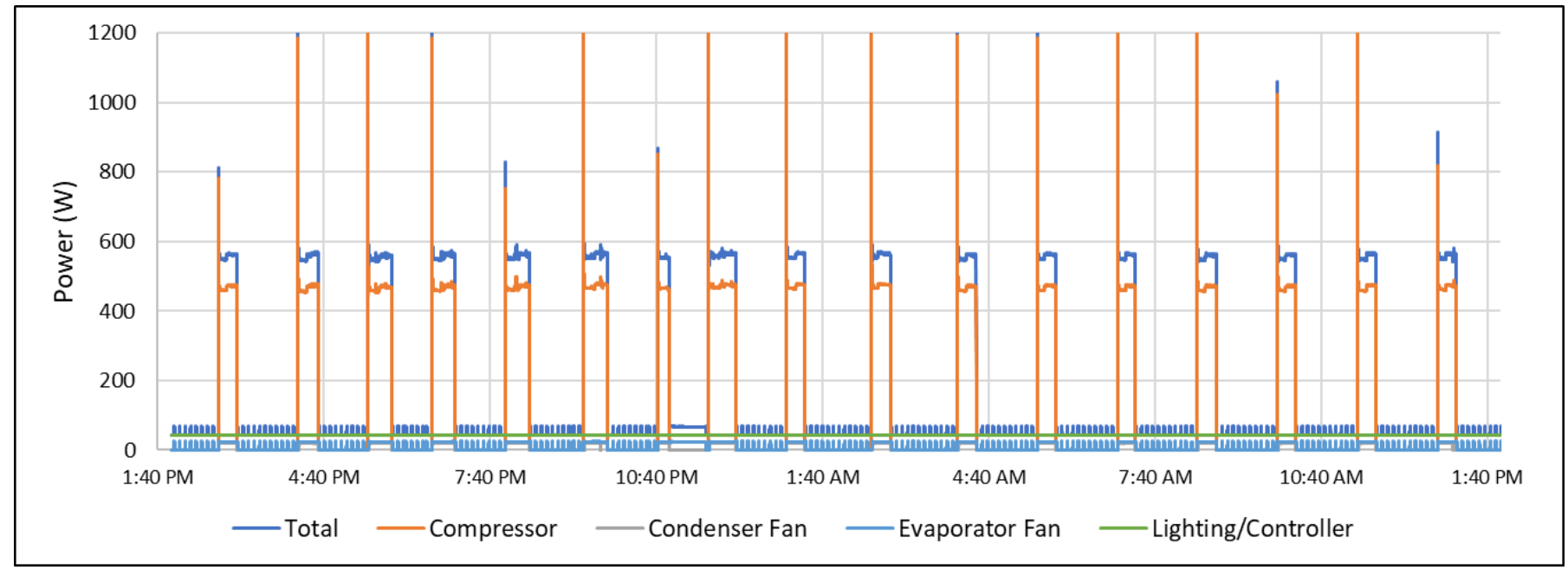

Figure 33. EE case A total and component power consumption under Upper Target environmental conditions (full 24-h cycle)

The total measured energy and mean on-cycle power consumption were adjusted to the internal volumetric capacity of the case. Because EE case A had no scheduled defrost, the energy consumption was unchanged by an adjustment to the time between defrost cycles. These values are provided in Table 13. The energy standard deviation is across individual 24-h cycles and the power standard deviation is across the total compressor run time. The corrected and normalized energy consumption and normalized mean on-cycle power consumption of the case components are also provided in Figure 34 . The 
difference between the sum of the component and total energy can be attributed to the cumulative error in measurement by the Wattnode power meters.

Table 13. EE Case A Energy and Mean On-Cycle Power Consumption Normalized to Time-BetweenDefrost and Internal Volumetric Capacity

\begin{tabular}{|c|c|c|c|c|c|c|}
\hline CONDITION & $\begin{array}{c}\text { Total Energy } \\
\text { Consump- } \\
\text { tion } \\
\text { (kWh/day) }\end{array}$ & $\begin{array}{l}\text { Total Energy } \\
\text { Consumption } \\
\text { Corrected to } \\
\text { Time-Between- } \\
\text { Defrost } \\
\text { (kWh/day) }\end{array}$ & $\begin{array}{l}\text { Total Energy } \\
\text { Consumption } \\
\text { Normalized to } \\
\text { Internal Volume } \\
\text { (kWh/m } \mathrm{m}^{3} \text { day) }\end{array}$ & $\begin{array}{c}\text { Total Energy } \\
\text { Consumption } \\
\text { Corrected to Time- } \\
\text { Between-Defrost } \\
\text { and Normalized to } \\
\text { Internal Volume } \\
\left(\mathrm{kWh} / \mathrm{m}^{3} \text { day }\right)\end{array}$ & $\begin{array}{l}\text { Mean On-Cycle } \\
\text { Power } \\
\text { Consumption (W) }\end{array}$ & $\begin{array}{c}\text { Mean On-Cycle } \\
\text { Power } \\
\text { Consumption } \\
\text { Normalized to } \\
\text { Internal Volume } \\
\left(\mathrm{W} / \mathrm{m}^{3}\right)\end{array}$ \\
\hline Janu & & $3.53 \pm 0.02$ & & & $446.56=$ & $385.25 \pm 141.69$ \\
\hline July & $3.63 \pm 0.07$ & .07 & $2.61 \pm$ & $2.61 \pm 0.05$ & $447.67 \pm 183.71$ & 385.63 \\
\hline $\begin{array}{l}\text { Upper } \\
\text { Target }\end{array}$ & $4.30 \pm 0.00$ & $4.30 \pm 0.00$ & $3.09 \pm 0.00$ & $3.09 \pm 0.00$ & $469.05 \pm 205.33$ & $401.29 \pm 160.50$ \\
\hline
\end{tabular}
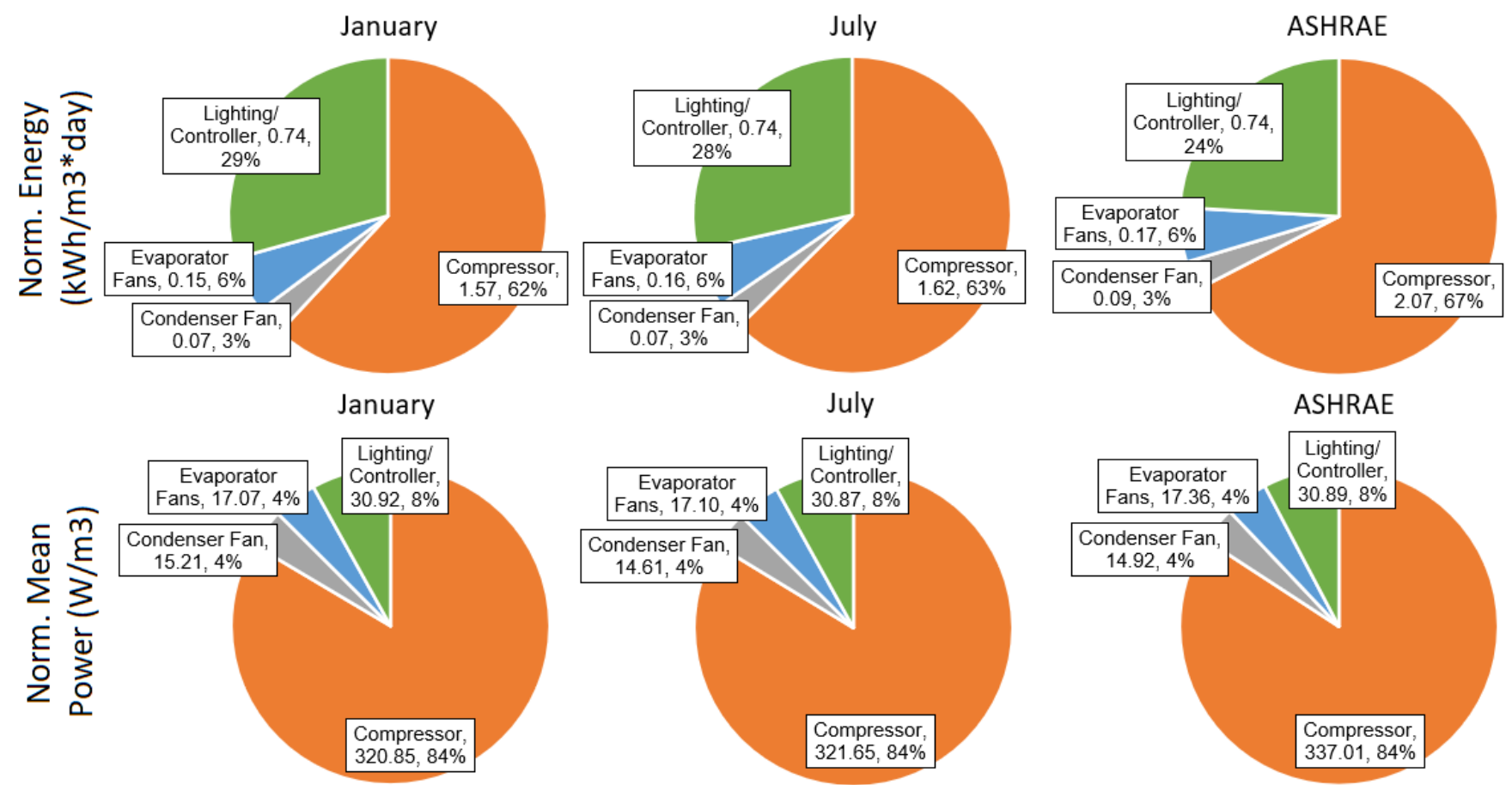

Figure 34. EE case A component daily energy normalized to time-between-defrost and internal volumetric capacity ( $\mathrm{kWh} / \mathrm{m}^{3}$ day, top) and mean on-cycle power consumption normalized to internal volumetric capacity $\left(\mathrm{W} / \mathrm{m}^{3}\right.$, bottom) at each environmental condition

\subsection{EE Case B Results}

EE case B consumed $6.13 \pm 0.02 \mathrm{kWh} /$ day under January indoor environmental conditions, $6.42 \pm 0.02$ $\mathrm{kWh}$ /day under July conditions, and $7.59 \pm 0.03 \mathrm{kWh}$ /day under Upper Target environmental conditions. Energy consumption was highest in Upper Target conditions due to the higher chamber DBT. More heat transfer into the case caused the compressor to cycle more frequently than under January and July conditions. To reject heat, the compressor also had to cycle on for a longer duration to reach higher setpoint due to a greater condensing temperature. 
The different energy consumption between January and July conditions was more so due to differences in chamber DPT/humidity than DBT. Higher water vapor content in the air generates more frost accumulation around the evaporator, inhibiting airflow. This forces the compressor to cycle on for a longer duration to reach the same cut-out temperature, increasing total energy consumption.

The greater accumulation of frost on the evaporator panel also forces defrost cycles to last longer to reach their termination temperature. Since EE case B had two defrost cycles over $24 \mathrm{~h}$, one of these cycles always occurred during the period of door openings. This forced warm chamber air over the evaporator, which reduced defrost cycle time. However, this reduction in defrost time was not enough to overcome the effect of humidity on the duration of compressor cycling. Therefore, greater DPT/humidity induced higher overall energy consumption. The energy consumption was corrected to the time between defrost cycles, as well as the calculated inner volumetric capacity of the case. This resulted in a corrected total energy consumption of $4.96 \pm 0.00 \mathrm{kWh} / \mathrm{m}^{3}$ day under January conditions, $5.17 \pm 0.02 \mathrm{kWh} / \mathrm{m}^{3}$ day under July conditions, and $6.09 \pm 0.02 \mathrm{kWh} / \mathrm{m}^{3}$ day under Upper Target conditions.

The product simulators were maintained at a mean temperature of $3.06^{\circ} \mathrm{C}\left(37.51^{\circ} \mathrm{F}\right)$ in January conditions, $2.99^{\circ} \mathrm{C}\left(37.38^{\circ} \mathrm{F}\right)$ in July conditions, and $3.01^{\circ} \mathrm{C}\left(37.42^{\circ} \mathrm{F}\right)$ in Upper Target conditions. Simulator temperatures exhibited modest fluctuation in response to the effect of door openings and defrost cycling. However, the average of simulator temperatures was consistently held within the required limits. The 8 -h door-opening period caused product simulators to drop by inducing more frequent compressor cycling. This caused the average simulator temperature to reduce to a minimum of $2.69^{\circ} \mathrm{C}\left(36.84^{\circ} \mathrm{F}\right)$ in January conditions, $2.57^{\circ} \mathrm{C}\left(36.63^{\circ} \mathrm{F}\right)$ in July conditions, and $2.33^{\circ} \mathrm{C}\left(36.19^{\circ} \mathrm{F}\right)$ in Upper Target conditions during door openings. The defrost cycles caused product temperatures to increase to their maximum value. Because one defrost cycle occurred during the period of door openings, the average simulator temperature increased even more during this cycle. The maximum of the simulator average here was $3.51^{\circ} \mathrm{C}\left(38.32^{\circ} \mathrm{F}\right)$ in January conditions, $3.51^{\circ} \mathrm{C}\left(38.32^{\circ} \mathrm{F}\right)$ in July conditions, and $3.70^{\circ} \mathrm{C}\left(38.66^{\circ} \mathrm{F}\right)$ in Upper Target conditions.

\subsubsection{EE Case B Cooling Performance}

The product simulator and internal air temperatures in EE case B during the January condition assessment are provided in Figure 35. The average of all product simulator temperatures was maintained within AHRI/FDA limits throughout operation [20,21] as shown. Only the average, and not individual simulator temperatures, are required to be maintained within this range. The middle shelf/center-rear product simulator exhibited both the coldest average and coldest peak temperatures. The bottom shelf/front-left product simulator exhibited both the warmest average and warmest peak temperatures. Mean product simulator temperatures across the operation period are provided in Table 14, color-coded based on temperature differential beyond the AHRI/FDA limits.

Evaporator outlet air temperatures were averaged from three thermocouple measurements located at the left, center, and right side of the evaporator discharge grille. The interior ambient temperature was measured at the geometric center of the case interior. These internal air temperatures are also shown in Figure 35 across a 1.5 -h segment around the end of the door opening period (hour 11). 

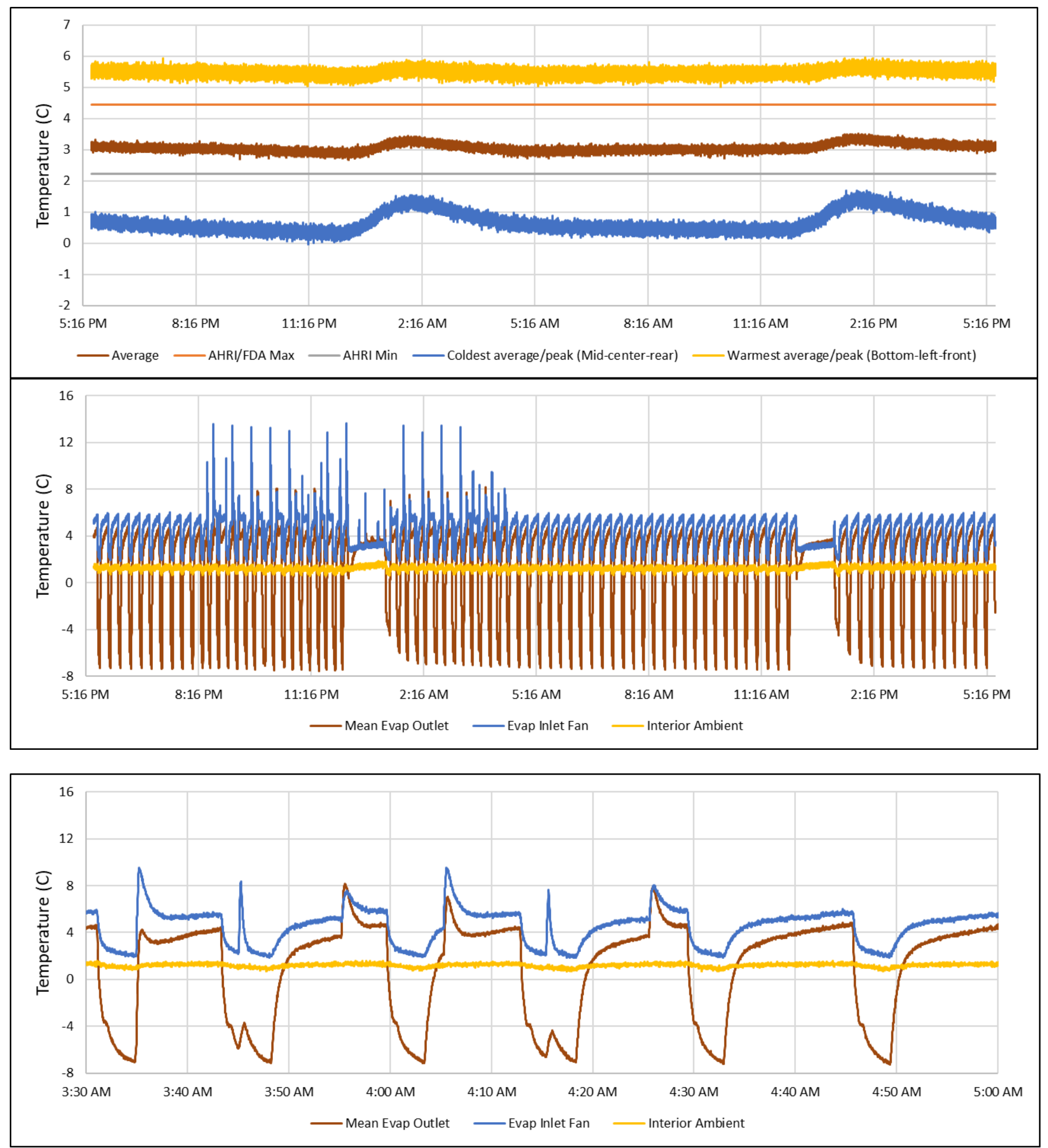

Figure 35. EE case B January condition transient product simulator temperatures (top) and internal air temperatures (middle) over $24 \mathrm{~h}$. Internal air temperatures over $1.5 \mathrm{~h}$ are shown around hour 11 (bottom) 
Table 14. EE Case B January condition average product simulator temperatures as a function of position. Color-coding is based on temperature differential beyond the AHRI/FDA limits (required only for the average).

\begin{tabular}{|c|c|c|c|c|}
\cline { 3 - 5 } \multicolumn{2}{c|}{} & \multicolumn{3}{c|}{ x-position } \\
\hline Shelf & y-position & Left & Center & Right \\
\hline \multirow{2}{*}{ Top } & Rear & $2.10^{\circ} \mathrm{C}$ & $0.70^{\circ} \mathrm{C}$ & $1.02^{\circ} \mathrm{C}$ \\
& Front & $5.18^{\circ} \mathrm{C}$ & $3.45^{\circ} \mathrm{C}$ & $3.98^{\circ} \mathrm{C}$ \\
\hline \multirow{2}{*}{ Middle } & Rear & $2.36^{\circ} \mathrm{C}$ & $0.67^{\circ} \mathrm{C}$ & $1.08^{\circ} \mathrm{C}$ \\
& Front & $4.59^{\circ} \mathrm{C}$ & $2.67^{\circ} \mathrm{C}$ & $3.32^{\circ} \mathrm{C}$ \\
\hline \multirow{2}{*}{ Bottom } & Rear & $3.40^{\circ} \mathrm{C}$ & $2.68^{\circ} \mathrm{C}$ & $3.06^{\circ} \mathrm{C}$ \\
& Front & $5.49^{\circ} \mathrm{C}$ & $4.01^{\circ} \mathrm{C}$ & $5.38^{\circ} \mathrm{C}$ \\
\hline
\end{tabular}

The average product simulator temperature was $3.06^{\circ} \mathrm{C}\left(37.51^{\circ} \mathrm{F}\right)$. Recall that due to the effect of altitude, cut-in and cut-out temperatures were lowered to $3.89^{\circ} \mathrm{C}\left(39^{\circ} \mathrm{F}\right)$ and $-0.56^{\circ} \mathrm{C}\left(31^{\circ} \mathrm{F}\right)$, respectively, to achieve this average simulator temperature. Door openings and defrost significantly affected product simulator temperatures. Door openings (between 8:16 p.m. and 4:16 a.m.) caused warm air to regularly enter the case. The case responded by cycling the compressor on more frequently, which caused the product temperature to drop to a minimum of $2.69^{\circ} \mathrm{C}\left(36.84^{\circ} \mathrm{F}\right)$. Defrost occurred twice for 1 $\mathrm{h}$ (around approximately 12:16 p.m./a.m.), which resulted in the average product temperature rising to a maximum $3.51^{\circ} \mathrm{C}\left(38.32^{\circ} \mathrm{F}\right)$.

The warmest average simulator was the bottom shelf/front-left simulator, which exhibited an average temperature of $5.49^{\circ} \mathrm{C}\left(41.88^{\circ} \mathrm{F}\right)$. The maximum peak temperature also occurred in this simulator during defrost, which was $5.97^{\circ} \mathrm{C}\left(42.75^{\circ} \mathrm{F}\right)$. The coldest average simulator was the middle shelf/center-rear simulator which exhibited an average temperature of $0.67^{\circ} \mathrm{C}\left(33.21^{\circ} \mathrm{F}\right)$. The minimum peak temperature also occurred in this simulator during the period in which doors were opening, since this caused the compressor to cycle more frequently. This simulator achieved a minimum temperature of $-0.01^{\circ} \mathrm{C}$ $\left(31.98^{\circ} \mathrm{F}\right)$ during that period.

The product simulators behind the side doors were much warmer than the simulators on the center shelves, and the front-shelf simulators were also warmer than the rear simulators. This was due to the direction of airflow from the evaporator. The evaporator sits directly behind the center door mounted to the case ceiling. Cold air is discharged from the rear of the evaporator and down the back wall. Airflow is directed forward and sideways toward the doors and side walls. Since product simulators at the rear and center of the case are closer to the evaporator outlet and thereby cooled first, they exhibited colder temperatures as expected. Likewise, product simulators closer to the doors and side walls exhibited warmer temperatures.

It is unclear why product simulators behind the left-side doors were warmer than the right-side simulators. Temperatures on both sides responded similarly to door openings and defrosts, as can be seen in Appendix A. It was not evident that one side was affected differently by either of these events. It is likely that the internal geometry of the case and/or evaporator panel causes slightly more cool air to be directed toward its left side. A more robust analysis of internal airflow patterns would be required to determine the cause of this discrepancy. 
Evaporator and internal air temperatures (Figure 35) varied with compressor cycling. The effect of January environmental conditions on compressor cycling is described in the following section. When the compressor cycled on, the mean evaporator discharge temperature dropped to a minimum of $-7.55^{\circ} \mathrm{C}$ $\left(18.41^{\circ} \mathrm{F}\right)$. This induced an air temperature of $0.57^{\circ} \mathrm{C}\left(33.03^{\circ} \mathrm{F}\right)$ at the geometric center of the case, and return air to the evaporator was warmed to $-1.79^{\circ} \mathrm{C}\left(35.22^{\circ} \mathrm{F}\right)$. The maximum internal air temperature increased to $1.84^{\circ} \mathrm{C}\left(35.31^{\circ} \mathrm{F}\right)$ during the first defrost, which occurred during the door opening period. Since the compressor was forced off for defrost, warm air infiltrating the case during door openings was left to equilibrate with the product. Since the evaporator inlet fans sit directly behind the middle door, these temperatures also spiked each time doors opened starting three hours into the test (8:16 p.m. in Figure 35$)$ to a $\max$ of $13.62^{\circ} \mathrm{C}\left(56.52^{\circ} \mathrm{F}\right)$.

Product simulator and internal air temperatures during the July condition assessment are provided in Figure 36. Overall, product temperatures were relatively the same as seen in January conditions. Internal air temperatures were relatively equivalent in magnitude, but varied slightly more frequently due to increased compressor cycling. Again, the average of product simulator temperatures was maintained within AHRI/FDA limits. The top shelf/center-rear and middle shelf/center-rear simulators exhibited very similar temperatures. Here, the top shelf/center-rear, and bottom shelf/front-left product simulators were both the coldest average and warmest average product simulator temperatures, respectively. The bottom shelf/front-left simulator was also the warmest peak simulator. The middle shelf/center-rear simulator, however, exhibited the lowest peak temperature. Mean product simulator temperatures across the operation period are provided in Table 15, color-coded based on temperature differential beyond the AHRI/FDA limits. 


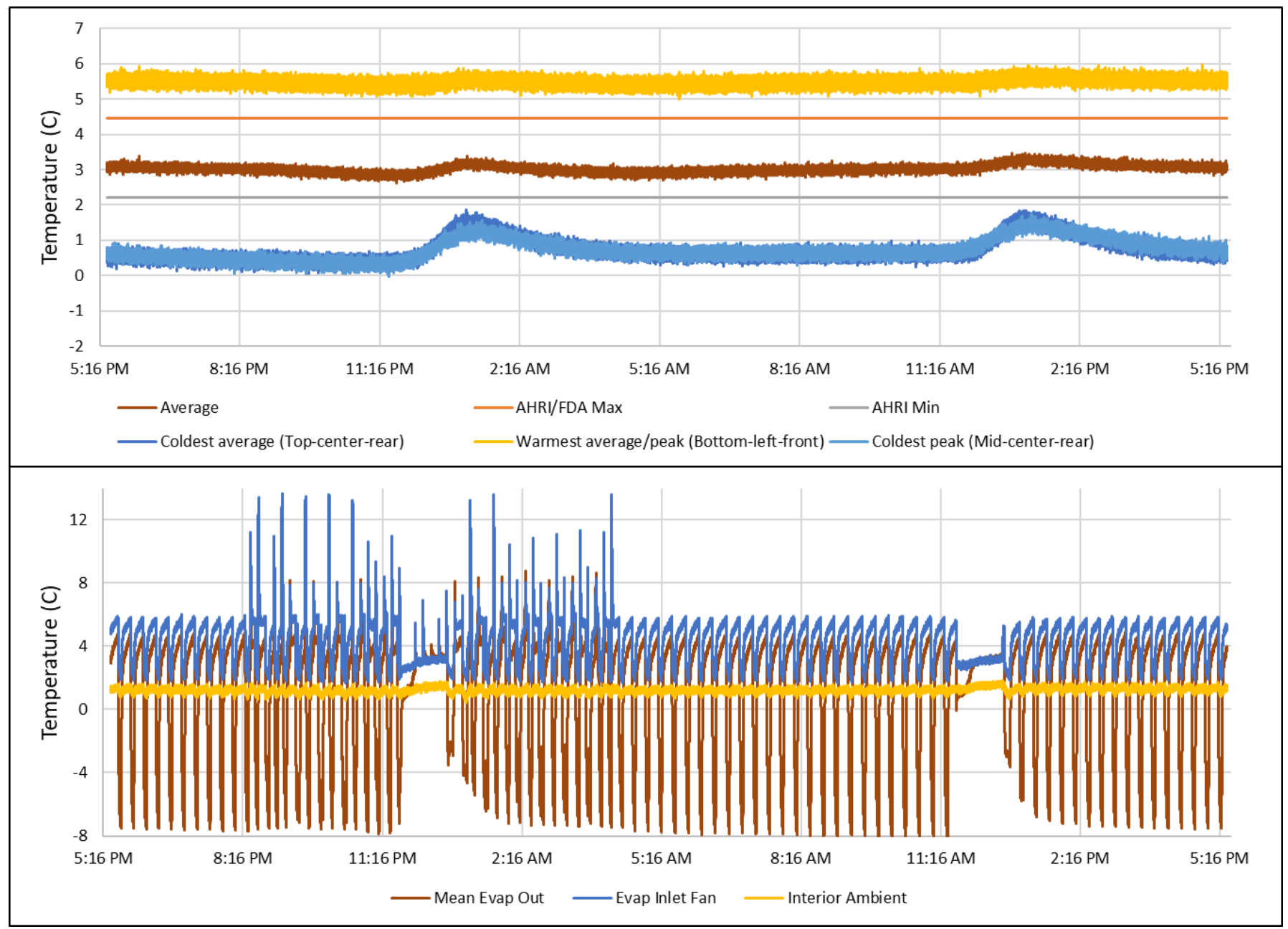

Figure 36. EE case B July condition transient product simulator temperatures (top) and internal air temperatures (bottom)

Table 15. EE Case B July condition average product simulator temperatures as a function of position. Color-coding is based on temperature differential beyond the AHRI/FDA limits (required only for the average).

\begin{tabular}{|c|c|c|c|c|}
\cline { 3 - 5 } \multicolumn{2}{c|}{} & \multicolumn{3}{c|}{ x-position } \\
\hline Shelf & y-position & Left & Center & Right \\
\hline \multirow{2}{*}{ Top } & Rear & $2.04^{\circ} \mathrm{C}$ & $0.73^{\circ} \mathrm{C}$ & $0.87^{\circ} \mathrm{C}$ \\
& Front & $5.07^{\circ} \mathrm{C}$ & $3.43^{\circ} \mathrm{C}$ & $3.82^{\circ} \mathrm{C}$ \\
\hline \multirow{2}{*}{ Middle } & Rear & $2.21^{\circ} \mathrm{C}$ & $0.73^{\circ} \mathrm{C}$ & $1.02^{\circ} \mathrm{C}$ \\
& Front & $4.52^{\circ} \mathrm{C}$ & $2.69^{\circ} \mathrm{C}$ & $3.25^{\circ} \mathrm{C}$ \\
\hline \multirow{2}{*}{ Bottom } & Rear & $3.43^{\circ} \mathrm{C}$ & $2.70^{\circ} \mathrm{C}$ & $3.06^{\circ} \mathrm{C}$ \\
& Front & $5.50^{\circ} \mathrm{C}$ & $4.07^{\circ} \mathrm{C}$ & $5.39^{\circ} \mathrm{C}$ \\
\hline
\end{tabular}

The average product simulator temperature was $3.03^{\circ} \mathrm{C}\left(37.45^{\circ} \mathrm{F}\right)$ in July conditions. The effect of door openings and defrost were relatively the same as in January conditions. Door openings caused the product temperature to drop to a minimum of $2.64^{\circ} \mathrm{C}\left(36.72^{\circ} \mathrm{F}\right)$, and defrost caused the temperature to rise to a maximum $3.47^{\circ} \mathrm{C}\left(38.25^{\circ} \mathrm{F}\right)$. The bottom shelf/front-left simulator average temperature was 
$5.50^{\circ} \mathrm{C}\left(41.90^{\circ} \mathrm{F}\right)$, and the top shelf/center-rear average temperature was $0.73^{\circ} \mathrm{C}\left(33.31^{\circ} \mathrm{F}\right)$. The maximum peak temperature during defrost was $5.97^{\circ} \mathrm{C}\left(42.74^{\circ} \mathrm{F}\right)$ in the bottom shelf/front-right simulator and the minimum peak temperature during door openings was $-0.02^{\circ} \mathrm{C}\left(31.96^{\circ} \mathrm{F}\right)$ in the middle shelf/center-rear simulator.

The magnitude of internal air temperatures were largely similar between January and July conditions. Compressor cycling was slightly less frequent under July conditions, and so the internal air temperatures responded accordingly. The mean evaporator discharge temperature dropped to a minimum of $-8.14^{\circ} \mathrm{C}$ $\left(17.35^{\circ} \mathrm{F}\right)$ when the compressor cycled on. This induced an air temperature of $0.46^{\circ} \mathrm{C}\left(32.83^{\circ} \mathrm{F}\right)$ at the geometric center of the case, and a return air temperature of $1.64^{\circ} \mathrm{C}\left(34.95^{\circ} \mathrm{F}\right)$ to the evaporator. The maximum internal air temperature during defrost $(\sim 11: 16$ a.m. in Figure 36$)$ was $1.82^{\circ} \mathrm{C}\left(35.28^{\circ} \mathrm{F}\right)$. The evaporator inlet fan temperature spiked to a maximum $13.66^{\circ} \mathrm{C}\left(56.59^{\circ} \mathrm{F}\right)$ when doors were opened (starting at 8:16 p.m. in Figure 36).

Product simulator and internal air temperatures under Upper Target environmental conditions are provided in Figure 37. The average product temperature was relatively the same as under January and July conditions. There was a slight decrease or increase in the temperature of the colder and warmer simulators, however. The compressor cycled far more frequently due to the higher chamber temperature, especially during door openings. This caused the evaporator discharge temperature to occasionally decrease to lower values than seen at other conditions. Otherwise, the magnitude of internal air temperatures were relatively similar to July and January conditions. Compressor cycles increased drastically during the door opening period, which resulted in an approximately $20 \%$ higher cycling frequency compared to January and July conditions. The effect of the chamber temperature on compressor cycling is explained in further detail in the following section.

The mean product simulator temperatures continued to be maintained within AHRI/FDA limits, despite varying to a greater degree during door openings and defrost. The top shelf/center-rear, and bottom shelf/front-left product simulators again exhibited the coldest average and warmest average product simulator temperatures, respectively. The bottom shelf/front-right simulator was also the warmest peak simulator. The top shelf/center-rear again exhibited the lowest peak temperature as was seen under July conditions. Mean product simulator temperatures across the operation period are provided in Table 16, color-coded based on temperature differential beyond the AHRI/FDA limits. 


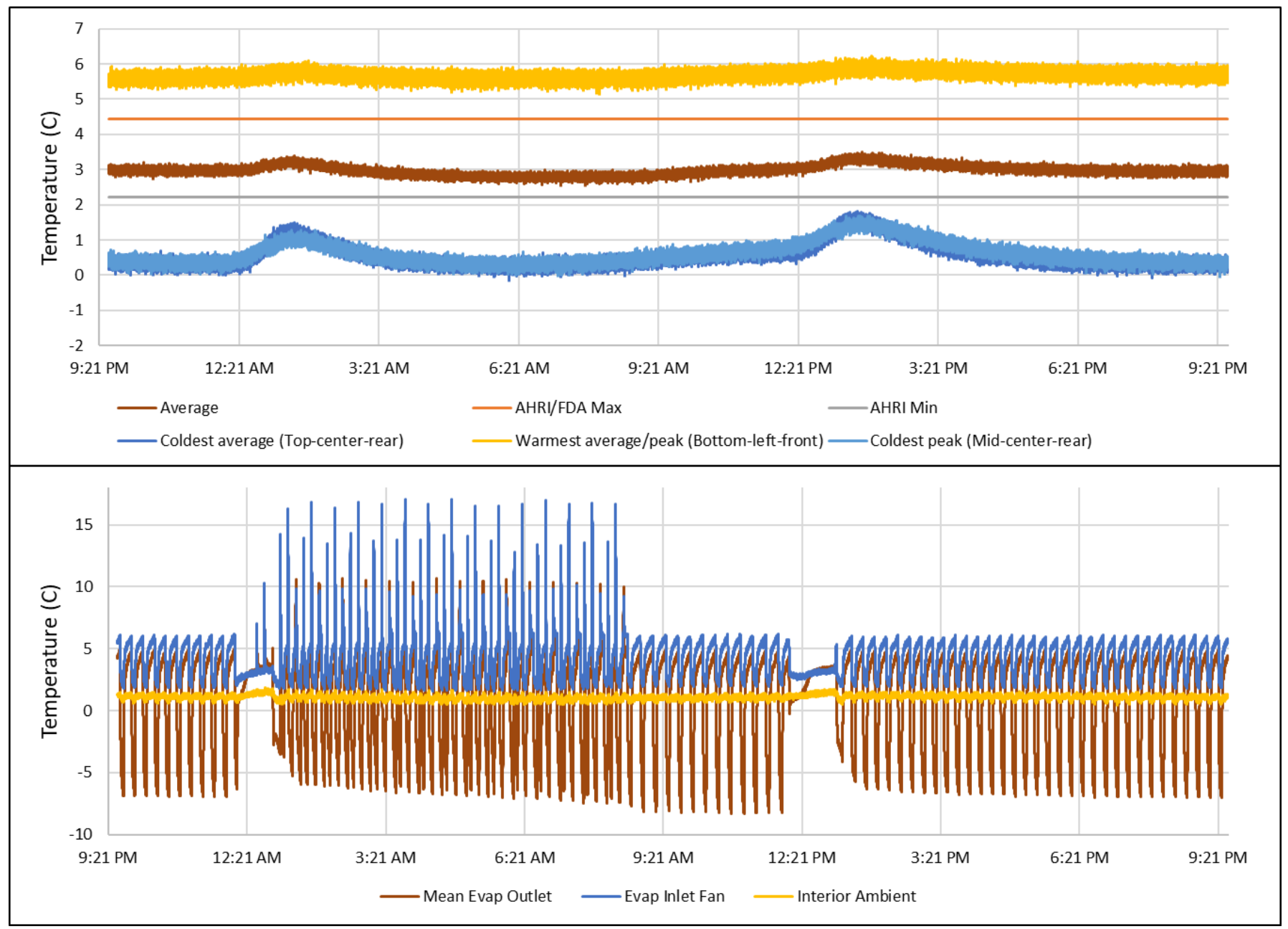

Figure 37. EE case B Upper Target condition transient product simulator temperatures (top) and internal air temperatures (bottom)

Table 16. EE Case B Upper Target condition average product simulator temperatures as a function of position. Color-coding is based on temperature differential beyond the AHRI/FDA limits (required only for the average).

\begin{tabular}{|c|c|c|c|c|}
\cline { 3 - 5 } \multicolumn{2}{c|}{} & \multicolumn{3}{c|}{ x-position } \\
\hline Shelf & y-position & Left & Center & Right \\
\hline \multirow{2}{*}{ Top } & Rear & $1.82^{\circ} \mathrm{C}$ & $0.55^{\circ} \mathrm{C}$ & $0.50^{\circ} \mathrm{C}$ \\
& Front & $5.18^{\circ} \mathrm{C}$ & $3.33^{\circ} \mathrm{C}$ & $3.67^{\circ} \mathrm{C}$ \\
\hline \multirow{2}{*}{ Middle } & Rear & $2.12^{\circ} \mathrm{C}$ & $0.60^{\circ} \mathrm{C}$ & $0.80^{\circ} \mathrm{C}$ \\
& Front & $4.56^{\circ} \mathrm{C}$ & $2.61^{\circ} \mathrm{C}$ & $3.15^{\circ} \mathrm{C}$ \\
\hline \multirow{2}{*}{ Bottom } & Rear & $3.50^{\circ} \mathrm{C}$ & $2.69^{\circ} \mathrm{C}$ & $3.19^{\circ} \mathrm{C}$ \\
& Front & $5.69^{\circ} \mathrm{C}$ & $4.20^{\circ} \mathrm{C}$ & $5.58^{\circ} \mathrm{C}$ \\
\hline
\end{tabular}

The average product simulator temperature was $2.99^{\circ} \mathrm{C}\left(37.38^{\circ} \mathrm{F}\right)$ in the Upper Target environmental conditions. The warmer chamber temperature generated more heat transfer through the case, as well as infiltration of warm air during door openings. This caused the compressor to cycle more frequently, 
which affected product simulator temperatures. Colder simulators below the evaporator discharge grille were cooled to slightly lower temperatures, and warmer simulators further from the evaporator and closer to the doors were warmed to a slightly greater degree. The average product temperature was reduced to a minimum of $2.57^{\circ} \mathrm{C}\left(36.63^{\circ} \mathrm{F}\right)$ during the door opening period (starting at $12: 21 \mathrm{a} . \mathrm{m}$. in Figure 37). During the defrost that occurred during door openings (also occurring around 12:21 a.m.), the mean simulator temperature rose to a maximum $3.51^{\circ} \mathrm{C}\left(38.32^{\circ} \mathrm{F}\right)$. Defrost induced a maximum peak temperature of $6.22^{\circ} \mathrm{C}\left(43.20^{\circ} \mathrm{F}\right)$ in the bottom shelf/front-left simulator. Door openings induced a minimum peak temperature of $-0.02^{\circ} \mathrm{C}\left(31.96^{\circ} \mathrm{F}\right)$ in the middle shelf/center-rear simulator. The bottom shelf/front-left simulator average temperature was $5.69^{\circ} \mathrm{C}\left(42.24^{\circ} \mathrm{F}\right)$, and the top shelf/center-rear average temperature was $0.55^{\circ} \mathrm{C}\left(32.99^{\circ} \mathrm{F}\right)$.

Internal air temperatures were similar to those seen in January and July conditions, despite varying more frequently due to increased compressor cycling. The increased cycling caused the evaporator discharge air temperature to gradually decrease to as low as $-8.30^{\circ} \mathrm{C}\left(17.06^{\circ} \mathrm{F}\right)$, which was lower than observed at previous conditions. Compressor cycling generated an air temperature of $0.49^{\circ} \mathrm{C}\left(32.88^{\circ} \mathrm{F}\right)$ at the geometric center of the case, and a return air temperature of $1.60^{\circ} \mathrm{C}\left(34.88^{\circ} \mathrm{F}\right)$ to the evaporator. The maximum internal air temperature during defrost was $1.88^{\circ} \mathrm{C}\left(35.38^{\circ} \mathrm{F}\right)$. The evaporator inlet fan temperature spiked to a much higher maximum value of $17.05^{\circ} \mathrm{C}\left(62.69^{\circ} \mathrm{F}\right)$ when doors were opening due to the higher chamber temperature compared to January and July conditions.

Because condensate pumping is optional and customers often supply their own condensate pumps, the mass of condensate collected was evaluated here. The condensate mass generated by EE case B over 24 $\mathrm{h}$ at each environmental conditions is shown below in Figure 38.

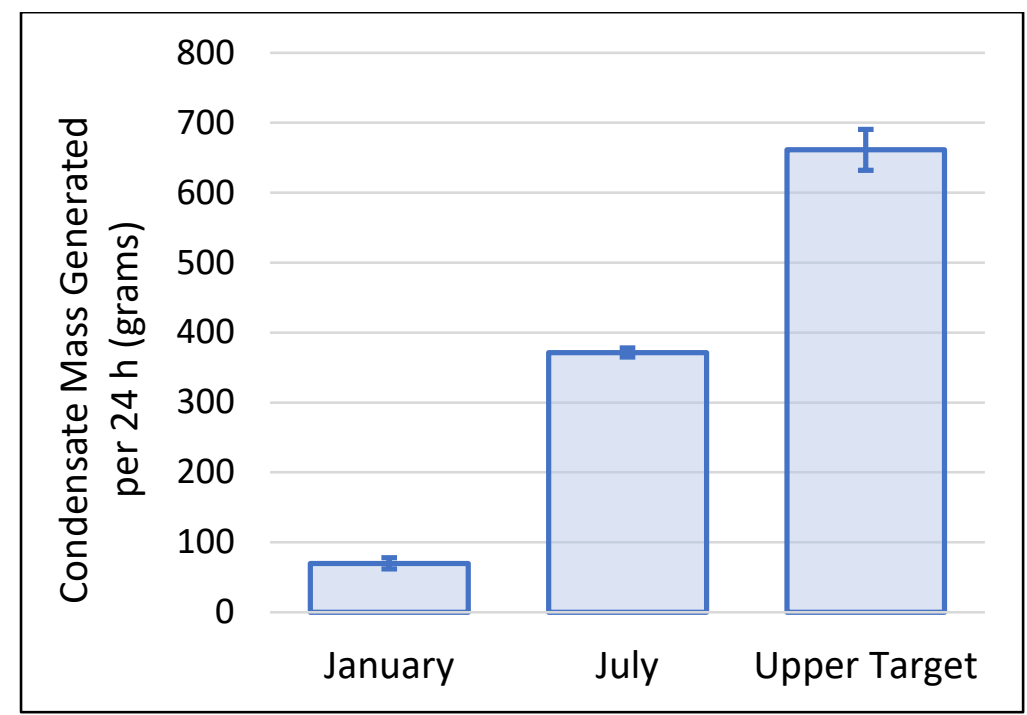

Figure 38. EE case $B$ condensate mass generated at each environmental condition

EE case B generated a relatively small amount of condensate as expected for doored refrigerator cases. In Upper Target environmental conditions, a typical pump reservoir was not completely filled over $24 \mathrm{~h}$ and so only small condensate pumps would consume energy to remove condensate here. It should be noted that due to the low condensate mass collected in January and July conditions, a significant fraction of the total condensate may have remained in the evaporator or drain line by surface tension. 


\subsubsection{EE Case B Power/Energy Consumption}

Figure 39 shows the total power consumption by EE case B in each environmental condition. Error bars indicate standard error across individual 24-h assessments. The case performed best in January conditions, consuming $6.13 \pm 0.02 \mathrm{kWh} /$ day. Upper Target environmental conditions, which exhibited the highest chamber temperature, induced the greatest energy consumption of $7.59 \pm 0.03 \mathrm{kWh} /$ day. In July environmental conditions, the case consumed $6.42 \pm 0.02 \mathrm{kWh} /$ day. The effect of different environmental conditions on the energy consumed by the different case components is shown in Figure 40. Environmental conditions affected only some components, which contributed to differences in total energy consumption. Differences between total energy consumption and the sum of components can be attributed to the Wattnode meters' uncertainty.

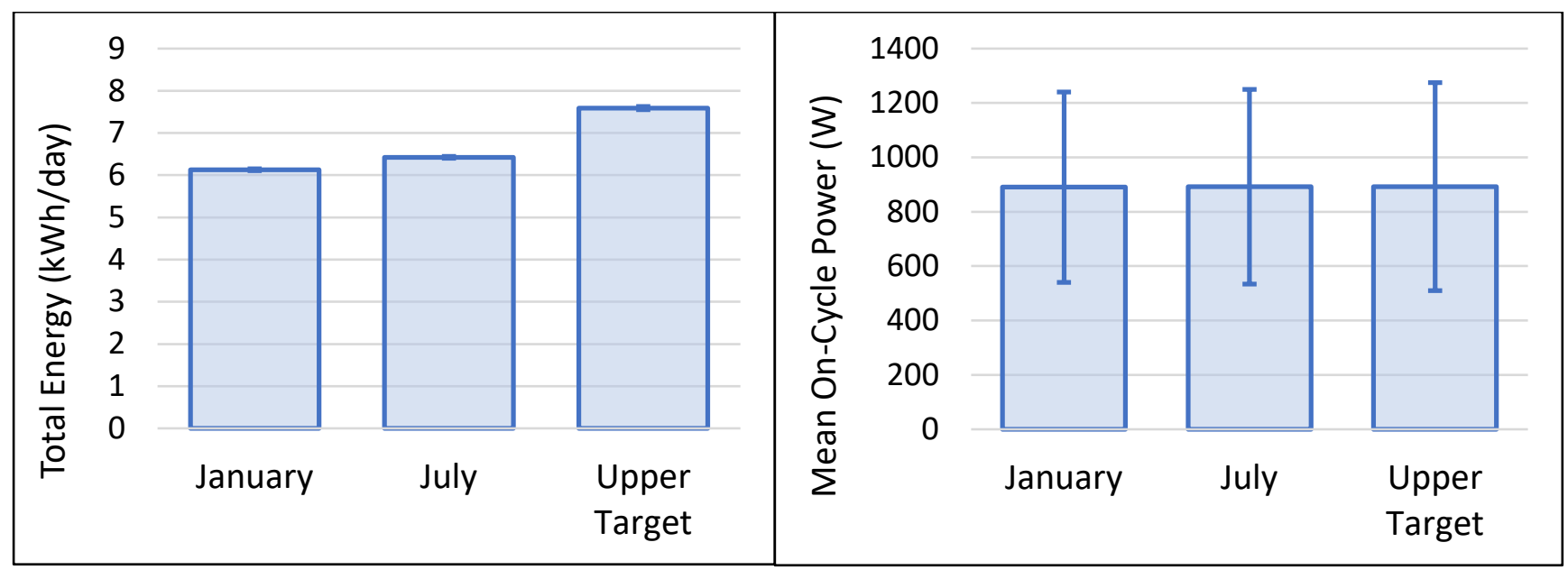

Figure 39. EE case B total energy consumption (left) and mean on-cycle power consumption (right) at each environmental condition
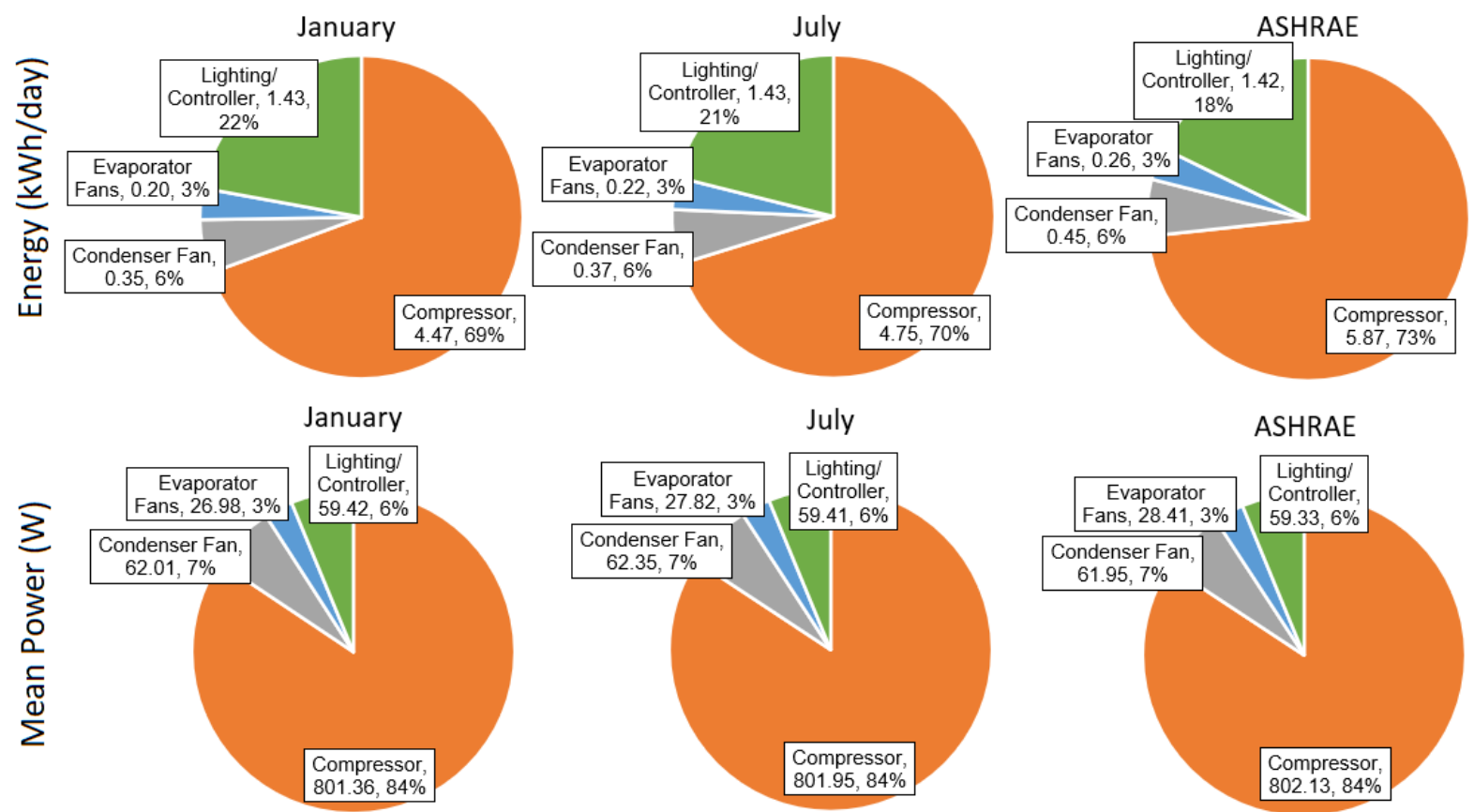

Figure 40. EE case B component daily energy (kWh/day, top) and mean on-cycle power consumption (W, bottom) at each environmental condition 
The compressor consumed the majority of the energy of EE case B, ranging between $69 \%$ and $73 \%$ across environmental conditions. The lighting and controller also consumed a significant fraction of the total energy: between $18 \%$ and $22 \%$. The energy consumed by the lighting and controller was affected little by the environmental conditions, as expected. The lighting and controller consumed between just 1.42 and $1.43 \mathrm{kWh} /$ day.

Total energy consumption was dominated by the compressor. The greatest change in energy consumption between environmental conditions also occurred in the compressor. This was due to its change in cycling duration and frequency between conditions. At higher chamber temperatures, the cooling load of the case increased and resulted in the compressor staying on longer to meet the setpoint due to a higher condensing temperature [22]. In warmer and more humid Upper Target environmental conditions, the compressor operated for the longest total duration over $24 \mathrm{~h}$, consuming $5.87 \mathrm{kWh} /$ day. The compressor however consumed only 4.47 and $4.75 \mathrm{kWh} /$ day under January and July conditions, respectively.

Between January and July conditions, there was little change in chamber DBT. Therefore, compressor energy use and cycling frequency were mainly affected here by the chamber DPT/humidity. Because of the higher water vapor content, compressor cycling time was increased due to the inhibited airflow by frost formation in the evaporator, but defrost cycles were increased to melt the additional ice. Overall, this effect resulted in an increase in compressor energy consumption across $24 \mathrm{~h}$ under July conditions. Since EE case B was scheduled to defrost once every $12 \mathrm{~h}$, one of the defrost cycles occurred during door openings. The infiltration of warm air during door openings caused the internal temperature to increase significantly. Since defrost occurred for a longer duration under July conditions, this caused the compressor to stay on longer following defrost, thereby slightly increasing the total energy consumption further compared to January conditions.

Both the condenser fan and evaporator fans were powered on concurrently with the compressor. Therefore, the power consumed by each fan was affected by environmental conditions proportionally to the compressor cycles. Environmental conditions affected both cycling frequency and duration. During January conditions, the compressor cycled on 30 times ( every $4 \mathrm{~min}$ ) during the 8-h door opening period, and 83 times total ( every 16 min outside this period). The total and component power consumption during the 24-h cycle are shown in Figure 41. Also shown is a 1.5-h segment at the end of the door opening period. Each time the compressor, condenser fan, and evaporator fans are cycled on, there is an initial spike in power followed by a plateau. This plateau is immediate for the condenser and evaporator fans however lasts for a longer duration in the compressor. 


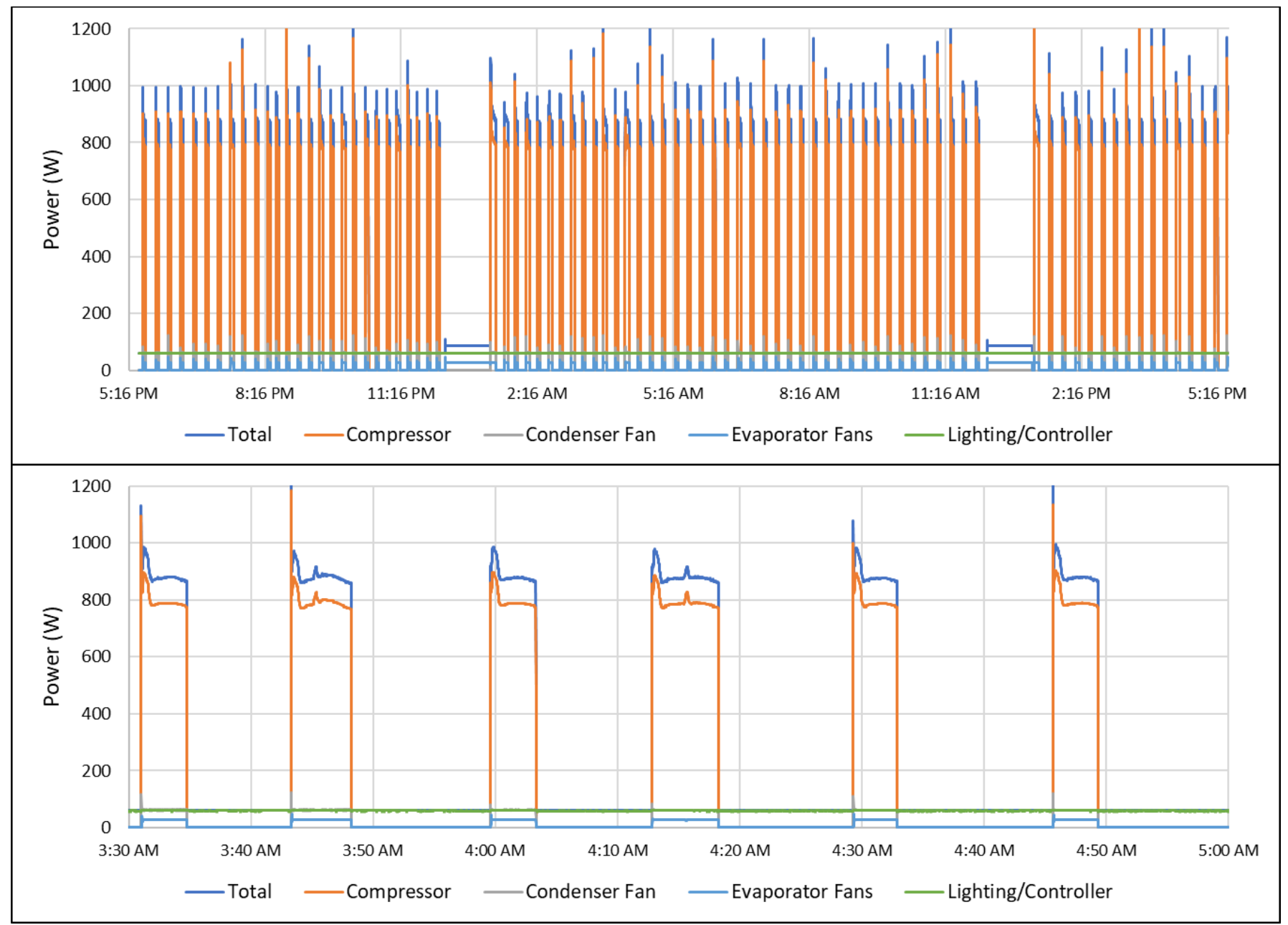

Figure 41. EE case $B$ total and component power consumption under January environmental conditions (top: full 24-h cycle; bottom: zoomed-in around hour 11)

The total and component power consumption during July conditions across the 24-h cycle are shown in Figure 42. The compressor cycled on 32 times ( every $15 \mathrm{~min}$ ) during the 8 -h door opening period and 86 times total ( $\sim$ every 16 min outside this period). The duration of compressor cycles under July environmental conditions ( $\sim 4$ min long outside door openings) was only slightly greater than under January conditions due to the higher latent load which increased compressor energy consumption. 


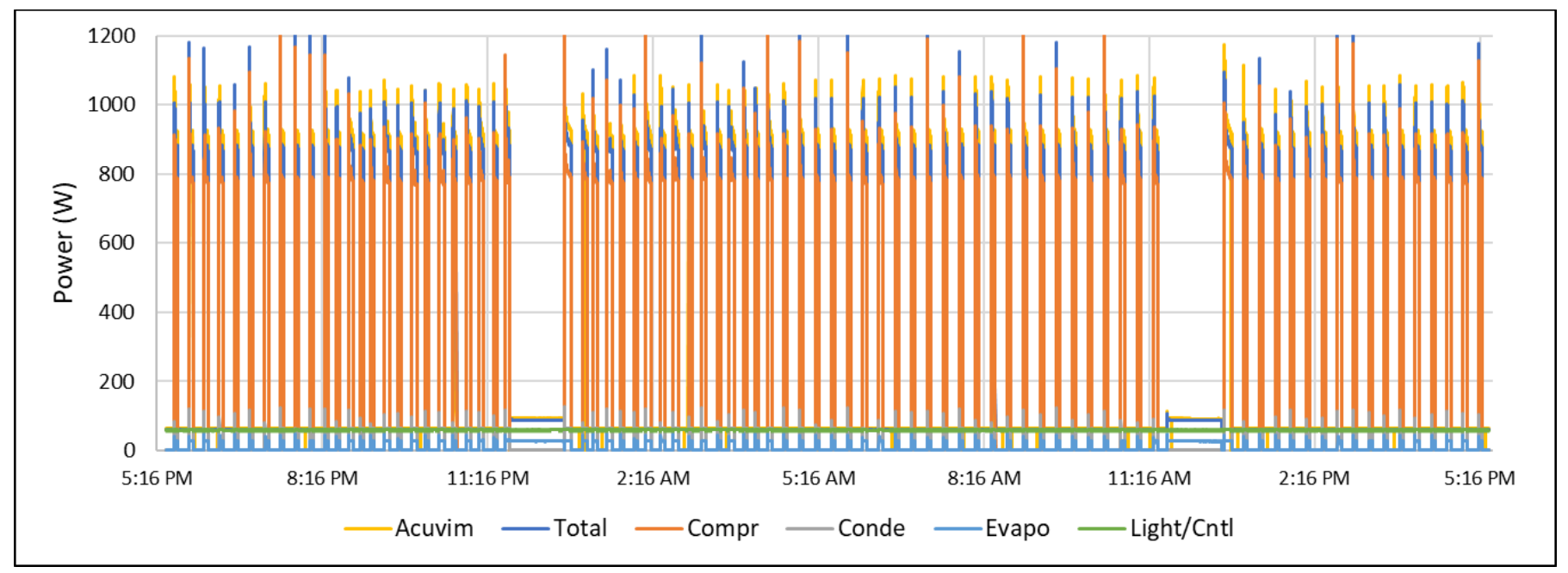

Figure 42. EE case B total and component power consumption under July environmental conditions (full 24-h cycle)

The total and component power consumption under Upper Target environmental conditions are shown in Figure 43 across a 24-h cycle. The compressor cycled on 57 times ( every 9 min) during the 8-h door opening period and 102 times total ( every 19 min outside this period). Due to the infiltration of warmer air during door openings in Upper Target conditions, the cycling frequency was far greater during this period than seen under previous conditions. This was because the internal air temperatures were increased to the compressor cut-in temperature more quickly. The mean cycling duration was only a few seconds greater than under July conditions. However, the total energy consumption still increased considerably due to the significant increase in compressor cycling frequency.

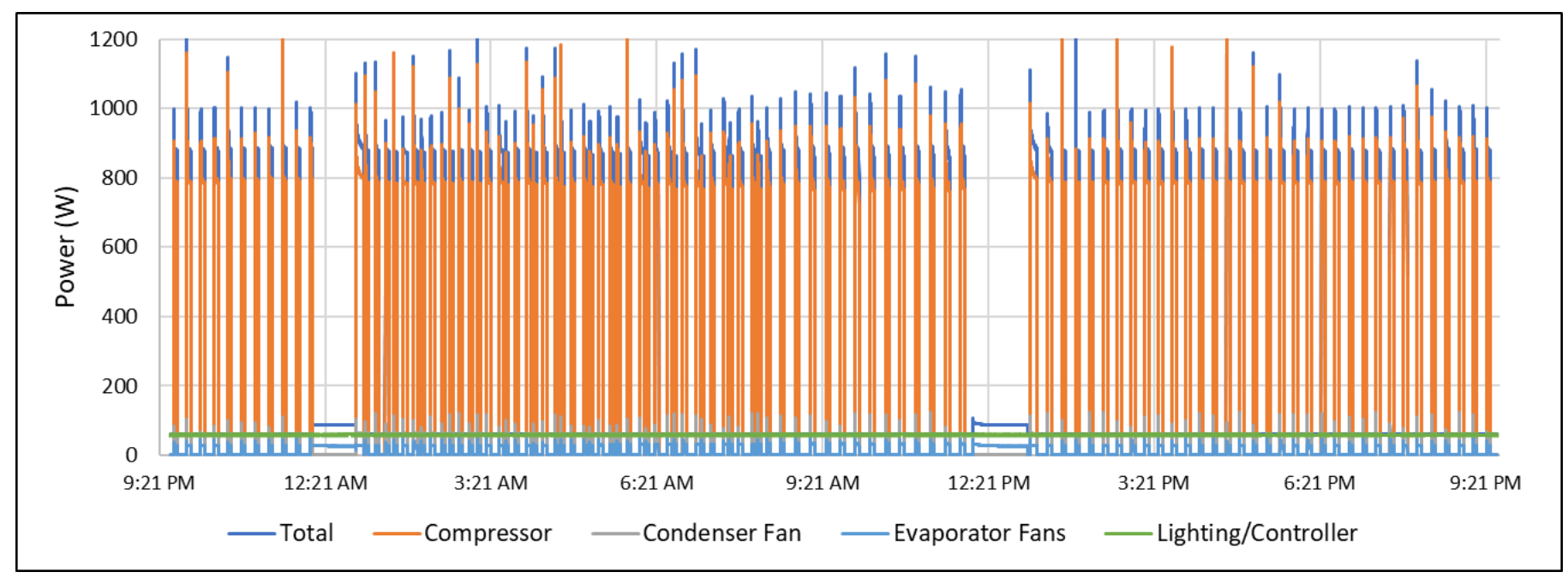

Figure 43. EE case B total and component power consumption under July environmental conditions (full 24-h cycle)

Here, total defrost time varied between environmental conditions as expected. The average defrost time was 2:18 0:03 under January conditions, 2:12 \pm 0:01 under July conditions, and 2:06 \pm 0:09 under Upper Target conditions. Typically, defrost occurs for a longer duration under environmental conditions that exhibit higher DPT/humidity. However, one defrost cycle always occurred during the period of door openings with this case. This caused the evaporator fan to force warm chamber air through the 
evaporator during defrost, reducing the overall defrost cycle time. The total energy consumption of the baseline case was adjusted to correct for the total time between defrost cycles. The energy and mean oncycle power consumption were also evaluated as a fraction of the internal volumetric capacity of the case. These values are provided in Table 17. The energy standard deviation is across individual 24-h cycles and the power standard deviation is across the total compressor run time. The corrected and normalized energy consumption and normalized mean on-cycle power consumption of the case components are also provided in Figure 44. The difference between the sum of the component and total energy can be attributed to the cumulative error in measurement by the Wattnode power meters.

Table 17. EE Case B Energy and Mean On-Cycle Power Consumption Normalized to Time-BetweenDefrost and Internal Volumetric Capacity

\begin{tabular}{|c|c|c|c|c|c|c|}
\hline CONDITION & $\begin{array}{c}\text { Total } \\
\text { Energy } \\
\text { Consump- } \\
\text { tion } \\
\text { (kWh/day) }\end{array}$ & $\begin{array}{l}\text { Total Energy } \\
\text { Consumption } \\
\text { Corrected to } \\
\text { Time-Between- } \\
\text { Defrost } \\
\text { (kWh/day) }\end{array}$ & $\begin{array}{l}\text { Total Energy } \\
\text { Consumption } \\
\text { Normalized } \\
\text { to Internal } \\
\text { Volume } \\
\text { (kWh/m } / \mathrm{m}^{3} \text { day) }\end{array}$ & $\begin{array}{l}\text { Total Energy } \\
\text { Consumption } \\
\text { Corrected to Time- } \\
\text { Between-Defrost } \\
\text { and Normalized to } \\
\text { Internal Volume } \\
\text { (kWh/m } / \mathrm{m}^{3} \text { day) }\end{array}$ & $\begin{array}{l}\text { Mean On- } \\
\text { Cycle Power } \\
\text { Consumption } \\
\text { (W) }\end{array}$ & $\begin{array}{c}\text { Mean On- } \\
\text { Cycle Power } \\
\text { Consumption } \\
\text { Normalized to } \\
\text { Internal } \\
\text { Volume }\left(\mathrm{W} / \mathrm{m}^{3}\right)\end{array}$ \\
\hline January & $6.13 \pm 0.02$ & $6.78 \pm 0.00$ & $4.48 \pm 0.01$ & $4.96 \pm 0.00$ & $\begin{array}{c}890.27 \pm \\
350.07\end{array}$ & $\begin{array}{c}651.07 \pm \\
256.01\end{array}$ \\
\hline July & $6.42 \pm 0.02$ & $7.07 \pm 0.02$ & $4.70 \pm 0.01$ & $5.17 \pm 0.02$ & $\begin{array}{c}891.95 \pm \\
357.95\end{array}$ & $\begin{array}{c}652.30 \pm \\
261.77\end{array}$ \\
\hline Upper Target & $7.59 \pm 0.03$ & $8.32 \pm 0.03$ & $5.55 \pm 0.02$ & $6.09 \pm 0.02$ & $\begin{array}{c}892.38 \pm \\
382.47\end{array}$ & $\begin{array}{c}652.61 \pm \\
279.71\end{array}$ \\
\hline
\end{tabular}
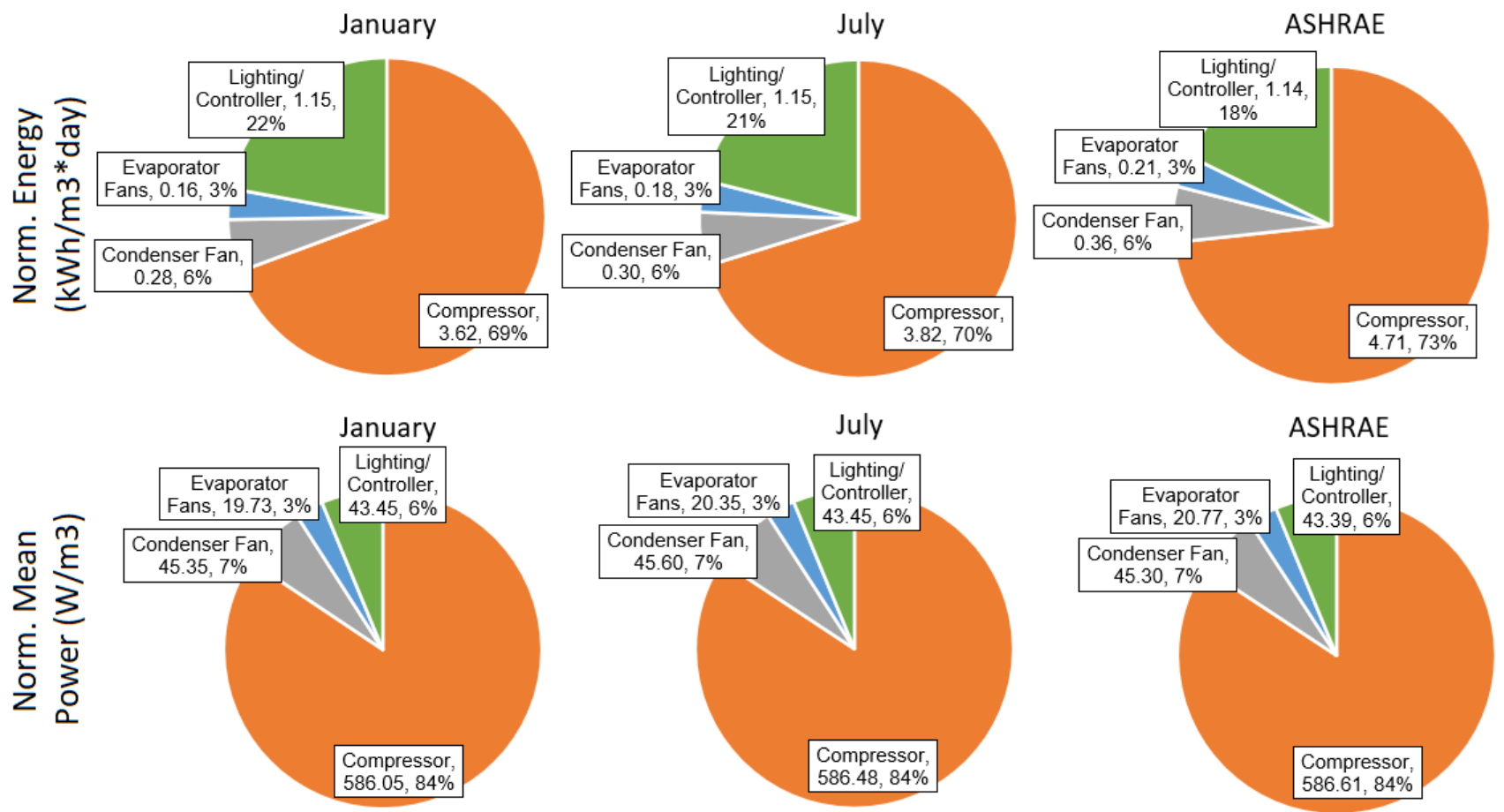

Figure 44. EE case B component daily energy normalized to time-between-defrost and internal volumetric capacity $\left(\mathrm{kWh} / \mathrm{m}^{3}\right.$ day, top) and mean on-cycle power consumption normalized to internal volumetric capacity $\left(\mathrm{W} / \mathrm{m}^{3}\right.$, bottom) at each environmental condition 


\section{Conclusion}

This report provides an assessment of two energy-efficient commercial, medium-temperature, selfcontained refrigerated display cases utilizing environmentally friendly refrigerants, as well as a baseline refrigerator case. The evaluated units will be included in incentivized utility measures based on the results of this assessment. This is critical because the recent 2020 EPA ban on hydrofluorocarbons does not include their use in existing systems. The evaluated cases were commercially available units that contain not only EPA-compliant refrigerants, but also energy-efficient components including condenser heat exchangers, evaporator fans, and lighting. The medium-temperature doored, self-contained refrigerated display case was selected due to its widespread use in convenience stores, restaurants, and small supermarkets.

The baseline case was a widely used, 3-doored case containing the hydrofluorocarbon refrigerant R134a. Energy-efficient (EE) case A included thermodynamically efficient high-purity propane (R290), and EE case B included R134a-retrofittable hydrofluoroolefin R513a. The performance of each case was evaluated in an environmental control chamber at indoor supermarket conditions within the utility territory climate zone during January and July. The performance was also evaluated at the upper extreme of environmental operating conditions. Temperatures were measured from 18 product simulators throughout the case, the interior air, and at the evaporator inlet and outlets. The cases were filled with water bottles as thermal mass and configured with door actuators to simulator regular door openings.

The baseline case exhibited unideal energy consumption. Mean product simulator temperatures were maintained within AHRI/FDA limits, but fluctuated in response to scheduled door openings and defrost cycles:

- The baseline case consumed $10.50 \pm 0.01 \mathrm{kWh} /$ day under January indoor environmental conditions, $10.34 \pm 0.06 \mathrm{kWh} /$ day under July conditions, and $11.26 \pm 0.01 \mathrm{kWh} /$ day under Upper Target environmental conditions.

- When the compressor cycled on, the baseline case consumed an average $909.27 \pm 355.08 \mathrm{~W}$ under January indoor environmental conditions, $920.88 \pm 356.80 \mathrm{~W}$ under July conditions, and $930.71 \pm 371.52 \mathrm{~W}$ under Upper Target environmental conditions.

- The baseline case had one defrost cycle that was affected by chamber dew-point temperature/humidity. Energy consumption was normalized to the operation time between defrost and the case's calculated volumetric capacity. This was $8.04 \pm 0.02 \mathrm{kWh} / \mathrm{m}^{3}$ day under January conditions, $7.95 \pm 0.02 \mathrm{kWh} / \mathrm{m}^{3}$ day under July conditions, and $8.64 \pm 0.02 \mathrm{kWh} / \mathrm{m}^{3}$ day under Upper Target conditions.

- The mean on-cycle power consumption was also normalized to the case's volumetric capacity. This was $664.96 \pm 259.67 \mathrm{~W} / \mathrm{m}^{3}$ under January conditions, $673.46 \pm 260.93 \mathrm{~W} / \mathrm{m}^{3}$ under July conditions, and $680.65 \pm 271.70 \mathrm{~W} / \mathrm{m}^{3}$ under Upper Target conditions.

- The higher chamber temperature and humidity in Upper Target conditions caused the compressor to consume more power, as well as more frequent/longer compressor cycles, both increasing energy consumption. 
- The higher latent load under July conditions caused the compressor power consumption to increase compared to January. However, due to variability in compressor cycling duration under constant conditions, overall energy consumption was slightly higher in January than in July. This variability was within the manufacturer-reported variability under constant conditions.

- The compressor consumed 52\% - 55\% of the total case energy across environmental conditions, followed by the lighting and controller $(27 \%-30 \%)$, the evaporator fans $(10 \%)$, and condenser fan $(8 \%)$.

- When the compressor cycles on, it consumes an average of $70 \%-71 \%$ of the total power across environmental conditions, followed by the lighting and controller $(13 \%-14 \%)$, condenser fan $(11 \%)$, and evaporator fans $(5 \%)$.

- The product simulators were maintained at a mean temperature of $2.99^{\circ} \mathrm{C}\left(37.38^{\circ} \mathrm{F}\right)$ in January conditions, $2.97^{\circ} \mathrm{C}\left(37.35^{\circ} \mathrm{F}\right)$ in July conditions, and $3.01^{\circ} \mathrm{C}\left(37.42^{\circ} \mathrm{F}\right)$ in Upper Target conditions.

- Simulator temperatures reduced significantly during scheduled door openings due to increased compressor cycling. During this period, the average simulator temperature was reduced to a minimum of $2.51^{\circ} \mathrm{C}\left(36.52^{\circ} \mathrm{F}\right)$ in January conditions, $2.42^{\circ} \mathrm{C}\left(36.36^{\circ} \mathrm{F}\right)$ in July conditions, and $2.33^{\circ} \mathrm{C}\left(36.19^{\circ} \mathrm{F}\right)$ in Upper Target conditions.

- Simulator temperatures increased to a maximum value during scheduled defrost. The maximum mean simulator temperature was $3.70^{\circ} \mathrm{C}\left(38.66^{\circ} \mathrm{F}\right)$ in January conditions, $3.61^{\circ} \mathrm{C}\left(38.49^{\circ} \mathrm{F}\right)$ in July conditions, and $3.70^{\circ} \mathrm{C}\left(38.66^{\circ} \mathrm{F}\right)$ in Upper Target conditions.

EE case A had very little energy consumption, and maintained stable product temperatures throughout operation:

- EE case A consumed $3.53 \pm 0.02 \mathrm{kWh}$ /day under January indoor environmental conditions, 3.63 $\pm 0.07 \mathrm{kWh} /$ day under July conditions, and $4.30 \pm 0.00 \mathrm{kWh} /$ day under Upper Target environmental conditions.

- When the compressor cycled on, the EE case A consumed an average $446.56 \pm 180.32 \mathrm{~W}$ under January indoor environmental conditions, $447.67 \pm 183.71 \mathrm{~W}$ under July conditions, and 469.05 $\pm 205.33 \mathrm{~W}$ under Upper Target environmental conditions.

- EE case A had no defrost cycle. Energy consumption normalized to the case's calculated volumetric capacity was $2.54 \pm 0.01 \mathrm{kWh} / \mathrm{m}^{3}$ day under January conditions, $2.61 \pm 0.05$ $\mathrm{kWh} / \mathrm{m}^{3}$ day under July conditions, and $3.09 \pm 0.00 \mathrm{kWh} / \mathrm{m}^{3}$ day under Upper Target conditions.

- The mean on-cycle power consumption normalized to the case's volumetric capacity was 385.25 $\pm 141.69 \mathrm{~W} / \mathrm{m}^{3}$ under January conditions, $385.63 \pm 144.05 \mathrm{~W} / \mathrm{m}^{3}$ under July conditions, and $401.29 \pm 160.50 \mathrm{~W} / \mathrm{m}^{3}$ under Upper Target conditions. Energy consumption was highest in Upper Target conditions. The higher chamber temperature caused the compressor to cycle on for a longer duration to compress refrigerant to a higher setpoint necessary to reach a higher condensing temperature. 
- Compared to January conditions, a higher dew-point temperature/humidity in July conditions resulted in higher frost formation, which hampered coil heat transfer and air circulation. Overall, this caused energy consumption to increase under July conditions.

- The compressor consumed $62 \%-63 \%$ of the total case energy across environmental conditions, followed by the lighting and controller $(28 \%-29 \%)$, the evaporator fan $(6 \%)$, and condenser fan $(3 \%)$.

- When the compressor cycles on, it consumes an average of $84 \%$ of the total power across environmental conditions, followed by the lighting and controller (8\%), evaporator fan (4\%), and condenser fan $(4 \%)$.

- The product simulators were maintained at a mean temperature of $2.91^{\circ} \mathrm{C}\left(37.24^{\circ} \mathrm{F}\right)$ in January conditions, $2.92^{\circ} \mathrm{C}\left(37.26^{\circ} \mathrm{F}\right)$ in July conditions, and $2.92^{\circ} \mathrm{C}\left(37.26^{\circ} \mathrm{F}\right)$ in Upper Target conditions.

- Simulator temperatures reduced slightly during scheduled door openings due to increased compressor cycling. Here, the average simulator temperature lowered to a minimum of $2.59^{\circ} \mathrm{C}$ $\left(36.66^{\circ} \mathrm{F}\right)$ in January conditions, $2.58^{\circ} \mathrm{C}\left(36.64^{\circ} \mathrm{F}\right)$ in July conditions, and $2.56^{\circ} \mathrm{C}\left(36.61^{\circ} \mathrm{F}\right)$ in Upper Target conditions.

- The maximum product simulator temperature reached $3.26^{\circ} \mathrm{C}\left(37.87^{\circ} \mathrm{F}\right)$ in January conditions, $3.25^{\circ} \mathrm{C}\left(37.85^{\circ} \mathrm{F}\right)$ in July conditions, and $3.27^{\circ} \mathrm{C}\left(37.89^{\circ} \mathrm{F}\right)$ in Upper Target conditions.

EE case B exhibited energy consumption slightly less than expected. Product simulator temperatures fluctuated modestly in response to door openings and defrost cycles:

- EE case B consumed $6.13 \pm 0.02 \mathrm{kWh} /$ day under January indoor environmental conditions, 6.42 $\pm 0.02 \mathrm{kWh} /$ day under July conditions, and $7.59 \pm 0.03 \mathrm{kWh} /$ day under Upper Target environmental conditions.

- When the compressor cycled on, the EE case B consumed an average 890.27 $\pm 350.07 \mathrm{~W}$ under January indoor environmental conditions, $891.95 \pm 357.95 \mathrm{~W}$ under July conditions, and 892.38 $\pm 382.47 \mathrm{~W}$ under Upper Target environmental conditions.

- EE case B had two defrost cycles scheduled every 12 hours. Energy consumption was normalized to the operation time between defrost and the case's calculated volumetric capacity. This was $4.96 \pm 0.00 \mathrm{kWh} / \mathrm{m}^{3}$ day under January conditions, $5.17 \pm 0.02 \mathrm{kWh} / \mathrm{m}^{3}$ day under July conditions, and $6.09 \pm 0.02 \mathrm{kWh} / \mathrm{m}^{3}$ day under Upper Target conditions.

- The mean on-cycle power consumption normalized to the case's volumetric capacity was 651.07 $\pm 256.01 \mathrm{~W} / \mathrm{m}^{3}$ under January conditions, $652.30 \pm 261.77 \mathrm{~W} / \mathrm{m}^{3}$ under July conditions, and $652.61 \pm 279.71 \mathrm{~W} / \mathrm{m}^{3}$ under Upper Target conditions.

- The higher chamber temperature in Upper Target conditions caused more frequent/longer compressor cycles, increasing energy consumption. 
- The higher dew-point temperature/humidity in July conditions compared to January caused longer compressor cycles, increasing energy consumption. One defrost cycle always occurred during scheduled door openings, so the total defrost cycle time decreased even at a higher chamber dew-point temperature/humidity.

- The compressor consumed $69 \%-73 \%$ of the total case energy across environmental conditions, followed by the lighting and controller $(18 \%-22 \%)$, the condenser fan $(6 \%)$, and the evaporator fans $(3 \%)$.

- When the compressor cycles on, it consumes an average of around $84 \%$ of the total power across environmental conditions, followed by the condenser fan (7\%), lighting and controller (6\%), and evaporator fans $(3 \%)$.

- The product simulators were maintained at a mean temperature of $3.06^{\circ} \mathrm{C}\left(37.51^{\circ} \mathrm{F}\right)$ in January conditions, $2.99^{\circ} \mathrm{C}\left(37.38^{\circ} \mathrm{F}\right)$ in July conditions, and $3.01^{\circ} \mathrm{C}\left(37.42^{\circ} \mathrm{F}\right)$ in Upper Target conditions.

- Simulator temperatures reduced modestly during scheduled door openings due to increased compressor cycling. During this period, the average simulator temperature was reduced to a minimum of $2.69^{\circ} \mathrm{C}\left(36.84^{\circ} \mathrm{F}\right)$ in January conditions, $2.57^{\circ} \mathrm{C}\left(36.63^{\circ} \mathrm{F}\right)$ in July conditions, and $2.33^{\circ} \mathrm{C}\left(36.19^{\circ} \mathrm{F}\right)$ in Upper Target conditions.

- Simulator temperatures increased during defrost. Temperatures were highest during the defrost cycle occurring during scheduled door openings. The maximum mean product simulator temperature was $3.51^{\circ} \mathrm{C}\left(38.32^{\circ} \mathrm{F}\right)$ in January conditions, $3.51^{\circ} \mathrm{C}\left(38.32^{\circ} \mathrm{F}\right)$ in July conditions, and $3.70^{\circ} \mathrm{C}\left(38.66^{\circ} \mathrm{F}\right)$ in Upper Target conditions.

Because customers often need to pump condensate removed by their refrigerator case to a remote floor drain, the mass of condensate produced by each case was evaluated at each environmental condition. The highest mass produced by any case was around $660 \mathrm{~g}(0.66 \mathrm{~L})$, which would only fill a very small condensate pump reservoir. Therefore, condensate mass would likely contribute a negligible effect on total energy consumption. 


\section{References}

1. 2019 Illinois Statewide Technical Reference Manual for Energy Efficiency Version 7.0, I.C. Commission, Editor. 2019.

2. U.N.E.P., The Kigali Amendment (2016): The amendment to the Montreal Protocol agreed by the Twenty-Eighth Meeting of the Parties. United Nations Environment Programme: Nairobi, Kenya.

3. ANSI, A., Method of Testing Open and Closed Commercial Refrigerators and Freezers. 2018, ANSI / ASHRAE.

4. Mota-Babiloni, A., P. Makhnatch, R. Khodabandeh, and J. Navarro-Esbri, Experimental assessment of R134a and its lower GWP alternative R513A. International Journal of Refrigeration, 2017. 74: p. 682-688.

5. Sánchez, D., R. Cabello, R. Llopis, I. Arauzo, J. Catalán-Gil, and E. Torrella, Energy performance evaluation of R1234yf, R1234ze (E), R600a, R290 and R152a as low-GWP R134a alternatives. International Journal of Refrigeration, 2017. 74: p. 269-282.

6. $\quad$ E.P.A., U.S. Understanding Global Warming Potentials. Greenhouse Gas Emissions 2020; Available from: https://www.epa.gov/ghgemissions/understanding-global-warming-potentials.

7. Choudhari, C. and S. Sapali, Performance investigation of natural refrigerant $R 290$ as a substitute to R22 in refrigeration systems. Energy Procedia, 2017. 109: p. 346-352.

8. $\quad$ S.C.E., Laboratory Assessment of Propane Type Horizontal Self-Contained Display Cases., in Emerging Technologies Coordinating Council Laboratory Assessment ET15SCE1030. February 2016, Southern California Edison.

9. Mota-Babiloni, A., J. Navarro-Esbrí, Á. Barragán-Cervera, F. Molés, B. Peris, and G. Verdú, Commercial refrigeration-an overview of current status. International Journal of Refrigeration, 2015.

10. He, M.-G., X.-Z. Song, H. Liu, and Y. Zhang, Application of natural refrigerant propane and propane/isobutane in large capacity chest freezer. Applied Thermal Engineering, 2014. 70(1): p. $732-736$.

11. U.S.D.A., 2016 USDA Food Environment Atlas. 2016, USDAEconomic Research Service.

12. Darby, M. Ozone layer treaty could tackle super polluting HFCs. 2014; Available from: rtcc.org.

13. Huber, M. and M. McLinden, Thermodynamic Properties of R134a (1, 1, 1, 2-tetrafluoroethane), in International Refrigeration and Air Conditioning Conference. 1992.

14. Cengel, Y.A., Introduction to thermodynamics and heat transfer. Vol. 846. 1997: McGraw-Hill New York.

15. NIST, Standard Reference Database 69: NIST Chemistry WebBook. National Institute of Standards and Technology, 2010.

16. Commission, I.-I.E., IEC 60335-2-89. 2012.

17. Embraco. Guide for the Use of HCs Refrigerants R600a and R290. 2019; Available from: embraco.com.

18. IEC 60079-15 - E. apparatus for explosive gas atmospheres - P. 15: Construction, test, and marking of type of protection " $n$ " electrical apparatus, in IEC. 2005, ed. 3.

19. Climalife, R513a Physical Properties. 2017, Dehon Service SA. Ref: FF.101/03.17/V1/EN. https://climalife.dehon.com/uploads/product/media/document/r-513a-fd-en-17.pdf.

20. ANSI, A., 2013 Standard for Performance Rating of Commercial Refrigerated Display Merchandisers and Storage Cabinets. 2013, ANSI / AHRI. 
21. U.S. Food \& Drug Administration (FDA). FDA Food Code 2017, in U.S. Public Health Service. 2017, U.S. Department of Health and Human Services.

22. Cole, P.J., Balancing latent heat load between display cases and store comfort cooling, in Civil, Environmental, and Architectural Engineering. 2013, The University of Canterbury/The University of Colorado - Boulder: ASHRAE.

23. Harrington, L., L. Aye, and B. Fuller, Impact of room temperature on energy consumption of household refrigerators: Lessons from analysis of field and laboratory data. Applied energy, 2018. 211: p. 346-357.

24. Masjuki, H.H., R. Saidur, I. Choudhury, and T. Mahlia. Factors effecting energy consumption of household refrigerator-freezers. in 2000 TENCON Proceedings. Intelligent Systems and Technologies for the New Millennium (Cat. No. 00CH37119). 2000. IEEE.

25. Grimes, J.W., W. Mulroy, and B.L. Shomaker, Effect of usage conditions on household refrigerator-freezer and freezer energy consumption. ASHRAE Transaction, 1977(83): p. pp 818-828. 


\section{Appendix A. Environmental Chamber Conditions}

The temperature measurements recorded in the environmental chamber during each assessment are provided in this appendix section. Dry-bulb temperatures (DBTs) were recorded on the ambient test measurement pole at the locations listed in Figure 8 titled $\mathrm{T}_{\mathrm{A}}$ and $\mathrm{T}_{\mathrm{B}}$. The dew-point temperature (DPT) and relative humidity $(\mathrm{RH})$ were measured on the test pole at location $\mathrm{T}_{\mathrm{A}}$. The prescribed limits for maintaining each DBT and DPT based on the values listed in Table 5 are shown in the provided figures. In each figure in the following section, the DBT and DPT are shown at $\mathrm{T}_{\mathrm{A}}$ within their prescribed limits. The DBT at $\mathrm{T}_{\mathrm{B}}$ was nearly the same as $\mathrm{T}_{\mathrm{A}}$ at all environmental conditions, and so only the DBT limits for $\mathrm{T}_{\mathrm{A}}$ are shown. Conditions were relatively the same across individual tests conducted at each environmental condition. Therefore, only the temperatures recorded during the individual tests shown in the results section are provided.

\section{A.1 Baseline Case Environmental Temperatures}

The chamber environmental DBTs at location $\mathrm{T}_{\mathrm{A}}$ and $\mathrm{T}_{\mathrm{B}}$, and the DPT at location $\mathrm{T}_{\mathrm{A}}$ during evaluation of the baseline refrigerator display case are shown in the following figures. January environmental conditions are shown in Figure 45. July environmental conditions are shown in Figure 46. Upper Target environmental conditions are shown in Figure 47. The temperatures were maintained within their prescribed limits throughout evaluation. During the period of scheduled door openings, and during defrost, the DBT at $\mathrm{T}_{\mathrm{A}}$ fluctuated to touching the prescribed limits. However, the DBT did not cross over these limits more than briefly.

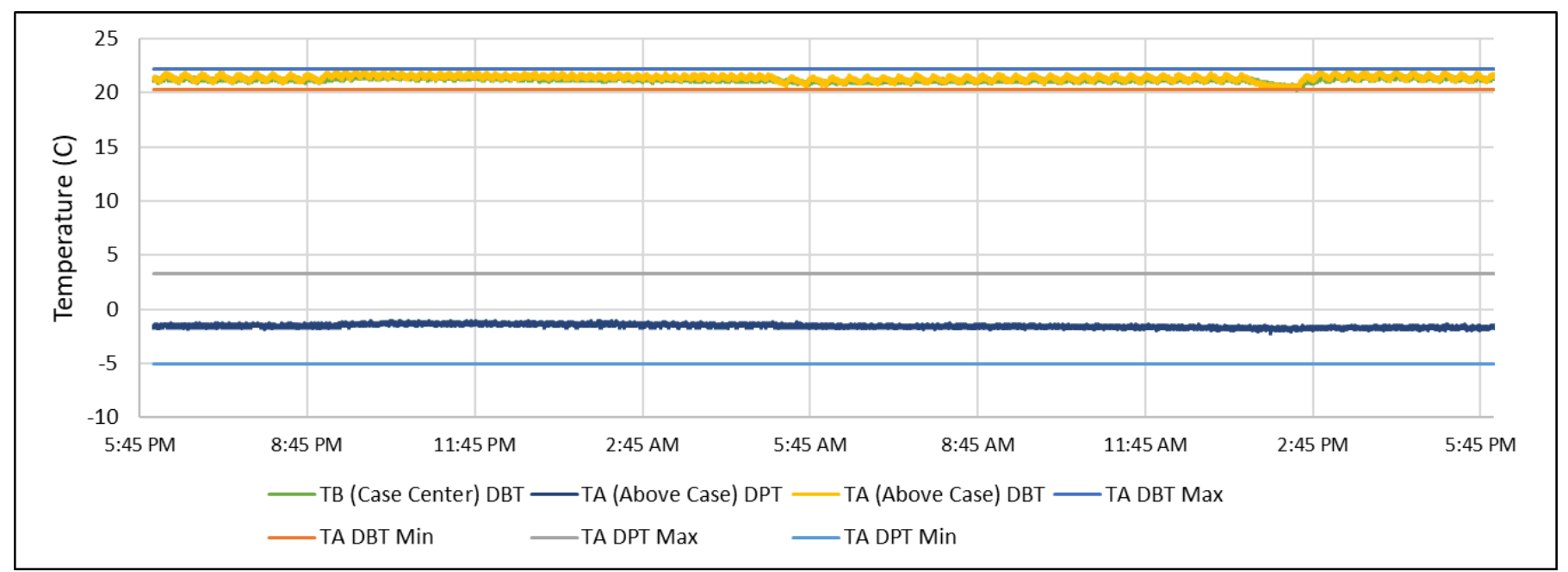

Figure 45. Chamber dry-bulb temperatures and dew-point temperature during baseline case testing in January environmental conditions 


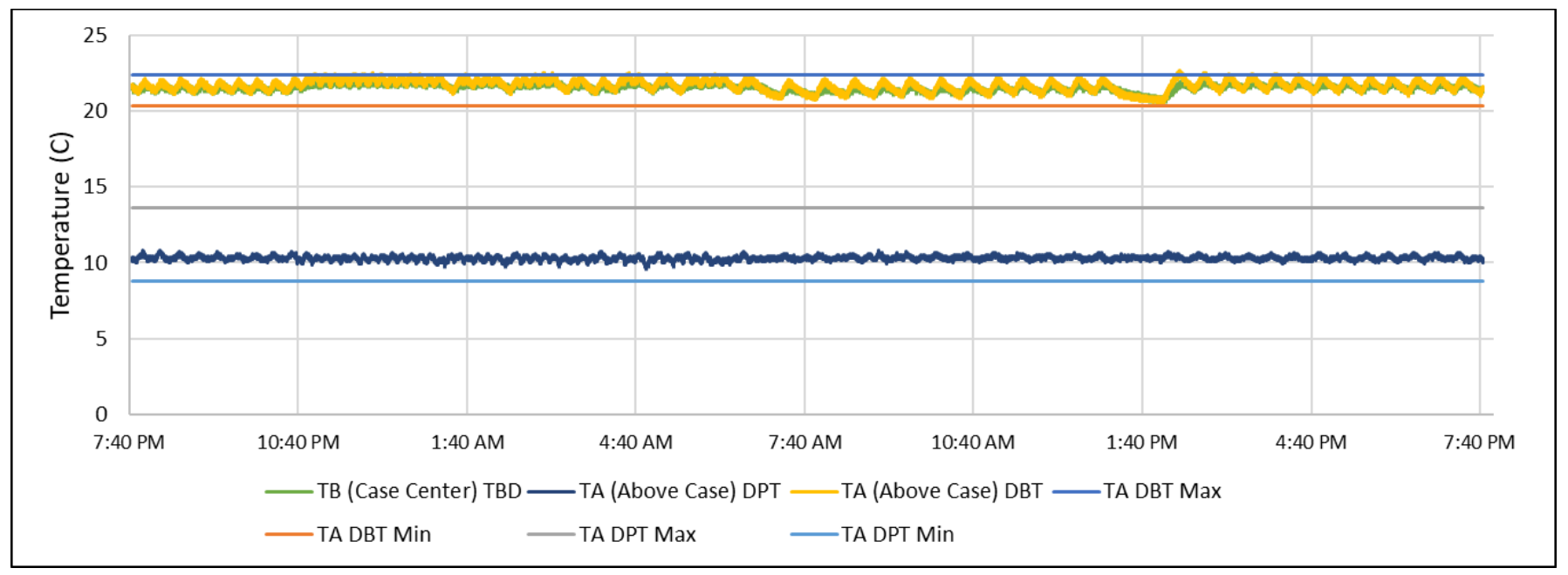

Figure 46. Chamber dry-bulb temperatures and dew-point temperature during baseline case testing in July environmental conditions

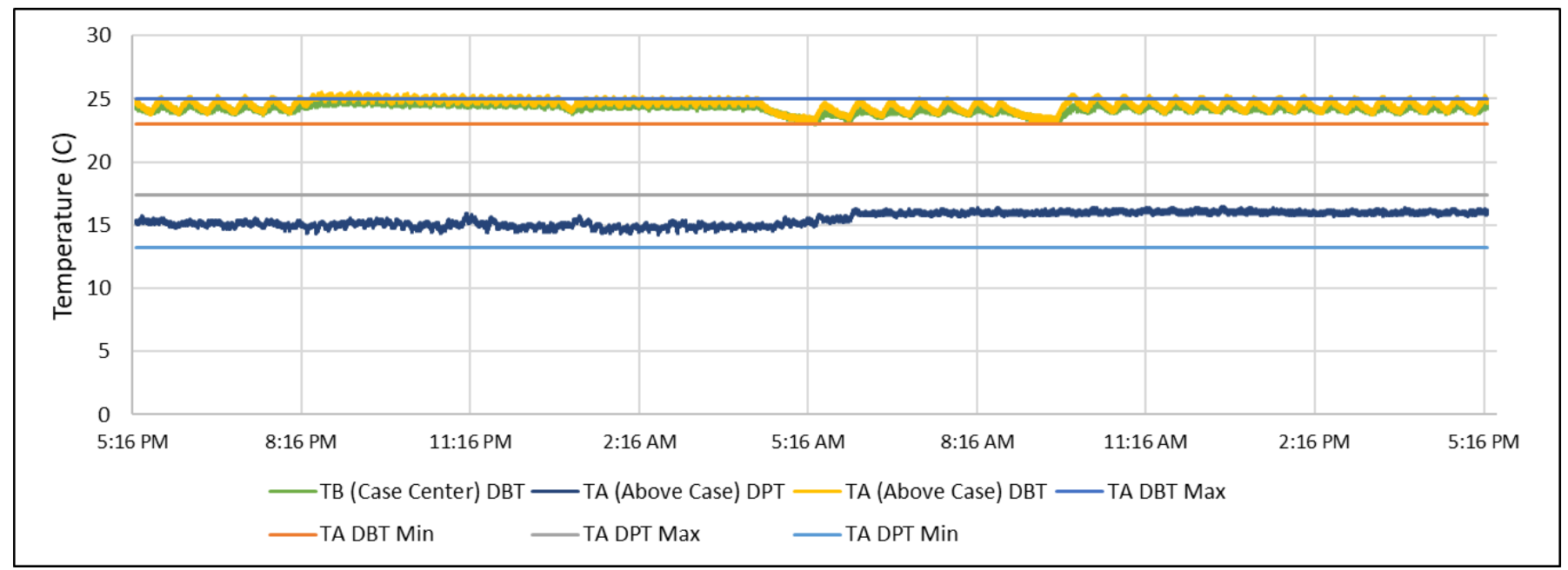

Figure 47. Chamber dry-bulb temperatures and dew-point temperature during baseline case testing in Upper Target environmental conditions

\section{A.2 EE Case A Environmental Temperatures}

The chamber environmental DBTs at location $\mathrm{T}_{\mathrm{A}}$ and $\mathrm{T}_{\mathrm{B}}$, and the DPT at location $\mathrm{T}_{\mathrm{A}}$ during evaluation of EE case A are shown in the following figures. January environmental conditions are shown in Figure 48. July environmental conditions are shown in Figure 49. Upper Target environmental conditions are shown in Figure 50. The temperatures were maintained within their prescribed limits throughout evaluation and never approached those limits. 


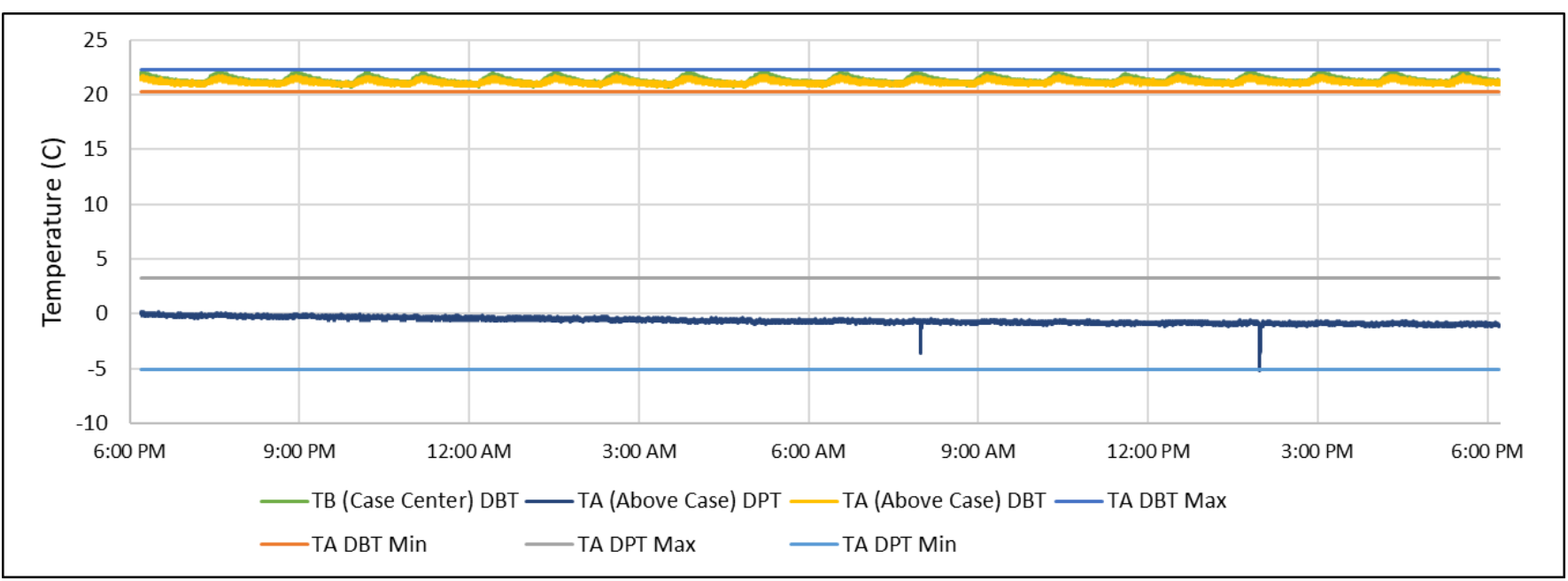

Figure 48. Chamber dry-bulb temperatures and dew-point temperature during EE case $A$ testing in January environmental conditions

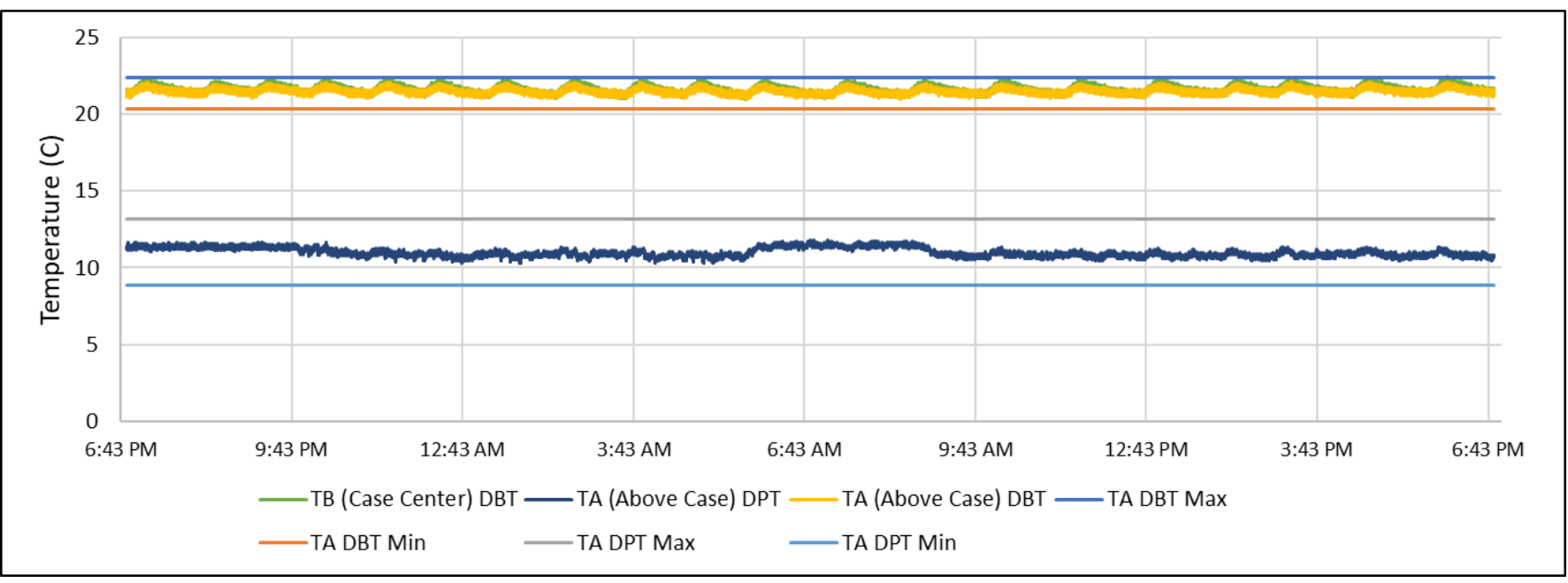

Figure 49. Chamber dry-bulb temperatures and dew-point temperature during EE case $A$ testing in July environmental conditions 


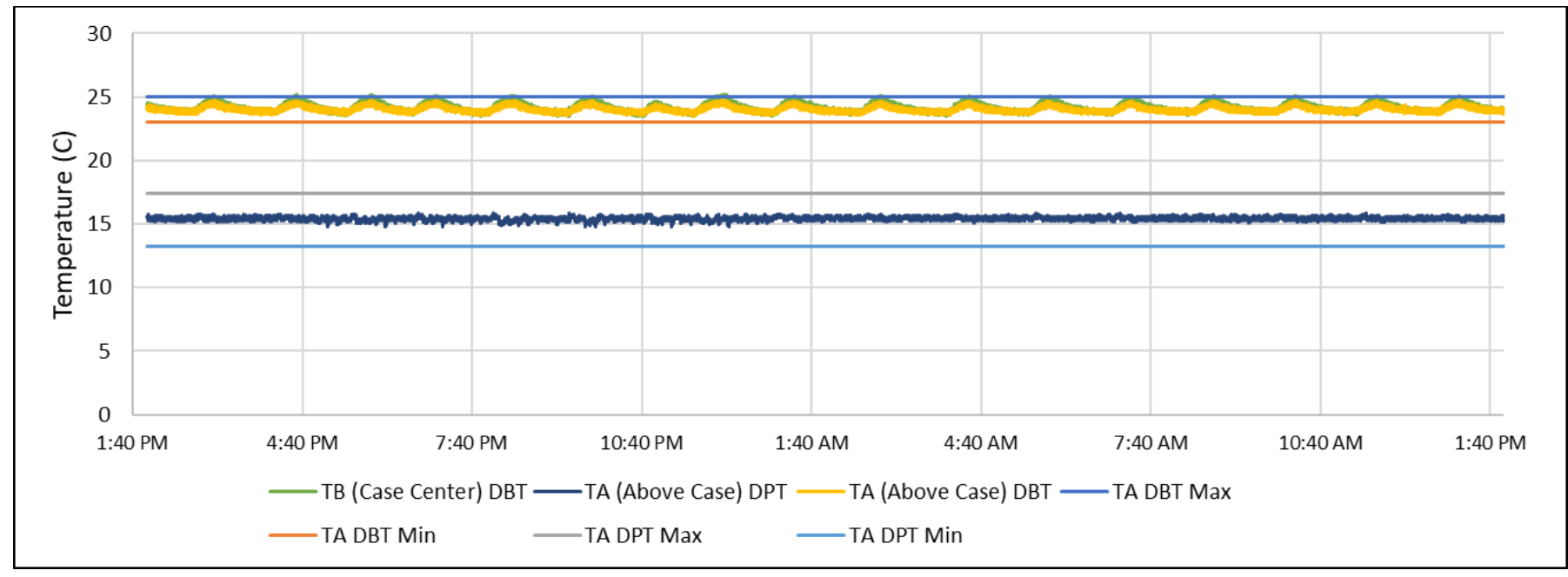

Figure 50. Chamber dry-bulb temperatures and dew-point temperature during EE case $A$ testing in Upper Target environmental conditions

\section{A.3 EE Case B Environmental Temperatures}

The chamber environmental DBTs at location $\mathrm{T}_{\mathrm{A}}$ and $\mathrm{T}_{\mathrm{B}}$, and the DPT at location $\mathrm{T}_{\mathrm{A}}$ during evaluation of the baseline refrigerator display case are shown in the following figures. January environmental conditions are shown in Figure 51. July environmental conditions are shown in Figure 52. Upper Target environmental conditions are shown in Figure 53. The temperatures were maintained within their prescribed limits throughout evaluation. During the period of scheduled door openings, and during defrost, the DBT at $\mathrm{T}_{\mathrm{A}}$ fluctuated to touching the prescribed limits. However, the DBT did not cross over these limits more than briefly.

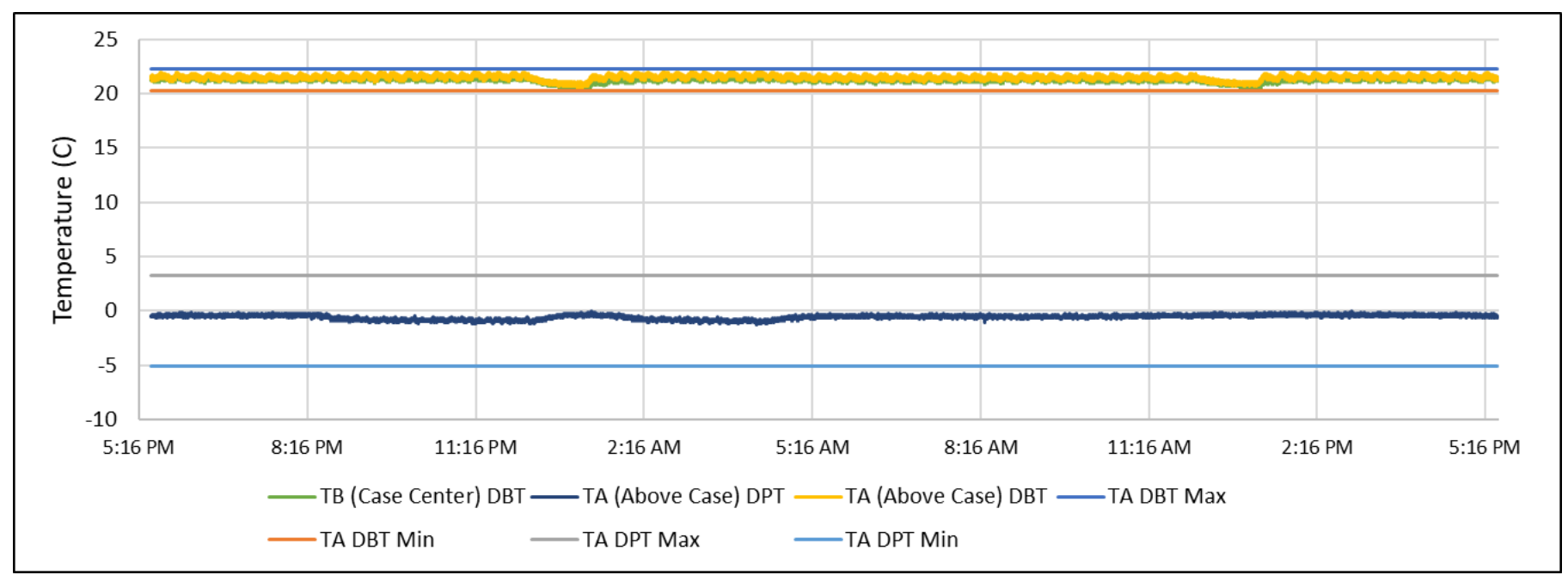

Figure 51. Chamber dry-bulb temperatures and dew-point temperature during EE case $B$ testing in January environmental conditions 


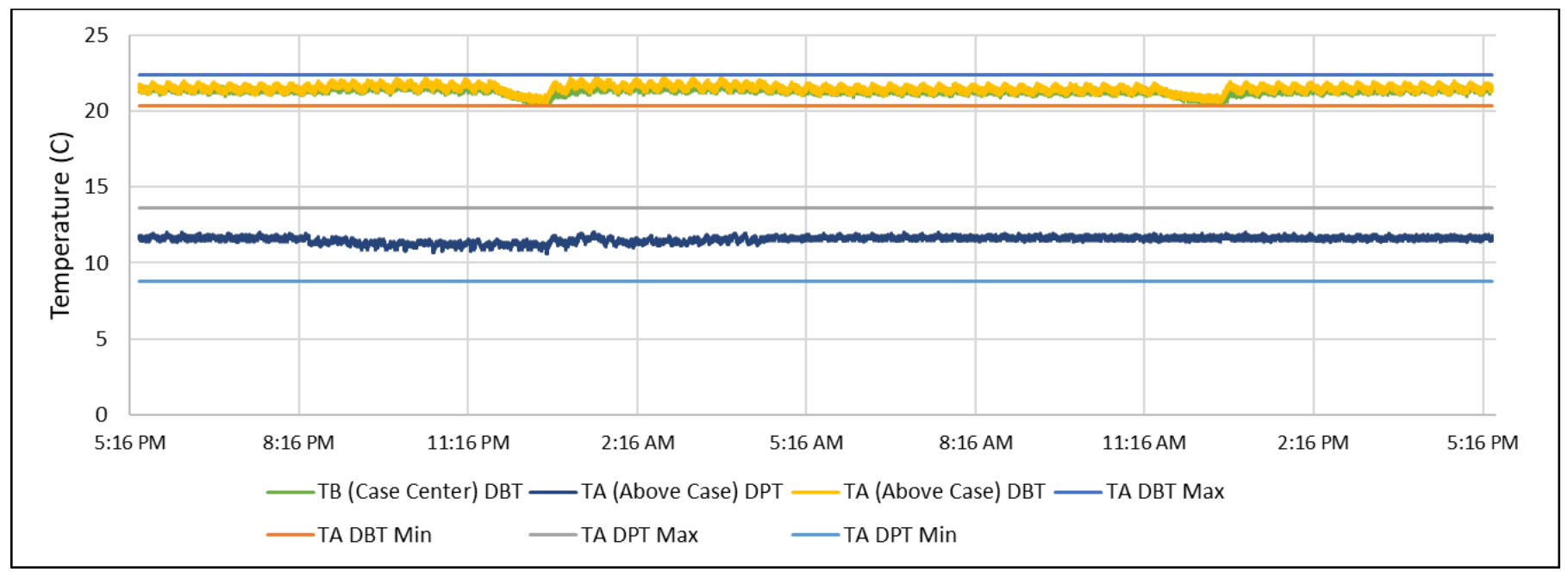

Figure 52. Chamber dry-bulb temperatures and dew-point temperature during EE case B testing in July environmental conditions

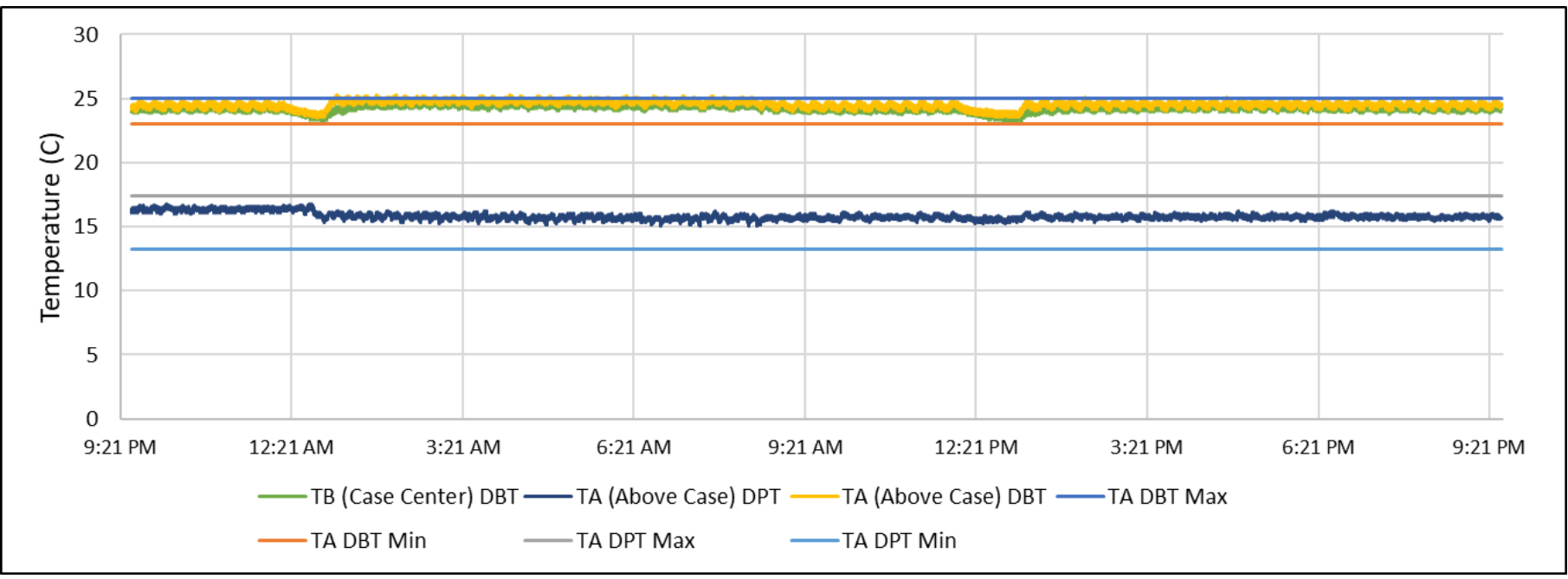

Figure 53. Chamber dry-bulb temperatures and dew-point temperature during EE case B testing in Upper Target environmental conditions 


\section{Appendix B. Refrigerant Piping Temperatures}

Surface temperature thermocouples were wrapped around the refrigerant piping and covered with insulation to record temperatures across each 24-h chamber evaluation. Without measuring refrigerant pressure, temperature cannot be used to determine the state of refrigerant in the vapor compression cycle. Additionally, the surface temperature of the refrigerant piping is not reflective of the actual refrigerant temperature due to the thermal resistance through the piping material. In order to evaluate the performance of commercially available refrigerated case technologies in a manner that most reflected customer use, it was critical to avoid conducting any measurements that could alter performance of the case. Therefore, thermocouple and pressure transducer taps were not made in the refrigerant lines. Here, surface temperature measurements were only used by NREL engineers to guide understanding of case performance. Therefore, the following refrigerant piping temperatures should not be considered performance indicators for these technologies under evaluated conditions.

\section{A.1 Baseline Case Refrigerant Piping Temperatures}

The baseline case refrigerant piping temperatures are shown below in the following figures. Refrigerant temperatures fluctuate accordingly with compressor cycles. The piping temperatures during the evaluation conducted under January conditions are shown in Figure 54. Piping temperatures during the July condition evaluation are shown in Figure 55, and piping temperatures during the Upper Target environmental condition evaluation are shown in Figure 56. Just as was done with case internal air temperatures and component power, the refrigerant piping temperatures are shown across a zoomed-in $1.5 \mathrm{~h}$ period around the end of the scheduled door openings. This was done only for January conditions shown in Figure 54. 

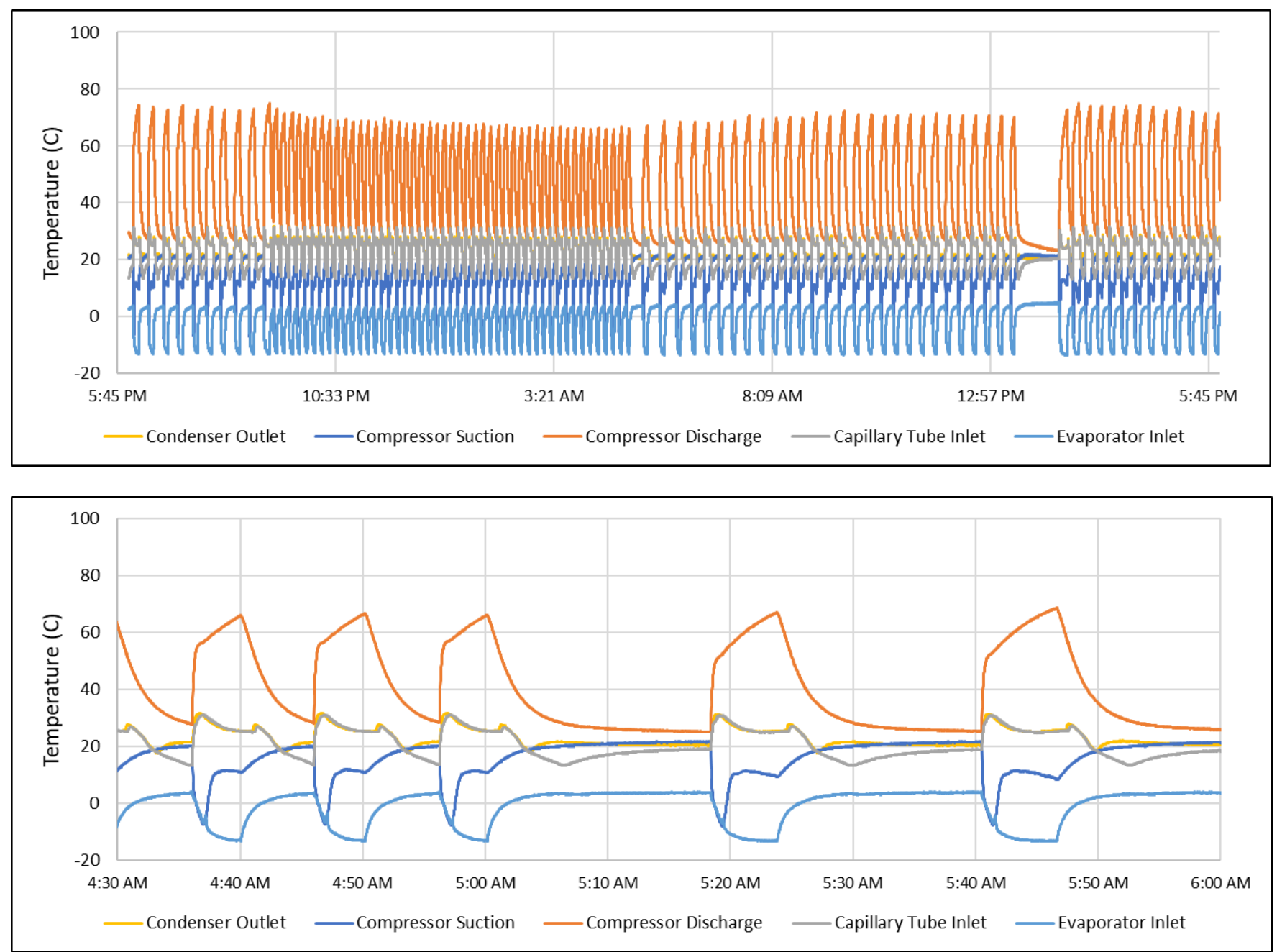

Figure 54. Refrigerant piping temperatures during baseline case testing in January environmental conditions

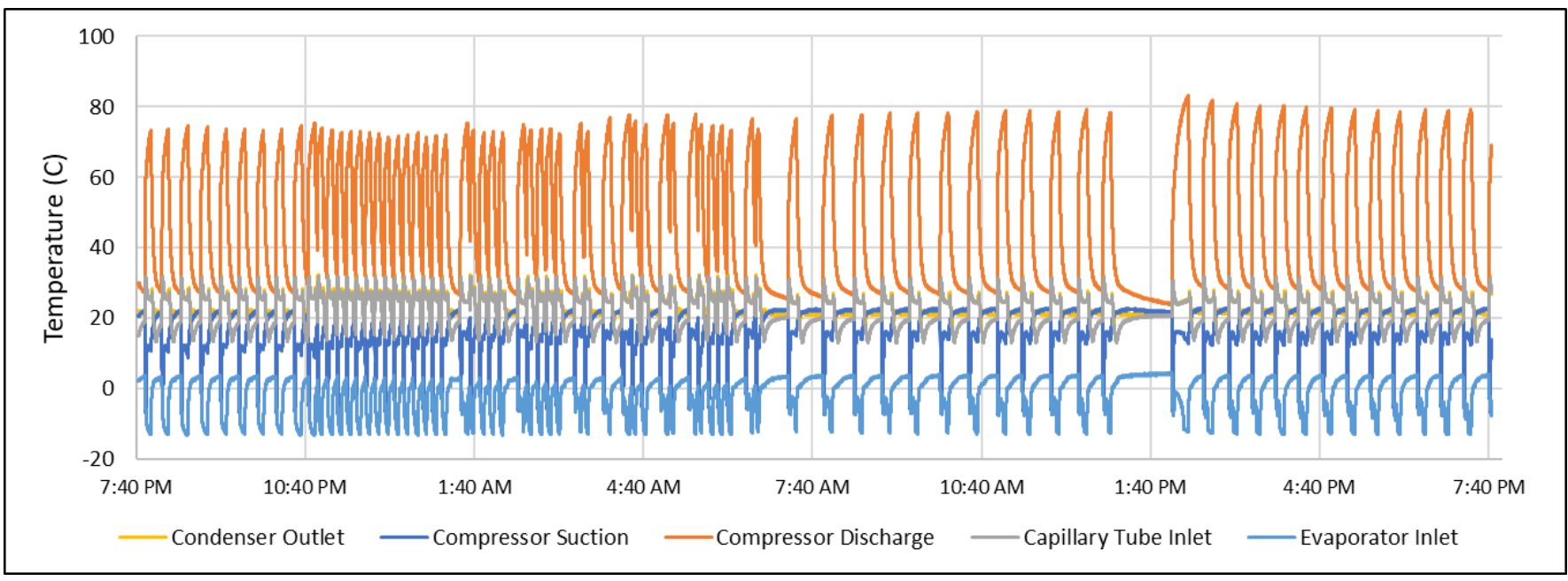

Figure 55. Refrigerant piping temperatures during baseline case testing in July environmental conditions

This report is available at no cost from the National Renewable Energy Laboratory (NREL) at www.nrel.gov/publications. 


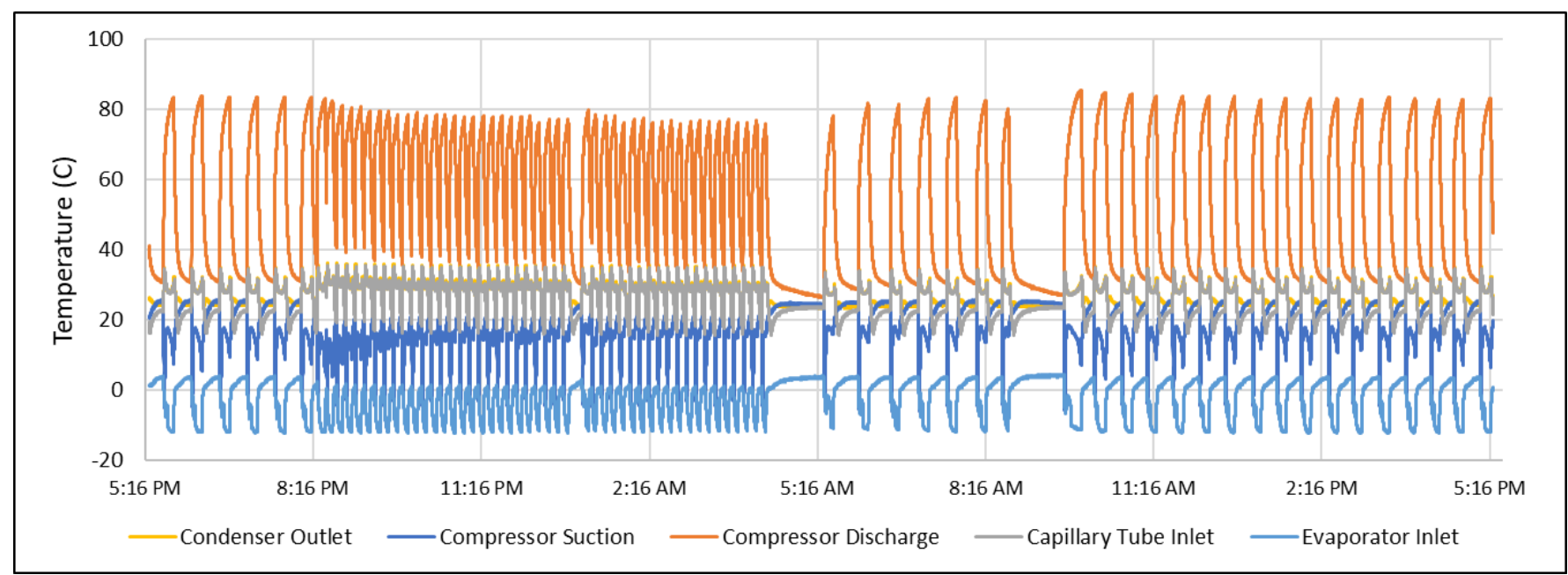

Figure 56. Refrigerant piping temperatures during baseline case testing in Upper Target environmental conditions

\section{A.2 EE Case A Refrigerant Piping Temperatures}

The refrigerant piping temperatures in EE case A are shown below in the following figures. Refrigerant temperatures fluctuate accordingly with compressor cycles. The piping temperatures during the evaluation conducted under January conditions are shown in Figure 57. Piping temperatures during the July condition evaluation are shown in Figure 58, and piping temperatures during the Upper Target environmental condition evaluation are shown in Figure 59. Just as was done with case internal air temperatures and component power, the refrigerant piping temperatures are shown across a zoomed-in 1.5 -h period around the end of the scheduled door openings. This was done only for January conditions shown in Figure 57. 


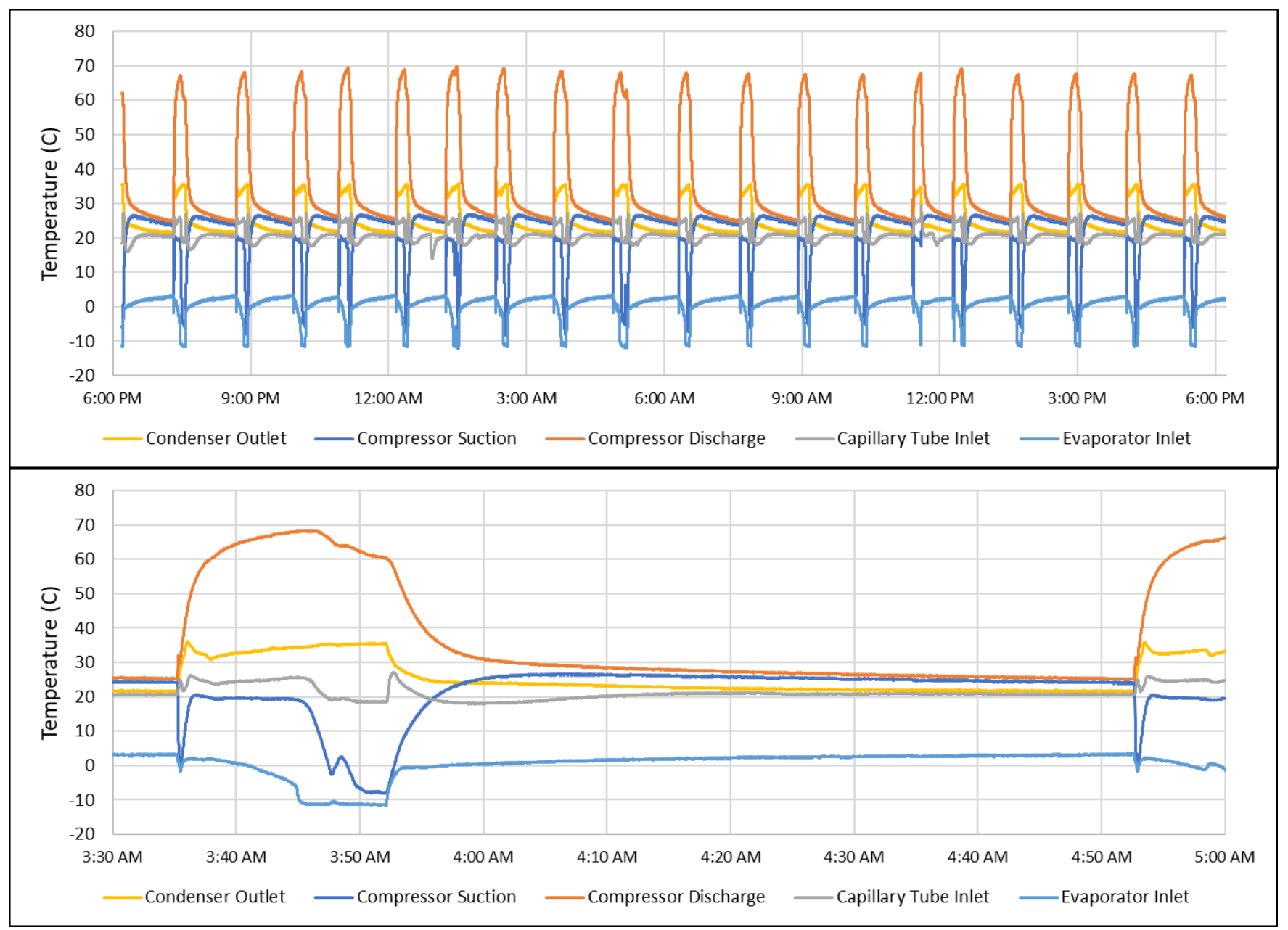

Figure 57. Refrigerant piping temperatures during EE case A testing in January environmental conditions

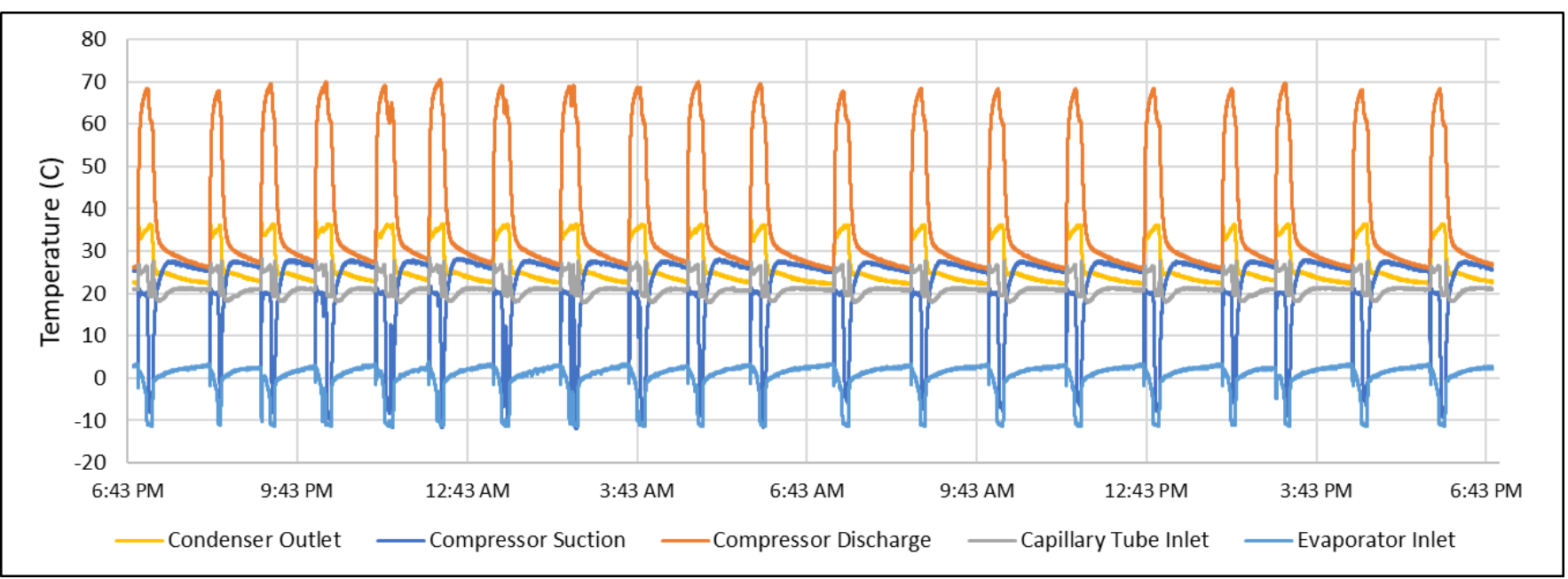

Figure 58. Refrigerant piping temperatures during EE case A testing in July environmental conditions 


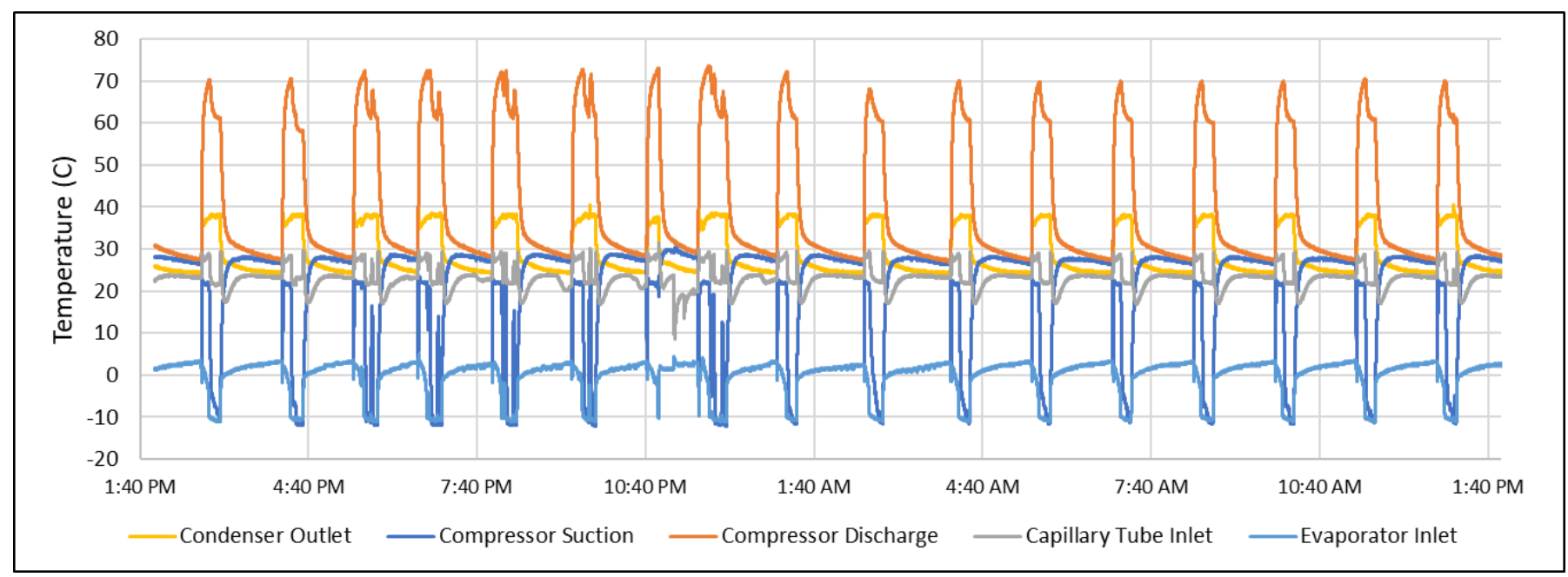

Figure 59. Refrigerant piping temperatures during EE case A testing in Upper Target environmental conditions

\section{A.3 EE Case B Refrigerant Piping Temperatures}

The refrigerant piping temperatures in EE case B are shown below in the following figures. Refrigerant temperatures fluctuated accordingly with compressor cycles. The piping temperatures during the evaluation conducted under January conditions are shown in Figure 60. Piping temperatures during the July condition evaluation are shown in Figure 61, and piping temperatures during the Upper Target environmental condition evaluation are shown in Figure 62. Just as was done with case internal air temperatures and component power, the refrigerant piping temperatures are shown across a zoomed-in 1.5-h period around the end of the scheduled door openings. This was done only for January conditions shown in Figure 60. 


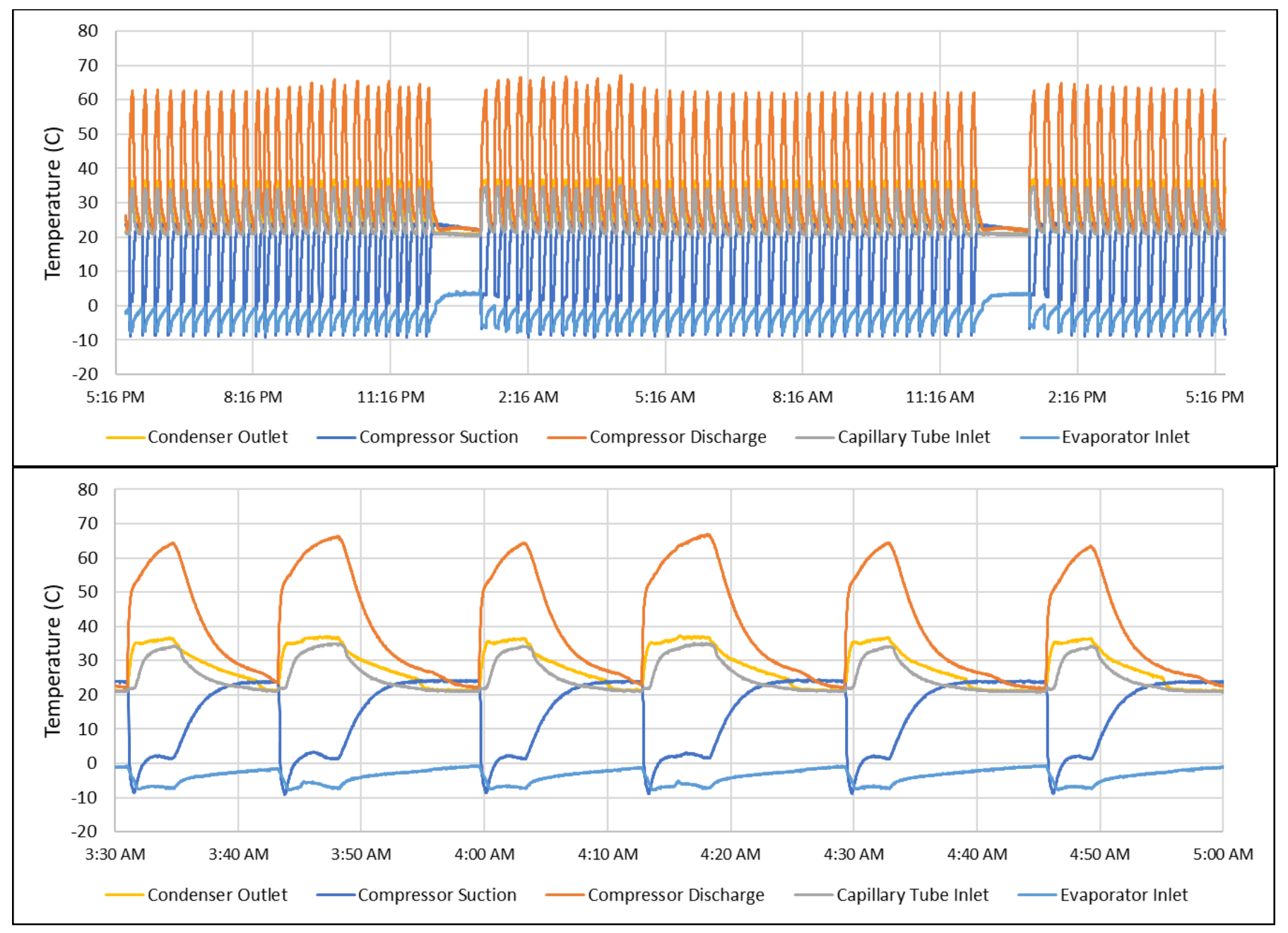

Figure 60. Refrigerant piping temperatures during EE case B testing in January environmental conditions

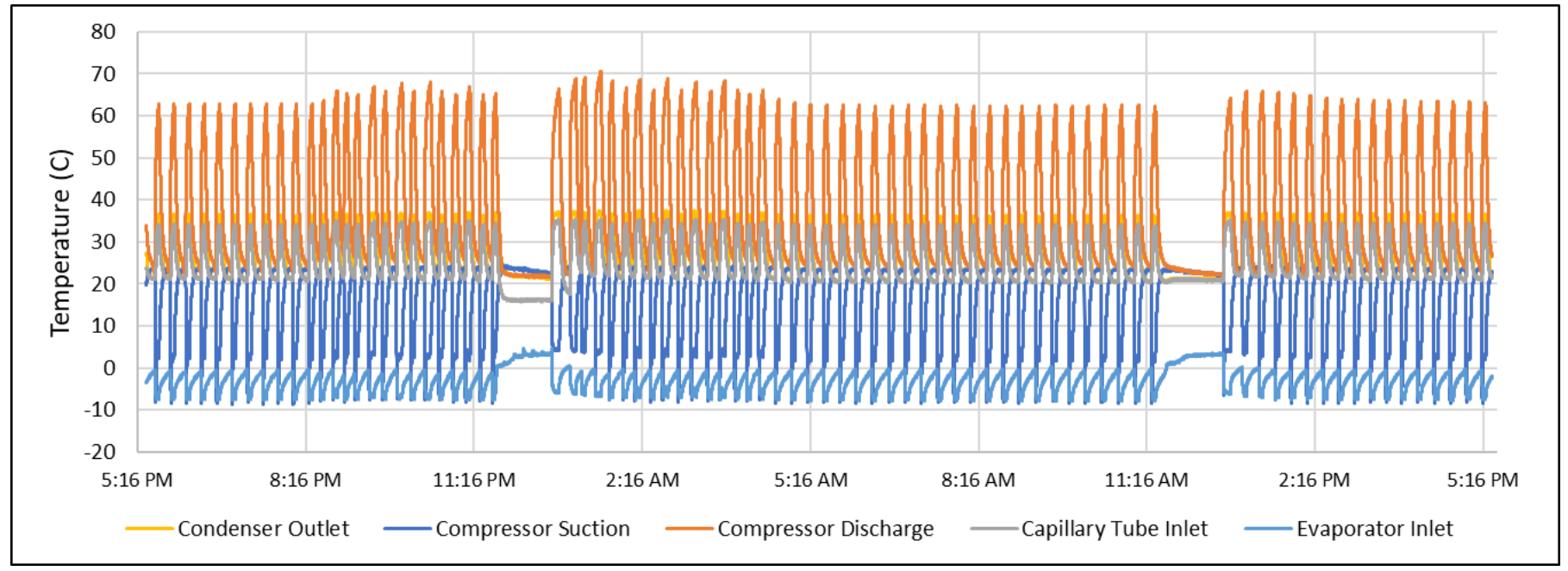

Figure 61. Refrigerant piping temperatures during EE case B testing in July environmental conditions

This report is available at no cost from the National Renewable Energy Laboratory (NREL) at www.nrel.gov/publications. 


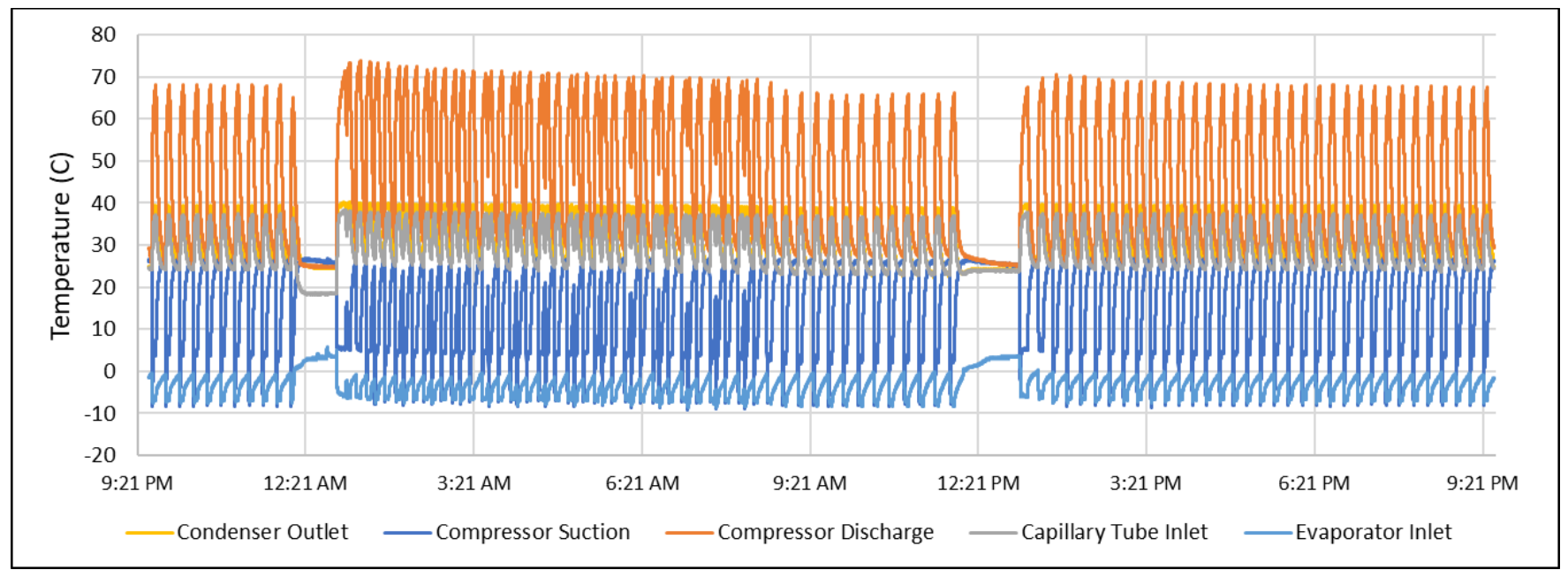

Figure 62. Refrigerant piping temperatures during EE case B testing in Upper Target environmental conditions

This report is available at no cost from the National Renewable Energy Laboratory (NREL) at www.nrel.gov/publications. 